\section{S1 INVERSE ASSOCIATION BETWEEN TUBERCULIN RESPONSES AND ATOPIC DISORDER}

\section{JM HOPKIN, T ENOMOTO, S SHIMAZU, T SHIRAKAWA} Oxford, UK there may be antagonism between different T-helper lymphocyte subsets and their cytokines. We surveyed 867 Japanese children, immunised with attenuated bovine M.tuberculosis (BCG) and naturally exposed to M.tuberculosis. We find a strong inverse association between the magnitude of tuberculin skin test response and total serum $\operatorname{IgE}(R=-0.492, \mathrm{p}<0.001)$. Children with positive rather than intermediate/negative tuberculin responses had less atopic disease (asthma, OR $0.31,95 \%$ CI 0.22 0.45 ) and less prominent Th2 cytokine profiles (interleukin-4, 0.92 cf $1.88 \mathrm{pg} / \mathrm{ml}, \mathrm{p}<0.05$; interferon- $\gamma, 13.2$ cf $7.8 \mathrm{pg} / \mathrm{ml}$, $\mathrm{p}<0.01$ ). Exposure to M.tuberculosis or other mycobacteria may, by modification of immune responses, inhibit the development of atopic disorder.
Lung Research Laboratory, Osler Chest Unit, Churchill Hospital,

Human immune responses are heterogeneous and plastic and

S2 EFFECT OF OZONE, THUNDERSTORMS AND OTHER WEATHER CONDITIONS ON THE RESPIRATORY FUNCTION OF ASTHMATICS G BENTHAM', BDW HARRISON ${ }^{2}$, IH LANGFORD', K ZALAVRA $^{3}$,
AL MCDONALD $^{3}$ and F ELENDER'

'School of Environmental Sciences, University of East Anglia, Norwich

2 Department of Respiratory Medicine, Norfolk and Norwich

Health Care NHS Trust, Norwich

${ }^{3}$ School of Health Policy and Practice, University of East Anglia, Norwich

There is concem that exposure to the air pollutant ozone may adversely affect respiratory function. Ozone is formed photochemically by the action of sunlight on pre-cursor pollutants and peak concentrations usually occur during spells of hot sunny weather in summer. There is also evidence that summer thunderstorms may exacerbate asthma. In order to investigate the possible effects of ozone and summer weather conditions on asthma a panel of 29 patients was recruited from outpatients from a hospital asthma clinic in Norfolk. Daily moming peak-flow measurements (pre-medication) were analysed for June, July and August 1994. For each subject the daily measurements were expressed as the percentage of their best peak-flow and the average for the whole panel was then calculated. Daily ozone measurements from the national air pollution monitoring site at Sibton and data on weather conditions in Norwich were also collected. Multiple regression analysis was used to examine the association between daily peak flow, ozone and a number of weather variables, including the occurrence of thunderstorms, with lags of up to 5 days. A significant positive association $(p<0.001)$ was found between peak flow and temperature over the previous 3 days. Peak flow was significantly negatively associated with the number of days with thunder in the previous 5 days $(p=<0.001)$, the number of days with poor ozone (at or above $90 \mathrm{ppb})$ in the last 3 days $(\mathrm{p}<0.001)$ and the number of days with rain in the last 4 days $(p<0.001)$. These 4 variables explained $48 \%$ of the variance in daily peak flow. The model estimate is that each day of poor ozone is associated with a change in peak flow (as \% of best) of $-1.07(95 \%$ c.i. $-1.52,-0.63)$ and each day with thunder -0.70 $(95 \%$ c.i. $-0.98,-0.43)$. During the summer period studied there was therefore evidence of small, but statistically significant adverse effects of ozone, thunderstorms and wet weather on the respiratory function of asthmatics in Norfolk.

\section{S4}

\section{ANTIOXIDANTS AND BRONCHIAL REACTIVITY}

Venables KM, Davidson AC*, Barker RD, Cannon J, Cook A, Fitzgerald B, Tee RD, Wallis $D^{*}$, Welch J. Imperial College School of Medicine at the National Heart \& Lung Institute, *Newham General Hospital.

There was an epidemic of asthma in England on the night of Friday 24-25 June 1994 after a major thunderstorm. About 1,000 excess asthma attacks presented to A\&E and about 1,500 to general practice. Such epidemics have been noted previously but the environmental and personal determinants are obscure. Suggested factors include allergy to fungal spores or to pollens.

We carried out a case control study in North East London, an area severely affected by the epidemic. Cases (102) were patients presenting with asthma to Newham General Hospital A\&E department between 1800 BST 24 June and 2400 BST on 25 June. Controls (88) were patients presenting with asthma at other times that summer. 68 cases and 30 controls were interviewed and 34 cases and 13 controls gave blood.

Two-thirds of the cases were young adults aged 20-39 whereas controls had a wider age distribution. More cases than controls reported a history of hayfever ( $90 \%$ vs $63 \%$ ) but fewer reported asthma (32\% vs $63 \%)$ or taking medication for breathing. All cases had detectable specific IgE against mixed grass pollen (Pharmacia CAP) and $91 \%$ had very high values; it was undetectable in $31 \%$ of controls and only $38 \%$ had very high values. There were no important differences between cases and controls for total IgE, specific IgE against mixed moulds, and specific IgE against house dust mite. This study supports a role for grass pollen in this epidemic of thunderstorm-related asthma.

We thank the National Asthma Campaign for support.

\section{A SEATON and A SOUTAR}

Department of Environmental and Occupational medicine, University Medical School, Foresterhill, Aberdeen AB25 2ZD

The harmfulness to the lung of inhaled particles depends not only on the particle, but also on the susceptibility of the lung to injury, a neglected area of study. There has been a substantial increase in the prevalence of allergic diseases over the past few decades. Over the same period the diet of the population has shown a substantial reduction in the intake of the major antioxidants, especially fresh fruit and vegetables. We have investigated the relationship between dietary intake of antioxidants and symptoms. Ninety individuals from a random population sample completed a detailed dietary questionnaire and 88 underwent bronchial challenge with methacholine. Cases were defined as those with increased bronchial reactivity $\left(\mathrm{PD}_{20} 12.25 \mu \mathrm{mol}\right.$ or less). With the exception of retinol and $\beta$-carotene, controls had higher intakes of antioxidants. Unadjusted and odds ratios were calculated for tertiles of each antioxidant. Relative to the highest tertile, the lowest intakes of vitamin $C$ (odds ratio $7.13,95 \%$ confidence interval 1.91-26.71, $\mathrm{p}=0.004$ ), magnesium (odds ratio $5.63,95 \%$ confidence interval 1.42-22.33, $\mathrm{p}=0.014$ ) and manganese (odds ratio $8.14,95 \%$ confidence interval 2.11-31.39, $\mathrm{p}=0.002$ ) were significant after adjustment for sex, age and smoking habits. These results support the concept that the lung's response to inhaled irritants is influenced by dietary intake of antioxidants and are consistent with the hypothesis that the observed reduction in antioxidant intake in the British diet over the last 25 years has been a factor in the increase in the prevalence of asthma over this period. 
S5 DOUBLE BLIND PLACEBO CONTROLLED FOOD CHALLENGE IN TYPE 1 \& TYPE 2 BRITTLE ASTHMA

\section{JC BAKER, WS TUNNICLIFFE, RD DUNCANSON and JG AYRES}

Brittle Asthma Unit, Birmingham Heartlands Hospital, Bordesley Green East, Birmingham B9 5SS

Scepticism about food intolerance in severe asthma is widespread amongst clinicians. In our clinic population of severe asthmatics (a history of at least one previous episode of near fatal asthma), $65 \%$ report food intolerance. To investigate our patients' claims we employed a protocol of 5 days of dietary exclusion, followed by a series of open food challenges. 29 patients with Type 1 or 2 brittle asthma, who felt dietary triggers to be important, completed the protocol; $14 / 29(48 \%)$ reacted to one or more foods. To improve objectivity we developed a protocol of 5 days dictary exclusion followed by a series of double blind, placebo controlled food challenges (DBPCFCs) with the most frequent food allergens (egg, milk, wheat, fish, citrus fruits, peanuts and soya) and those under suspicion as triggers. Each food allergen is masked for texture, colour, taste and smell in a lentil based soup. They are given one at a time (via a straw from a covered opaque beaker), double blind, in random order. Nose clips are wom throughout. Foods thought to cause anaphylaxis are excluded. Outcomes are recorded in terms of symptoms and changes in FEV, and PEF, followed for four hours. No systematic attempt has yet been made to identify possible late responses. The protocol has been piloted in 8 patients with type 1 or 2 brittle asthma with positive skin prick tests to one or more of the listed food allergens. Each was admitted to hospital and underwent a 5 day dietary exclusion, their nutritional needs being met by a hypoallergenic formula drink (Elemental E028 Extra) and mineral water. In 6/8 patients, PEFs improved significantly and they went on to the DBPCFCs. All six had positive reactions (defined as $>15 \%$ fall in FEV, or a fall of $>100 \mathrm{l} / \mathrm{min}$ in PEF) to more than one of the masked food allergens; 3 to two foods, 1 to three foods and 2 to four. They followed wheat(4), citrus fruit(3), yeast(3), soya(2), milk(1), fish(1) peanut(1), potato(1) and onion(1). Removal of the identified allergens from the subjects' diets has resulted in sustained symptomatic improvement in all 6 patients. This has been confirmed in 2, to date; mean daily PEFs increasing by $32 \%$ and $38 \%$ respectively, following alleregen exclusion. We now have a basic tool for investigating food intolerance in brittle asthma. Further objective measures of clinical outcome will be incorporated in the future.

S7 PRE-EXPOSURE OF A RHINOVIRALINFECTED HUMAN BRONCHIAL EPITHELIAL CELL LINE TO CYTOKINES AFFECTS SURFACE ICAM-1 LEVELS

\section{SK SETHI, R KNIGHT and MA SPITERI}

Lung Injury and Inflammation Research Group, Dept of Respiratory Medicine, North Staffordshire Hospital.

Human Rhinoviruses (HRV) are the major cause of upper respiratory tract infections. Critical to the relationship between HRV and allergic airway inflammation is the ability of HRV to attach to epithelial cells via a specific receptor Intercellular Adhesion Molecule-1 (ICAM-1) the expression of which is modulated through cytokines. Rhinoviral attachment to epithelial cells may upregulate local ICAM-1 expression in a positive feedback mechanism that facilitates viral binding and invasion. This study examines the role of pro-inflammatory mediators in the upregulation of ICAM-1 in HRV infection of an epithelial cell model using the cell line H292. Monolayers were exposed to optimal concentrations of TNF- $\alpha$, IL-1, IFN- $\gamma$ and IL-8 singularly and in combination for $24 \mathrm{hrs}$, infected with HRV-14 and incubated for 90 mins at $34^{\circ} \mathrm{C}$. Cells were cultured until $>80 \%$ of the monolayer exhibited a cytopathic effect. Immunocytochemical evaluation of surface ICAM-1 expression with a monoclonal antibody was made by using a POX score. TNF- $\alpha$ pretreated HRV-infected cells showed an enhanced expression of surface ICAM-1 (POX 363) over HRV-infected cells alone (POX 203) and TNF- $\alpha$ stimulated cells alone (POX 200) $(p<0.001)$. HRV-infected cells pre-exposed to IFN- $\gamma$ exhibited a lower expression (POX 90) compared to cells pre-exposed to IFN- $\gamma$ alone (POX 140) $(p<0.001)$. These data suggest that rhinoviral binding to epithelial cell ICAM-1 receptors is dependent on the relative proportion of specific cytokines such that predominant TNF- $\alpha$ would induce increased susceptibility to rhinovirus and IFN- $\gamma$ an anti-viral state.
S6 THE EFFECT OF INFLUENZA VACCINATION ONAIRWAY RESPONSIVENESS IN PATIENTS WITH STABLE ASTHMA

S J BOURKE, D W REID, C L BROMLY, N LEITCH, S C STENTON, and D J HENDRICK

Department of Respiratory Medicine, Newcastle General Hospital, University of Newcastle upon Tyne, NE4 6BE

Infection with influenza A virus causes exacerbations of asthma and increased airway responsiveness (AR). Annual vaccination is recommended. Live vaccines and some older killed vaccines caused increased $A R$. More recent studies using purified sub-unit vaccines suggest no effect on $A R$ but some patients report exacerbations of asthma and there is reluctance to adhere to vaccination recommendations. There is therefore a need for further studies of the effect of current vaccines on $A R$ and asthma control.

We studied 22 subjects (mean age 41 (range 19-71) years; 8 male) with mild (FEV $>60 \%$ predicted) stable asthma. All were taking inhaled $\beta$ agonists and 20, inhaled steroids; 13 had previously had influenza vaccination. Subjects were randomized to receive placebo $(n=5)$ or inactivated surface antigen vaccine (Evans Ltd) $(n=17)$. They kept records of asthma symptoms, medication used and adverse events. FEV, and AR (as the dose of methacholine provoking a $20 \%$ fall in $F E V_{1}: P_{20}$ ) were measured twice before vaccination and at 48 and 96 hours post vaccination.

There was no significant difference in pre and post vaccination FEV , or $A R$ in either the placebo or vaccinated groups: mean FEV, changed from $2.9 \mathrm{~L}$ pre vaccine to 2.83 and $2.9 \mathrm{~L}, 48$ and 96 hours post vaccine; mean $\mathrm{PD}_{20}$ changed from $120 \mu \mathrm{g}$ pre vaccine to 102 and $101 \mu \mathrm{g}, 48$ and 96 hours post vaccine. No subject showed a significant fall in FEV, or $\mathrm{PD}_{20}$, or had a change in asthma symptoms or medication; 7 of those given vaccine had fever and malaise, and one had a local reaction.

We conclude that inactivated surface antigen vaccine does not generally exert any adverse effect on asthma.

S8 Human $\mathrm{CD4}^{+} \mathrm{T}$-cell recognition of influenza $\mathrm{A}$ haemagglutinin is precisely defined by HLA-DR. C.M. Gelder Section of Respiratory, Medicine, University of Wales College of Medicine, Llandough Hospital, Cardiff CF64 2XX.

$\mathrm{CD}^{+} \mathrm{T}$-cells play a central role in defence against influenza $\mathrm{A}$ virus infection: As well as controlling neutralising antibody production, they amplify cytotoxic $T$ lymphocyte responses, and may participate more directly in viral clearance by the secretion of interferon- $\gamma$. The immune recognition of influenza $A$ haemagglutinin (HA) is important because it is the primary component of the widely used subunit influenza vaccines. Adult human $\mathrm{CD}^{+} \mathrm{T}$-cell recognition of $\mathrm{HA}$ following both recent natural infection and influenza subunit vaccination has recently been shown to be primarily directed towards highly conserved regions of the molecule (Gelder, C. M., et al. 1995. J. Virol. 69:7497-7506. Gelder, C. M., J.R. Lamb, and B.A. Askonas. 1986. J. Virol. 70.4787-4790.), which have not been subject to frequent drift mutations amongst human $\mathrm{H} 3 \mathrm{~N} 2$ influenza $A$ strains since the emergence of the subtype in 1968. By chance both studies included pairs of unrelated donors who expressed identical HLA-DR alleles, and each pair responded to identical HA peptide pools, with only minor variations in the magnitude of their responses in spite of differences in their age, nationality and exposure to influenza $A$ viruses.

In order to extend these observations, and to explore in detail epitope selection by MHC class II, the HA specific repertoires of 6 unrelated individuals who were selected because they expressed identical HLADRB $1 * 0701$, and *1501 alleles but differed in previous exposure to influenza viruses, have been examined. Short term $C D 4^{+} \mathrm{T}$-cell lines were selected with full length HA A/Beijing/32/92 (H3N2), prior to and 3 months following vaccination with a trivalent subunit influenza vaccine containing $\mathrm{HA}$ A/Beijing/32/92. Epitope recognition was examined using a panet of 118 synthetic peptides 16 amino acid in length and overlapping by 11 residues, that spanned the entire HA A/Beijing/32/92 molecule.

Following influenza vaccination the donors were found to recognise identical conserved regions of the HA molecule and when responses to these regions were localised the donors were found to recognise identical HA peptides. These results clearly demonstrate the profound influence of $\mathrm{MHC}$ class II over $\mathrm{CD}^{+} \mathrm{T}$-cell epitope selection in man, and the experimental techniques employed are widely applicabte.

This work was supported by the Wellcome Trust. 
S9 THE EFFECT OF HAEMOPHILUS INFLUENZAE ENDOTOXIN ON THE EXPRESSION OF TRANSCRIPTION FACTORS BY CULTURED HUMAN BRONCHIAL EPITHELIAL CELLS AND THE INFLUENCE OF ANTI-INFLAMMATORY AGENTS

OA KHAIR, JL DEVALIA, MM ABDELAZIZ, RJ SAPSFORD AND RJ DAVIES

Academic Department of Respiratory Medicine, St. Bartholomew's and The Royal London School of Medicine and Dentistry, The London Chest Hospital, Bonner Road, London E2 9JX, UK

Several studies have suggested that transcription factors which influence the genetic regulation of pro-inflammatory cytokines may play a critical role in inflammatory airway diseases, such as chronic bronchitis. We have hypothesised that $\boldsymbol{H}$. influenzae endotoxin-induced release of inflammatory cytokines from primary cultures of human bronchial epithelial cells (HBEC)(Khair OA et al, Eur Respir J 1994; 7:2109-2116) may be a result of increased expression of transcription factors by these cells. To test this hypothesis, we cultured HBEC and incubated these with endotoxin from non-typeable and type b $H$. influenzae strains $\pm 10^{-5} \mathrm{M}$ hydrocortisone or $1 \mu \mathrm{g} / \mathrm{ml}$ erythromycin for 24 hours. At the end of incubation the cultures were immunostained for the transcription factors $c$-fos, $c$-jun, and NF- $\mathrm{kB}$, using monoclonal and polyclonal antibodies. Incubation of HBEC in the presence of endotoxin from nontypeable $H$. influenzae significantly increased the mean percentage of cells staining positively for c-Jun, c-Fos and NF- $\mathrm{kB}$, from baseline levels of $30 \%$, $48.6 \%$, and $51.2 \%$ to $83 \%(\mathrm{p}<0.001), 95 \%(\mathrm{p}<0.001)$ and $90 \%$ $(\mathrm{p}<0.001)$, respectively. The mean percentage of cells staining positively for $c$-Jun and $c$-Fos was also increased significantly from the baseline values to $75 \%(p<0.001)$ and $79.1 \%(p<0.001)$, respectively, in HBEC incubated with endotoxin from type b $H$. influenzae. The expression of $\mathrm{NF}-\mathrm{\kappa B}$ was not altered by this endotoxin. Treatment of the cells with either hydrocortisone or erythromycin abrogated the endotoxin-induced expression of all three transcription factors. These studies suggest that $H$. influenzae endotoxin may modulate its inflammatory effects in the airways by up-regulating the expression of transcription factors in airway epithelial cells and that agents such as hydrocortisone and erythromycin exert their anti-inflammatory effects possibly by interfering with this expression.

S11 Alveolar Lymphocytes and Macrophages are an Important Source of HIV-1 in Patients with AIDS.

John R Clarke ${ }^{1}$, Amanda J. Gates ${ }^{1}$, Azin Alimohammadi ${ }^{1}$, Richard J Coker ${ }^{2}$, Robert F. Miller ${ }^{3}$, David M. Mitchell².

1. Department of Virology. 2. Department of Respiratory Medicine, St. Mary's Hospital, London. W2 1PG, England. 3. Department of Medicine, Middlesex Hospital, London.

Whilst the lung is a major target for opportunistic microorganisms in the later stages of AIDS the role of HIV-1 infection of the lung in the disease process remains controversial. To clarify this question we have used limited cell dilution PCR for the detection of HIV-1 proviral DNA and have also cultured the virus. Limited cell dilution PCR for the detection of HIV-1 DNA from $\mathrm{PBMC}$ and alveolar cells indicated that more cells were infected with HIV-1 in matched PBMC samples from 7 out of 9 individuals. Closer examination of purified alveolar lymphocytes and alveolar macrophages showed that higher numbers of alveolar lymphocytes (10 out of 14) had detectable HIV-1 proviral DNA. Interestingly HIV-1 could be isolated in culture from 8 out of 14 alveolar lymphocyte samples and 9 out of 14 alveolar macrophage samples. In this respect the removal of $\mathrm{CD}^{+}$alveolar lymphocytes from the cultures greatly facilitated the replication of HIV-1 in alveolar macrophages. Our conclusion is that the replication of HIV-1 is extremely efficient in alveolar macrophages when CD8+ lymphocytes are not present and therefore $\mathrm{AM}$ are an important source of HIV-1 in AIDS.

\section{S10 CIRCULATING NEUTROPHIL $\beta_{2}$-INTEGRIN EXPRESSION AND INTRACELLULAR OXIDATIVE METABOLISM IN COMMUNITY ACQUIRED PNEUMONIA}

P GLYNN, I KILGALLEN, R COAKLEY and S ONEILL

Dept. Respiratory Medicine, Beaumont Hospital, Dublin 9, Ireland

Neutrophil migration to the lungs in pneumonia is partly dependant on neutrophil $\beta_{2}$-Integrin (CD11b) expression which we postulated would be increased in pneumonia. Secondary to neutrophil activation there may also be increased intracellular oxidative metabolism, which may be of prognostic significance.

Peripheral blood was taken from 17 healthy controls and 24 patients with pneumonia. The neutrophils were labelled with FITCconjugated monoclonal antibodies to CDIlb, and analysed by flow cytometry. Intracellular oxidative metabolism was measured by respiratory burst activity pre- and post-stimulation with E Coli, using flow cytometric analysis, and expressing the results as mean channel fluorescence (MCF)

There was a trend towards increased baseline respiratory burst on Day 1 in the pneumonia patients: $11.3(8.1)$ vs. $6.0(2.3)$ in the controls, $\mathrm{p}=0.07$, but there was no difference in respiratory burst post E Coli stimulation: 177(157) vs. 131(47) or in CD11b expression: $405(266)$ vs. $280(126)$. 3 patients died, and they had significantly reduced respiratory burst response to E Coli compared to the other patients: $55.5(34)$ vs. $197(161), p<0.05$, and compared to controls: $55.5(34)$ vs.131(47), $p<0.05$, although CD11b was similar in both patient groups. Neutrophil respiratory burst and CD1 lb expression were independent of patient age. We conclude that in a patient group with non-bacteremic pneumonia CD11b expression and oxidative metabolism were comparable to controls. However, the patients who died had low intracellular oxidative metabolism and this may be of prognostic significance.

S12 Genotypic variants of HIV-1 from peripheral blood and lung of AIDS patients.

Azin Alimohammadi ${ }^{1}$, Dalbir K. Sohi' ${ }^{1}$, Richard Coker ${ }^{2}$, Robert Miller ${ }^{3}$, David Mitchell2 ${ }^{2}$, John D. Williamson ${ }^{1}$, John R. Clarke ${ }^{1}$.

1. Department of Virology, 2. Department of Respiratory Medicine, St. Mary's Hospital, London W2 1PG,

3. Department of Medicine, Middlesex Hospital, London WC1N 8AA.

The lung is an important target organ for HIV infection and AIDS associated disease. Pulmonary infection by opportunistic microorganisms is a major cause of morbidity and mortality in AIDS patients. We have carried out an investigation which has enabled us to distinguish genotypic differences between HIV proviral DNA variants from blood and alveolar leukocytes.

Bronchoalveolar lavage and heparinised peripheral blood were collected from HIV positive patients undergoing investigation for respiratory complications. Adherent and non-adherent cell populations were separated and HIV proviral DNA was extracted from each population 1. Heteroduplex Mobility Assay (HMA), a PCR-based analysis, was used to distinguish the genotypic variations in the V1 to V5 region of env gene in the different HIV proviral populations ${ }^{2}$. Significant variation was seen in the env gene of HIV-1 proviral populations from blood and lung in 16 of 27 AIDS patients.

In conclusion, using HMA we have been able to distinguish different genotypes in peripheral blood and alveolar leukocytes. This suggests that HIV in target organs such as lung may evolve independently of viruses in peripheral blood. This observation is important for vaccine

development to take account of HIV variants in different organs.

References:

1. Clarke J.R et al. Clin. Exp. Immunol. 1994; 96:182-186

2. Delwart E.L et al. Science 1993; 262:1257-1261 
S13 FACILITIES FOR INVESTIGATION AND TREATMENT OF SLEEP APNOEA IN THE UK

GJ GIBSON, *N J DOUGLAS and + $J$ R STRADLING

Department of Respiratory Medicine, Freeman Hospital NHS Trust, Newcastle upon Tyne, * Royal Infirmary, Edinburgh and + Churchill Hospital, Oxford

We have surveyed the current facilities for investigation and treatment of obstructive sleep apnoea (OSA) in the UK by sending a questionnaire to all physicians known to be offering this service in the financial year 1995-6. Replies were received from 42 of the 45 physicians approached.

The number of diagnostic sleep studies performed over 12 months was 11,486. The total number of patients receiving treatment with nasal continuous positive airway pressure (CPAP) was 7006 . Of these, CPAP treatment had been initiated in 2288 (32.7\%) during the year surveyed. Based on the conservative estimates of prevalence of OSA used in the Royal College of Physicians Report on Sleep Apnoea (1993), the approximate number of patients with symptomatic OSA who might benefit from CPAP treatment in the UK is at least 51,480 .

of the 42 physicians who responded, the numbers reporting problems with NHS funding for sleep apnoea services in relation to diagnostic studies, CPAP systems and support staff were respectively 23,25 and 24 . Only 9 physicians experienced no financial problems related to the service in 1995-6.

We conclude that less than 1 in 7 of potentialiy suitable patients with OSA in the UK are currently being treated with CPAP and that major problems of funding are being faced by the majority of physicians attempting to provide an appropriate level of service.

\section{S15 VALIDATION AND CLINICAL USE OF HOME SLEEP STUDIES IN THE SLEEP APNOEA/HYPOPNOEA SYNDROME}

\section{A T WHITTLE, S P FINCH, I L MORTIMORE and N J DOUGLAS}

Sleep Laboratory, The Royal Infirmary of Edinburgh NHS Trust, Edinburgh, EH3 9YW

The tarnished gold-standard investigation for diagnosis of the Sleep Apnoea/Hypopnoea Syndrome (SAHS) is polysomnography (PSG), but rising referral rates make limited sleep studies attractive. We have validated and put into practice unsupervised limited sleep studies in the patient's home using the EdenTrace system (Edentec 3711) which records oronasal airflow, heart rate, chest wall movements and $\mathrm{SaO}_{2}$

For validation, 20 patients underwent full overnight PSG and then a limited sleep study in their own home the following night. The frequency of respiratory events observed in the limited studies (mean 23.8 apnoeasthypopnoeas per hour in bed, SD 12.3) was lower than the Apnoea/Hypopnoea Index (AHI) from PSG (mean $31.4 \mathrm{~A}+\mathrm{H} / \mathrm{hr}$ asleep, SD 19) but the two methods were significantly correlated $(r=0.83, p<0.001)$ No patient with a frequency of respiratory events $>30 / \mathrm{hr}$ on a limited study had an AHI $<15 / \mathrm{hr}$ on PSG.

We then performed a prospective study in which 150 local patients under investigation for possible SAHS had a limited home sleep study as an initial investigation. Forty-three $(29 \%)$ showed $>30 \mathrm{~A}+\mathrm{H} / \mathrm{hr}$ and proceeded direct to inpatient CPAP titration. Twenty-two (15\%) patients who did not complain of daytime sleepiness and showed $<15 \mathrm{~A}+\mathrm{H} / \mathrm{hr}$ were given no further investigation. Eighty-five (57\%) patients, including 27 (18\%) in whom the limited study was technically unsuccessful, proceeded to full PSG to establish a diagnosis. One patient defaulted.

Compared with a control group of 75 patients who underwent PSG as an initial investigation, this protocol gave a diagnosis more quickly (median 18 days for home study group vs 47 days for controls, $p=0.002$ ) and cheaply (mean $£ 220$ vs $£ 309, p<0.001$ ). It did not alter the proportion of patients offered CPAP (63\% vs $65 \%$, NS) nor their subsequent usage of CPAP (mean 4.7 vs $5.0 \mathrm{hrs} /$ night, NS). We conclude that limited home sleep studies can be used for the diagnosis of SAHS with benefits in time and cost, but that PSG may still be required in $50-60 \%$ for diagnostic reliability.

\section{S14 QUALITY OF LIFE BEFORE AND AFTER NASAL CONTINUOUS POSITIVE AIRWAY PRESSURE (NCPAP) TREATMENT FOR OBSTRUCTIVE SLEEP APNOEA (OSA)}

\section{JR STRADLING*, C JENKINSON and S PETERSEN}

Health Services Research Unit, University of Oxford, Radcliffe Infirmary, OXFORD, OX2 6HE and "Osler Chest Unit, Churchill Hospital, OXFORD, OX3 7LJ

Although the benefits of treating OSA are obvious to patient and physician, purchasers of health care are not impressed by this subjective and anecdotal evidence. Controlled data are available, but not always using outcome measures that allow the estimation of health gain to be compared with other treatments in other conditions. This study compares the quality of life of OSA patients with a normal population, and measures the health gain from NCPAP treatment using two well accepted assessment techniques, the SF-36 and Functional Limitations Profile (FLP). The SF-36 provides a set of indices (eg energy/vitality), conveniently totalled as the Physical and Mental Component Summaries (PCS and MCS) standardised against a normal population. The FLP also provides a set of indices (eg alertness) summarised as the Total Score. 64 patients completed the SF-36 and FLP questionnaires prior to, and 6 weeks after, starting NCPAP for OSA. The response to treatment is quoted as 'effect size' (mean change in variable divided by SD of variable, where 0.2 is regarded as small, 0.5 moderate, and 0.8 large).

\begin{tabular}{|c|c|c|c|c|}
\hline \multirow{3}{*}{ SF-36 } & Measure & Before & After & Effect size \\
\hline & Energy/vitality* & $38(21)$ & $60(22)$ & 1.0 \\
\hline & Physical Component ${ }^{* x}$ & $39(12)$ & $47(12)$ & 0.6 \\
\hline \multirow{5}{*}{ FLP } & Mental Component ${ }^{* x}$ & $40(12)$ & $49(10)$ & 0.8 \\
\hline & Sleep and Rest ${ }^{\dagger}$ & $30(24)$ & $9(18)$ & 0.9 \\
\hline & Alertness ${ }^{\dagger}$ & $29(28)$ & $12(24)$ & 0.6 \\
\hline & Social Interaction ${ }^{\dagger}$ & $19(20)$ & $8(16)$ & 0.6 \\
\hline & Total Score ${ }^{t}$ & $11(9)$ & $4(7)$ & 0.7 \\
\hline
\end{tabular}

These results (all $\mathrm{P}<0.001$ ) indicate a pre-treatment reduction in quality of life similar to many other severe disorders (e.g. Parkinson's, chronic heart failure) and a large response to treatment compared to other therapies in other disorders.

\section{S16 HOME OXIMETRY VERSUS FULL POLYSOMNOGRAPHY IN THE DETECTION OF OBSTRUCTIVE SLEEP APNOEA (OSA)}

\section{AH KENDRICK, $\mathbf{N}$ WILTSHIRE and JR CATTERALL}

Sleep Unit \& Respiratory Department, Bristol Royal Infirmary, Bristol

Pulse oximetry is a simple method of detecting OSA. It can be performed at home where patients sleep better than in hospital. We are not aware of studies comparing pulse oximetry at home (HS) to laboratory polysomnographic studies (LS). Methods: 102 consecutive HS plus LS were included. Each patient used the Minolta Pulsox 5 pulse oximeter at home on the night before the LS. For LS, standard electrophysiological measures, chest wall and abdominal movement, nasal-oral airflow and on-line pulse oximetry recordings were obtained with the Aequitron SleepLab system. The number of $4 \%$ hypoxic dips/hour (DI - Desaturation Index) was obtained for both studies. From LS, the number of manually scored apnoeas and hypopnoeas per hour (AI - Apnoea Index and AH - ApnoeaHypopnoea Index) was obtained, and the percentage of respiratory events associated with the hypoxic dips calculated. Results: The mean (SD) age of the group was 54.8 (12.1) yr, body mass index was $28.5(6.6) \mathrm{kg} \cdot \mathrm{m}^{-2}$ and Epworth score was 11.9 (5.1). All patients had a resting awake saturation of $>92 \%$. The mean (range) $\mathrm{DI}_{\mathrm{HS}}$ of $7.7(0$ to 69.5$)$ was significantly greater $(\mathrm{p}<0.005)$ than the $\mathrm{DI}_{L S}$ of $5.9(0$ to 56.1$)$. The difference (HS LS) was 1.80 (-27.9 to 23.0). The AI and AH were 5.0 (0 to 65.1) and 8.6 ( 0 to 73.9$)$ respectively. The mean total number of apnoeas and hypopnoeas was 55.2 ( 0 to 586 ), of which $48.2 \%$ ( 0 to 100) were associated with a $4 \%$ hypoxic dip. Using a cut-off of DI $>10 \mathrm{hr}^{-1}, 85$ home studies were negative and 17 positive, whilst 79 studies were negative and 23 positive for an $\mathrm{AH}>10 \mathrm{hr}^{-1}$. Assuming that OSA was present if either test were positive, then 71 studies were negative and 31 positive. The sensitivity was $55 \%$ for HS and $\mathbf{7 4 \%}$ for LS. Home studies correctly classified $89 / 102(87 \%)$ studies, whilst $\mathrm{DI}_{\mathrm{HS}}$ and $\mathrm{AH}$ agreed in $80 / 102$ studies. Conclusion: These results suggest that home oximetry is more sensitive than oximetry performed in hospital as part of polysomnography, and that some cases of OSA missed by polysomnography may potentially be diagnosed by home oximetry. Home oximetry can be useful in the diagnosis of OSA, with the added benefits of convenience and low cost. 
S17 A DISTRICT GENBRAL HOSPITAL SLESP SERVICE BASED ON BOES OXIMETRY

CS THOMPSON, M STOBART and ARH WARLEY

Respiratory Dept, Salisbury District Hospital, SALISBURY, Wilts, SP2 8BJ

There is neither consensus on the exact definition of sleep related breathing disorders nor the optimum investigation of patients in whom such disorders are apnoea (OSA) and the majority of sleep studies are performed to rule out this particular condition. os exhibits a wide spectrum of severity in respect of objective parameters and these in turn do not always correlate with the severity of symptoms in an individual patient. Nasal continuous positive airway pressure (nCPAP) represents the most effective treatment for the (ncPap) represents the most effective treatment for the symptomatic benefit is substantial.

oymptomatic benefit is substantial. In the 30 months olnce the sleep service was established we have carried out 371 ) sleep studies using home oximetry alone (Ohmeda 3740). Patients with a history of snoring, symptoms of excessive daytime somnolence (Epworth score $>10 / 24$ ) and any suggestion of sleep apnoea on the oximeter trace have been offered a trial of nCPAP. In order to maximise the chance of success the nCPAP trials are carried out during one night in hospital on a low dependency ward. Patients are shown the use of the machine by the respiratory nurse and/or doctor. Following the trial, patients are offered a machine for home use. Compliance is checked at 8 ix weeks and patients have easy access to the respiratory nurse and patients have easy access to the resplratory nurse during that perlod in the event of technical problems. 108 patients have accepted trials of nCPAP of which 86 have been so far completed. 10 have declined to proceed further with the treatment after the trial and 22 are on the waiting list for a machine to use at home.

of the remaining 54 patients 43 have demonstrated continued use at 6 weeks (compliance > 28 hours per week) and 42 at 8 ix months. Our practice is to withdraw the machine at either time point if the patient wishes or if the compliance figures suggest an average usage of $<28$ hours a week.

This simplified screening technique has 1 . Obviated the need for hospital admission in 71 of patients referred $(263 / 371)$. 2. Identified nCPAP responsive disordered night-time breathing in a minimum of $118(42 / 371)$.

3. Shown that $678(43 / 64)$ of patients assessed for nCPAP in this way have responded to it.

S19 DIVIDED DOSES OF DNA:LIPOSOME COMPLEXES PRODUCE SUBOPTIMAL GENE EXPRESSION FOR A GIVEN DNA DOSE.

E. HILLERY', S. CHENG ${ }^{2}$, D.M. GEDDES', AND E.W.F.W. ALTON ${ }^{\prime}$ 'Ion Transport Unit, National Heart \& Lung Institute, London, U.K. ${ }^{2}$ Genzyme Corporation, 1 Mountain Road, Framingham, MA, U.S.A

In vivo gene transfer is at present sub-optimal. One potential way to circumvent this is the administration of increasing doses of DNA at a time when the response to a first application has not subsided. To address this possibility, DNA encoding the chloramphenicol acetyl transferase (CAT) reporter gene, driven by a CMV promoter, was complexed to lipid \#67, a cationic lipid. This was then administered to the lungs of female Balb $\mathrm{C}$ mice by the application of this complex to the nose. Animals ( $n=6$ at all time points) were then sacrificed 24, 72, 120 and 168 hours later. A single dose of $80 \mu \mathrm{g}$ of DNA in a final volume of $100 \mu \mathrm{l}$ gave a readily discernible signal on day 1 of $21.6 \times 10^{-6} \mathrm{CAT} U / \mu \mathrm{g}$ protein. This level decreased slowly over time so that even by day 7 , transgene expression was still detectable, being approximately $30 \%$ of the original day 1 signal $\left(6.2 \times 10^{-6} \mathrm{CAT} \mathrm{U} / \mu \mathrm{g}\right.$ protein). We then assessed the effect of administering the DNA-liposome complex on 2 occasions separated by either 24 or 48 hours. In both cases, transgene expression was highest on day 1 decreasing again to approximately one third of this level by day 7 . However, transgene expression was not significantly increased from the level of expression seen within the single dose time course. In addition, since the divided dose protocols now administered twice the amount of DNA, we also assessed the effect of $160 \mu \mathrm{g}$ of DNA (in $200 \mu \mathrm{l}$ ) given on a single occasion. The level of transgene expression on day 1 produced with this dose $\left(72.4 \times 10^{-6}\right.$ CAT U/ug protein) was approximately three times the level for the same day for those with doses separated by 24 hours ( $16.8 \mathrm{CAT} \mathrm{U/ \mu g} \mathrm{protein)} \mathrm{and} \mathrm{twice} \mathrm{that} \mathrm{for}$ those with doses separated by 48 hours (33.6 CAT U/ $\mu$ g protein). With this assay system therefore, it would seem that divided doses are suboptimal in producing gene expression for a given DNAdose. Possibilities include that either (1) the cells, after transfection, become refractory to further transfection for a period of time, or that (2) different populations of cells were transfected at the second administration.

\section{S18 MANDIBULAR POSITIONING DEVICES FOR THE CONTROL OF SNORING}

\section{JR STRADLING, T NEGUS *, B LANGFORD and D M SMITH}

Osler Chest Unit, Churchill Hospital, Oxford, OX3 7LJ and

*Royal Hospital, Haslar, Gosport, Hants, PO12 2AA

Patients complaining of antisocial snoring have few options available to them of proven efficacy. There are a plethora of 'gadgets', most having no evidence to justify their appearance on the market. Surgery, such as uvulopalatopharyngoplasty, is an option but many patients do not feel that the pain, risks, and unpredictability of this operation are justified. Oral devices worn at night, to hold the lower jaw forward, have recently been shown to help mild to moderate obstructive sleep apnoea (OSA). There are no controlled studies on the use of such devices for the management of antisocial snoring. 14 snorers with no evidence of significant OSA on their diagnostic study, already established on oral appliances for the control of snoring, participated in this study. They were studied overnight at home on two occasions, using a portable device (RM50, Parametric Recorders) on the third consecutive night sleeping either with, or without, their oral devices (in randomised order). Snoring (using a throat microphone), oxygen saturation, posture, and indirect beat to beat blood pressure were measured. The latter (using pulse transit time) provided an index of 'autonomic arousals' as well as a measure of respiratory effort. In all but one of these highly selected patients, the oral devices clearly reduced the amount of snoring $(P<0.006)$ from an average of 205(SD147) to 68(SD80) snores/hour (maximum number about $900 / \mathrm{hr}$ with a respiratory rate of $15 / \mathrm{min}$ ). There were no significant overall changes in respiratory effort, arousals or $>4 \% \mathrm{SaO}_{2}$ diprates. These patients represent only those who were able to tolerate the appliance, and we do not know how many snorers referred for the provision of such devices use them long term. However, with such clear evidence of their potential efficacy, and no suggestion from other studies of any harm, it would seem reasonable to introduce this approach into the management of antisocial snoring.

S20 IN VITRO AND EX VIVO APPROACHES TO DETERMINING THE MECHANISMS OF LIPOSOMEMEDIATED GENE TRANSFER

C.KITSON', L.HUANG ${ }^{2}$, F.SORGI ${ }^{2}$, DM.GEDDES ${ }^{1}$ \& EWFW.ALTON

'Ion Transport Unit, National Heart \& Lung Institute, London. ${ }^{2}$ Department of Pharmacology, University of Pittsburgh, USA

Gene therapy has reached clinical phase I studies for a number of disorders. One consistent conclusion is the low efficiency of gene transfer. To address this issue we have assessed the relative importance of the plasma cell membrane, the cytoplasmic compartment and the nuclear membrane as barriers for liposomemediated gene transfer under in vitro conditions. Using $\operatorname{Cos} 7$ cells and the reporter gene $\beta$ Galactosidase ( $\beta G$ al) we have shown that gene transfer is dependant on incubation time with efficient expression seen after 3-6 hours incubation. With the use of fluorescent tracers and a fluorescent plasmid/liposome complex we have determined that uptake is through receptor-mediated endocytosis. Complex uptake closely parallels gene expression suggesting the plasma membrane as a barrier to gene transfer. A hypertonic environment inhibits both uptake and expression further suggesting an endocytic mechanism. Cytochalasin D although inhibiting complex uptake results in a 3 fold increase in gene expression over control. This would suggest cytoplasmic trafficking as a barrier to gene transfer. Cells arrested in mitosis have no nuclear membrane and transfecting cells in this state results in a 3-4 fold increase in gene expression over controls. The nuclear membrane may also be a barrier to overcome. However, drawing conclusions from in vitro assays may not be relevant to in vivo situations. Therefore we have begun a series of experiments on freshly excised tissue from sheep trachea. Identical transfection conditions (to Cos7 cells) results in no detectable gene expression. Further, no detectable expression was seen after increasing both contact time and dose of plasmid. Having defined the potential ceullular mechanics for gene transfer in vitro, should allow the localisation of the inefficient step(s) in the pr viun mortel 
S21 SAFETY OF AEROSOL ADMINISTRATION OF ESCALATING DOSES OF A CATIONIC LIPID (LIPID 67) FORMULATION TO THE LUNGS OF NORMAL VOLUNTEERS

\section{'SL CHADWICK, ${ }^{2} \mathrm{HD}$ KINGSTON, ${ }^{2} \mathrm{BJ}$ O'CONNOR, ${ }^{3} \mathrm{SH}$ CHENG, ${ }^{3} \mathrm{D}$ MEEKER, 'DM GEDDES, AND 'EWFW ALTON}

'Ion Transport Unit, National Heart and Lung Institute, London. ${ }^{2} \mathrm{Clinica}$ Studies Unit, Royal Brompton Hospital, London. ${ }^{3}$ Genzyme Corporation, Cambridge, MA , USA.

Gene therapy for respiratory disease has increasingly focussed on the use of cationic liposomes as gene transfer agents. Transfer of the cystic fibrosis transmembrane conductance regulator gene (CFTR) into the nasal epithelium of patients with cystic fibrosis (CF) using DC CholDOPE showed no evidence of toxicity. To date no human data are available regarding the safety of intra-pulmonary cationic liposome delivery. In preparation for a trial of pulmonary delivery of the CFTR gene, we have now assessed the safety of nebulised lipid \#67 (Genzyme), the cationic lipid to be used in this study. 15 healthy volunteers were given incremental doses of lipid \#67 via a Pari LC Jet nebuliser with 3 volunteers given each dose at weekly intervals. Markers of safety included clinical assessment, measurement of lung function, chest CT scan, serological testing and analysis of induced sputum. Measurements were taken prior to administration and at intervals upto 21 days thereafter. No statistically significant changes in spirometry or gas transfer were seen. There were no clinically significant changes in any of the blood parameters measured and no CT changes were seen. Comparisons of the cellular subpopulations (neutrophils, eosinophils, lymphocytes and macrophages) present in the induced sputum showed no significant alterations following administration of the lipid. This study suggests that an aerosol formulation of lipid \#67 does not result in clinically detectable changes when given by nebulisation into the lungs of normal volunteers. We conclude that lipid \#67 is a suitable gene transfer agent for the forthcoming gene therapy trial in CF patients.

S23 IN VIVO TRANSFER OF THE $\beta$-GALACTOSIDASE GENE INTO MALIGNANT MESOTHELIOMA CELLS INDUCES TUMOUR REJECTION

'KATALIN V LUKACS, ' OLIVIER PARDO, 'COLIN PORTER, 'JAMES BROWNING, 'NATASHA J CAPLEN, 'MICHELLE MANVELL, ${ }^{2}$ MARY $K$ L COLLINS, 'DUNCAN M GEDDES AND 'ERIC W F W ALTON

'National Heart and Lung Institute, Imperial College, Manresa Rd, London SW3 6LR

${ }^{2}$ Institute of Cancer Research, Chester Beatty Laboratories, Fulham Rd, London SW3 6JB

Malignant mesothelioma is an aggressive, fatal serosal tumour with no effective treatment. However, the potential accessibility of the tumour localized to the pleural or peritoneal cavities, and the relative absence of metastases makes it a suitable candidate for gene therapy. In order to optimize the gene delivery system we used the $\beta$-galactosidase ( $\beta$-gal) reporter gene delivered into a model of malignant mesothelioma. Mice were injected with $10^{6}$ AC29 tumour cells (an asbestos-induced mesothelioma cell line) into the peritoneal cavity. Three days later the $\beta$ gal gene was delivered either by retrovirus, non-capsulated retrovirus or cationic liposome-complexed plasmid DNA. Mice were sacrificed 12 days later, tumour size determined and both histological and quantitative $\beta$-gal assays carried out to detect transduced cells in tumour samples, spleen, liver and peritoneum. Untreated controls (tumor size:1.68 $\pm 0.15 \mathrm{~g}$ ) or animals treated with the vehicle (liposome) only $(1.61 \pm 0.11 \mathrm{~g})$, rapidly developed disseminated tumours in the peritoneum. Mice injected with the non-capsulated virus showed no protection against tumour growth $(1.88 \pm 0.17 \mathrm{~g})$. However, mice injected with retrovinus $(0.65 \pm 0.1 \mathrm{~g})$ or plasmid-liposome complexes $(0.14 \pm 0.12 \mathrm{~g})$ showed a highly significant decrease $(p<0.001)$ in the tumour size. These data are in keeping with in vitro studies in which AC29 cells can be transfected with both retroviral and plasmid liposome vectors but not with the non-capsulated virus. However, neither histological analysis nor a quantitative assay detected $\beta$-gal positive cells in the tumour samples of treated mice. These results indicate the elimination of both transduced and untransduced tumour cells after in vivo gene transfer of a foreign protein. They also suggest that the efficiency of in vivo gene transfer is not accurately accessed by using bacterial marker genes, in keeping with data emerging in other areas of gene therapy.
S22 LOWER AIRWAY POTENTIAL DIFFERENCE MEASUREMENTS IN NON-CF AND CF SUBJECTS

'EWFW ALTON, 'SL CHADWICK, 'SN SMITH, 'M STERN, ${ }^{2} U$ PASTORINO, ${ }^{3} \mathrm{M}$ SCALLAN, 'DM GEDDES

'Ion Transport Unit, National Heart and Lung Institute, ${ }^{2}$ Dept of Cardiothoracic Surgery, ${ }^{3}$ Dept of Anaesthaesia, Royal Brompton Hospital, London, UK.

Clinical trials of gene therapy for cystic fibrosis (CF) are reaching the stage of intrapulmonary gene delivery. To assess the efficacy of this a technique to measure lower airway potential difference (PD) would be useful. We have, therefore, studied the baseline PD and responses to sequential perfusion with a low chloride solution, amiloride $(100 \mu \mathrm{M})$, isoprenaline $(100 \mu \mathrm{M})$ and ATP $(100 \mu \mathrm{M})$ in non-CF $(n=13)$ and $C F(n=6$, all $\triangle F 508$ FEV $1>70 \%$ predicted) subjects. Recordings were made under general anaesthesia to avoid the effects of lignocaine. For baseline PD measurements were made at 12 sites (trachea $\times 4$ ), (main bronchus $\times 4$ ), main, segmental, subsegmental airways and a 'wedge' recording. Drug perfusion was undertaken at 2 sites (segmental and tracheal, in that sequence) in each subject. Baseline PD was more negative at all sites in the CF subjects: trachea: non-CF $-8.2 \mathrm{mV}(1.1), \mathrm{CF}-16.1 \mathrm{mV}$ (2.3), main nonCF -7.4 (1.2), CF - 17.7 mV (3.0), lobar non-CF -5.4 mV (1.0), CF -21.1 $\mathrm{mV}$ (4.9), segmental non-CF -5.8 mV (1.0), CF -18.1 mV (4.4), subsegmental $-6.7 \mathrm{mV}(0.6), \mathrm{CF}-11.3 \mathrm{mV}(2.3)$, wedge non-CF $-4.5 \mathrm{mV}$ (0.8), CF $-7.7 \mathrm{mV}$ (2.1). Regions of high (more negative) PD were patchy in the CF subjects with maximum values for each region of: trachea -34.3 , main -38.5, lobar -39.7 , segmental -30.0 , subsegmental -24.0 , wedge -14.0 . Perfusion with a low chloride solution clearly distinguished the two genotypes in the segmental airways (non CF +13.7 mV (3.5), CF $-7.4 \mathrm{mV}$ (1.9)) and the trachea (non CF $+3.4 \mathrm{mV}(0.5), \mathrm{CF}-3.7 \mathrm{mV}$ (1.5). Similarly the response to amiloride was increased in the CF subjects: segmental (nonCF $28.6 \%$ (9.4), CF $69.3 \%$ (8.9)) trachea (non-CF $31.4 \%$ (7.9), CF $53.0 \%$ (11.2)). The responses to isoprenaline were abolished in the CF subjects: segmental (non-CF +4.4 mV (1.5), CF $0.0 \mathrm{mV}(0.0)$ ) trachea (non-CF +2.3 $\mathrm{mV}(1.0)$, CF $0.2 \mathrm{mV}(0.2)$ ). Responses to ATP were variable and small in non-CF but more readily seen in the CF subjects. We conclude that the lower airways of CF subjects demonstrate many of the electrophysiological features documented for the nasal epithelium, suggesting that these measurements may be useful for the assessment of gene transfer.

S24 HOLAN ALPHA 1-ANTITRYPSIN GENE TRANSFER WITH CATIONIC LIPOSOMES IN VITRO AND IN VIVO

H ROYAMA ${ }^{2}$, NJ CAPLEN ${ }^{2}$, S CHENG ${ }^{2}$, F SORGI ${ }^{3}$, L HUANG ${ }^{3}$, DM Geddes $^{1}$, EWFW ALTON ${ }^{1}$

${ }^{2}$ Ion Transport Unit, National Heart and Lung Institute, Imperial College, Manresa Road, London, UK, '2enzyme Imperial College, Manresa Road, London, UK, Genzyme Corp. Framingham, MA, USA, Dept. of
University of Pittsburgh, Pittsburgh, USA.

Protease-antiprotease imbalance is thought to play a major role in the development of emphysema. As alpha 1antitrypsin ( $\alpha \mathrm{AT})$ has been considered to be an important antiprotease in the prevention of emphysema, we evaluated the possible expression of human $\alpha A T$ following gene transfer. A plasmid containing the human QAT CDNA was transfected into COS-7, 16HBE140 and A549 cells using the cationic liposome DC-chol:DOPE, and to the lungs of Balb-C mice using liposomes containing the proprietary lipid ( 167 . Cenzyme Corp Framingham uSA) by nasal application. Human $\alpha A T$ expression was assayed by a double antibody sandwich ELISA. COS-7 cells maintained expression of human aAT for 8 days in both cell lysates and supernatants. The maximum level of human aAT detected in cell lysates from $\cos -7$ cells was human OAT detected in cell lysates from cos-7 cells was $84.0 \pm 10.6 \mathrm{ng} / \mathrm{mL}$, and in supernatants $171.7 \pm 12.8 \mathrm{ng} / \mathrm{mL}$. Levels of human aAT were lower in $16 \mathrm{HBE} 140$ and A549 cells (e.g. supernatants on day $2,16 \mathrm{HBE} 140$
$\mathrm{ng} / \mathrm{ml}$ and $\mathrm{A} 549: 7.6 \pm 1.2 \mathrm{ng} / \mathrm{mL}$ ) compared to cos-7 cells. $\mathrm{ng} / \mathrm{ml}$ and $\mathrm{A} 549: 7.6 \pm 1.2 \mathrm{ng} / \mathrm{mL}$ ) compared to cos-7 cells. homogenates following in vivo nasal administration of $80 \mu \mathrm{g}$ of $\alpha$ AT plasmid DNA $(52.1 \pm 3.7 \mathrm{ng} / \mathrm{mL})$. There was no significant increase in $\alpha A T$ expression following administration of 120 and $160 \mathrm{\mu g}$ of DNA (53.3 15.7 and $50.2 \pm 2.8 \mathrm{ng} \mathrm{mL}$, respectively). Gene expression was maximal on day $1(3.8 \mathrm{pg} / \mu \mathrm{g}$ of protein). To localise the site of human $\alpha A T$ expression, perfused and unperfused lungs were compared and lungs were separated into trachea/bronchi and parenchymal tissue. No significant decrease in $\alpha A T$ level was observed in perfused lungs compared to unperfused lungs $(111.6$ and $100.2 \mathrm{ng} / \mathrm{mL}$, respectively), suggesting that the expressed aAT was located within the pulmonary interstitium and/or airspace. Separate assessment of interstitium and/or airspace. Separate assessment of trachea/bronchi and lung parenchyma showed predominant expression in the latter. These results suggest that aAT gene transfer to lung parenchyma using cationic modulating proteolysis associated with emphysema. 
S25 CANCER CARE DELIVERY: ARE THE STANDARDS IN THE WHITEHOUSE REPORT ATTAINABLE

\section{A Mearns and M B Allen}

Department of Thoracic Surgery and Medicine, Bradford Royal Infirmary, Duckworth Lane, Bradford, BD9 6RJ

The Whitehouse report published in 1994 outlined the ideal periods between different stages of lung cancer care. We have examined if the standards suggested are attainable over 2 two month periods; Nov plus Dec 1994 and Jan plus Feb 1996 in two populations of patients, those referred to two chest physicians and to two thoracic surgeons offering a regional service at one hospital. Delays are expressed as median days (range). For some delays data was incomplete.

\begin{tabular}{|c|c|c|c|c|c|}
\hline & & $\begin{array}{l}\text { Physi } \\
104\end{array}$ & ians & $\begin{array}{r}\text { Sur } \\
11+120\end{array}$ & ons \\
\hline STA & ANDA & & & & \\
\hline Sample size & & 24 & 37 & 22 & 28 \\
\hline $\begin{array}{l}\text { delay from CXR } \\
\text { report to referral }\end{array}$ & $7 / 7$ & $4(0-16)$ & $2(0-13)$ & $9(0-90)$ & $4(0-6)$ \\
\hline $\begin{array}{l}\text { delay before } \\
\text { OPD }\end{array}$ & $14 / 7$ & $8(0-25)$ & $3(0-27)$ & $7(4-25)$ & $7(0-15)$ \\
\hline $\begin{array}{l}\text { delay before } \\
\text { bronchoscopy }\end{array}$ & $7 n$ & $10(2-44)$ & $8(1-42)$ & $7(0-23)$ & $7(1-18)$ \\
\hline $\begin{array}{l}\text { delay for } \\
\text { pathology } \\
\text { result }\end{array}$ & $7 / 7$ & $5(0-30)$ & $6(2-10)$ & $6(0-61)$ & $6(0-19)$ \\
\hline $\begin{array}{l}\text { median delay } \\
\text { (in weeks) from } \\
\text { CXR report to } \\
\text { surgery }\end{array}$ & $6-8 / 5$ & $9(3-13)$ & $11(3-25)$ & $5(3-12)$ & $10(6-20)$ \\
\hline
\end{tabular}

Most patient achieve the standards suggested and where delays occurred there was usually a clear reason. This audit suggests that the standards from the Whitehouse report are achievable for both physicians and surgeons.

\section{S27 IN-PATIENTS WITH LUNG CANCER: A STUDY OF THE EXTENT OF NON-REFERRAL TO SPECIALIST CARE}

\section{P.H.JOHNSON, L.HEATH, J.BRUNSKILL and I.D.A.JOHNSTON}

University Hospital, Nottingham NG7 2UH

There is evidence that a substantial proportion of patients with lung cancer (LC) may not be receiving specialist assessment, and concern that this could be partly responsible for the continuing poor survival from LC in the U.K. To define the extent and causes of non-referral of in-patients with LC to a specialist multidisciplinary team (MDT), we audited all admissions to our hospital during 1995 with an ICD code of thoracic or pleural cancer listed as a diagnosis on discharge.

199 such patients were admitted on 434 occasions. 152 patients were known, from a database kept by the MDT, to have had specialist assessment at some point. A Respiratory Physician (RP) was not involved during the admissions for 47 patients (23.6\%). Notes were available for review for 45 ( 21 female) accounting for 80 separate admissions. Of these 45, 25 (mean age 70) had had input from an RP elsewhere and 22 were still under active follow-up by an RP or Oncologist elsewhere for LC. Three had been lost to follow-up. Of these 25 patients, $40 \%$ were moribund on admission and died in hospital, $20 \%$ had routine surgery for problems related to LC, $30 \%$ had medical problems related to $\mathrm{LC}$ and $10 \%$ had unrelated problems

20 patients ( $10 \%$ of entire sample) (mean age 77 ) had no input from an RP or Oncologist at any stage. $65 \%$ of these 20 were admitted with problems related to advanced cancer and $75 \%$ died in hospital. In our opinion, non-referral to an RP led to inappropriate management in only three cases

We have shown that while 80 out of $434(18.4 \%)$ admissions of patients with LC were not under specialist care, most patients had indeed had specialist input at some point. The data provide no support for the contention that lack of access to specialist care is a major cause of poor survival in LC.
S26 WAITING TIMES IN LUNG CANCER: WHAT IS ACHIEVABLE BY A MULTIDISCIPLINARY TEAM?

P C DEEGAN, S STEVENS, L HEATH, J BRUNSKILL, W J M KINNEAR and I D A JOHNSTON

Department of Respiratory Medicine, University Hospital, Nottingham NG7 2UH

The Calman-Hine (1995) report has focused attention on standards of care in lung cancer. A multidisciplinary team (MDT) approach is recommended but little is known of the extent to which a MDT can achieve suggested waiting times to patient diagnosis and management. We have therefore prospectively studied 92 consecutive patients (median age 69.5 yrs [36-85], 67\% male) referred to our lung cancer MDT with a high suspicion of lung cancer over a five month period. Of these, $48 \%$ were GP referrals to outpatients (86\% seen within 14 days of receipt of referral [R]) and $46 \%$ were hospital consultant referrals (all inpatients seen within 2 days, and all outpatients within 14 days). Referral times were similar for all age groups. A definite diagnosis was already established at [R] in $8 \%$ patients. Of the remainder, $73 \%$ were booked when first seen [S] to either a flexible bronchoscopy ( $90 \%$ within 14 days of $[R]$ and $83 \%$ within 7 days of [S]) or percutaneous needle biopsy ( $70 \%$ within 14 days of $[R]$ and $83 \%$ within 7 days of $[S])$. Lung cancer was diagnosed in 81 patients $(88 \%)$ with a tissue diagnosis in $90 \%$. Diagnosis was obtained and given more rapidly from a "FastTrack" clinic with same day investigation ( $84 \%$ within 28 days of [R]), compared to a standard outpatients (64\% within 28 days of $[R])$. The diagnosis was given to the patient by a senior member of the MDT in $96 \%$ of cases, with $72 \%$ seeing an Oncology Nurse Specialist on the same day. Chemotherapy was given to $21 / 25$ with small cell cancer (all within 14 days of diagnosis given). Surgery was performed in 7 patients, all within 6 weeks of diagnosis given, and radical radiotherapy in one patient.

Conclusion: Waiting times were acceptable for a high proportion of patients. Nevertheless, even with an aggressive MDT approach, some patients waited longer than recommended. Whether such delays are due to service or patient factors needs further review.

S28 INFLUENCE OF THORACIC CT AND GUIDED FINE NEEDLE BIOPSY ON MANAGEMENT OF SOLITARY PULMONARY NODULES $\leq 3 \mathrm{~cm}$ IN DIAMETER

D R BALDWIN, ' A WELLS, J KOLBE, D MILNE, E STEELE, M WILSHER, T EATON, T CHRISTMAS, J MERCER, and J GARRETT

Departments of Respiratory Medicine, City Hospital, NOTTINGHAM,' UK. and Green Lane Hospital, AUCKLAND, New Zealand

The clinical utility of Computed Tomography (CT) and fine needle biopsy (FNB) in the assessment of patients with lung nodules is not known, especially in smaller, peripheral nodules (SPN). Aim: To determine the effect of CT and FNB on the clinical management decision in patients with solitary pulmonary nodules $\leq 3 \mathrm{~cm}$ in diameter on the initial chest radiograph. Method: The hospital notes of 117 patients having SPN $\leq 3$ $\mathrm{cm}$ were reviewed retrospectively and clinical, physiological and outcome data entered into a database. Chest radiographs and CTs were reported according to specified criteria by an expert radiologist. Computer generated summary sheets were used to present cases to each of 6 clinicians. Each case was presented 3 times, firstly with clinical data and chest radiograph only (CO), secondly with the addition of the CT report (CT); and finally with all data including the result of the FNB (FB). Clinicians were asked to specify their management each time. Reproducibility was assessed by re-evaluating 25 cases after a one month interval. Results: Kappa values for reproducibility showed median values of 0.79 to 0.89 (similar for each level of clinical data). Interobserver agreement was improved by addition of CT and FNB data (median kappa increased from 0.32 to 0.50 for management decision). The ratio of decisions which agreed with outcome to those that disagreed increased with addition of CT reports and further with the FNB report $(p=0.006$ Friedman's test). See table:

\begin{tabular}{lccc} 
& Agreements (\%) & Disagreements (\%) & Ratio Agree/Disagree \\
\hline CO & 48.8 & 49.6 & 0.90 \\
CT & 56.2 & 42.3 & 1.32 \\
FB & 64.9 & 33.5 & 2.08 \\
\hline
\end{tabular}

Conclusion: In the managment of SPN $\leq 3 \mathrm{~cm}$ in diameter, both CT and FNB improve the appropriateness of clinical decisions and agreement between clinicians. 
S29 QUALITY OF LIFE (QOL) IN PATEENTS WTTH LUNG CANCER: AN IMPORTANT PROGNOSTIC PACTOR

\section{A Montazeri,' R Milroy, ${ }^{2}$ CR Gillis, ${ }^{3}$ \& J McEwen'}

1 Department of Public Health, University of Glasgow, 2 Lilybank Gardens G12 8RZ; ${ }^{2}$ Department of Respiratory Medicine, Stobhill Hospital NHS Trust; ${ }^{3}$ West of Scotland Cancer Surveillance Unit.

A population-based study was conducted to measure $Q O L$ in patients with lung cancer. Data were collected from a series of interviews with patients attending a chest clinic in Stobhill Hospital, Glasgow. QOL was measured at baseline and three months after diagnosis, using the Nottingham Health Profile (NHP) and the EORTC QLQ-C3O and QLQ-LC13. Baseline assessments were scheduled after referral by GPs and before the diagnosis was made. At the time of baseline interview both interviewer and patients were blind to the diagnosis.

In all, 129 lung cancer patients were interviewed (mean age $67.5 \pm 9.1$ years). Of these, $77(60 \%)$ were male.

The Cox's regression analysis using the forward conditional model was performed to determine predictors of survival. Global QOL prior to diagnosis was found to be the strongest predictor of the length of survival even after adjusting for the known prognostic factors: age, gender, performance status, extent of disease, and weight loss. The results are listed below:

\begin{tabular}{lll}
\hline Parameter & Hanard ratio & P \\
\hline Age & 1.07 & 0.003 \\
Extensive disease & 3.07 & 0.003 \\
Global QOL (poorer) & 3.19 & 0.002 \\
\hline
\end{tabular}

This study indicates the importance of measuring QOL, and suggests that QOL prior to diagnosis is a clear and significant prognostic factor and should prospectively be evaluated in lung cancer patients.

\section{S31 RISK FACTORS FOR DRUG RESISTANCE IN PATIENTS WITH TUBERCULOSIS IN ENGLAND AND WALES 1993-94}

\section{HAYWARD AC, BENNETT DE, HERBERT J, WATSON JM}

\section{PHLS COMMUNICABLE DISEASE SURVEILLANCE CENTRE LONDON UK}

Introduction In light of recent outbreaks of multidrug resistant tuberculosis (MDRTB) in London and increasing concerns about drug resistant tuberculosis worldwide there is a need to understand the epidemiology of drug resistant tuberculosis in this country. We describe a case control study of risk factors for drug resistance. Data collection is ongoing.

Methods Subjects were drawn from the MYCOBNET database (the UK reference laboratory reporting system for tuberculosis). Cases ( $n=306$ ) were all culture confirmed cases of tuberculosis with resistance to either isoniazid (H) or (R) (or both) from England and Wales in 1993/4. 306 controls with fully sensitive tuberculosis were selected. Data on risk factors was obtained from surveillance information, Consultants in Communicable Disease Control and clinicians Data on HIV infection was obtained by matching the MYCOBNET dataset with the HIV/AIDS datasets at the PHLS AIDS Centre, Logistic regression analysis was used to calculate odds ratios (OR) and $95 \%$ confidence intervals $(95 \% \mathrm{Cl})$ controlled for confounders.

Results Independent risk factors for drug resistance included:- Ethnicity Indian subcontinent ethnic group (OR 2.3, (95\% CI-1.3-4.1) and black African ethnic group (OR $2.2(1.0-4.4) \mathrm{p}=0.01)$; previous treatment (OR 3.1 (1.8-5.3) $\mathrm{p}<0.0001)$, HIV (OR 4.3 (1.9-9.8) $\mathrm{p}=0.0003$; chronic illness (OR 2.9 (CI 1.0-8.5) $\mathrm{p}=0.04$ ) and residence in London (OR 1.7 (1.22.5) $\mathrm{p}=0.006$ ) Drug resistance was more common in younger adults and more recent immigrants Independent risk factors for multidrug resistant tuberculosis (resistance to $H$ and $R$ with or without other drugs) $(n=56)$ were male gender (OR 2.2 (1.1-4.3) $\mathrm{p}=0.024)$; birth in India (OR 4.6 (1.2-18.1); previous treatment (OR 11.7 (5.5-25) p<0.0001); HIV (OR 8.9 (2.1-38.7) $\mathrm{p}=0.003)$ and residence in London (OR 4.0 (1.7-9.3) $\mathrm{p}=0.001)$. Both resistant and multidrug resistant patients were more likely to remain culture positive for more than one year (OR 11.8 (3.1-44.3) and 17.7 (3.7-84.3) respectively. Discussion The results highlight those groups in whom drug resistance should be suspected.

\section{S30 EFFECTS OF IATTERSTITIAN IASER}

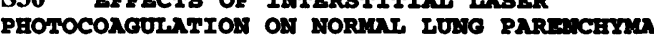

D.I.FIELDING , G.BUONACCORSI , A. HANBY ,

M.HETZEL and S.G.BOWN

University College London Medical School and

Imperial Cancer Research Fund, London WC1E6JJ

Poor lung function can preclude surgical cure of non small cell lung cancer and post radiation fibrosis limits the role of radiotherapy. An alternative treatment in patients unfit for surgery may be the use of interstitial laser surgery may be the use of interstitial laser percutaneously into tumours as for a fine needle biopsy and necrosis is produced by gentle localised heating from a low power laser.As tumour ablation will require treatment of some normal adjacent tissue we investigated the effects of ILP on normal lung parenchyma.

In Wistar rats a $0.4 \mathrm{~mm}$ fibre was inserted percutaneously under general anaesthetic into the the left lung. All rats had fluoroscopic screening immediately after ILP to detect pneumothorax.

Lesions were ellipsoid in shape centred around the fibre tip . Maximum diameter of necrosis at 4 days was $12 \mathrm{~mm}$ using $3 \mathrm{~W} \times 333 \mathrm{~s} .(\mathrm{n}=15)$ Histology demonstrated well demarcated thermal necrosis at 4 days and by 6 months showed a small fibrous granuloma surrounding remnants of charred tissue. In groups of at least 4 animals using 2 W250s, mean lesion sizes at $4,10,60120$ and 180 days were lesion sizes at $4,10,60120$ and 180 days were
$5.5,5.5,3.5,4.5$ and $4 \mathrm{~mm}$ respectively. 8 of 60 rats developed pneumothorax, due in 5 cases to laser effect at the proximal end of the fibre causing a hole in the chest wall in these small animals

The acute effects of ILP on the lung are comparable to that seen in other organs and there is satisfactory long term healing.The low incidence of pneumothorax may be due to a sealing effect on the lung by the laser. Multiple fibres could be used simultaneously.

Conclusion: ILP is safe in normal lung parenchyma and may be appropriate for treating small peripheral tumours.

\section{S32 DRUG RESISTANT TUBERCULOSIS IN ENGLAND} AND WALES, 1993-1995

D E BENNETT, A R BRADY, J HERBERT, F DROBNIEWSKI, $M$ CHADWICK, I FARRELL, N LIGHTFOOT, B WATT, R WILLIAMS, A HAYWARD and J M WATSON

Introduction The Mycobacterial Resistance Network, a laboratory based reporting system for Mycobacterium tuberculosis complex isolates, was launched in 1993. All major mycobacterial laboratories in the country participate. The system was developed to detect changes in antibiotic resistance patterns and associated risks.

Methods Information reported on all initial Mycobacterium tuberculosis complex isolates in a calendar year is collated and deduplicated at the Public Health Laboratory Service Communicable Disease Surveillance Centre. Data held includes antibiotic resistance patterns and a minimum dataset including demographic, geographic, and other risk factors. Missing data items are sought by the CDSC co-ordinators from clinical and public health. Proportions of culture positive tuberculosis cases resistant to first line antituberculous drugs were calculated and analysed using chi-square test for trend. Population rates were calculated for 1993/1994 using denominators from the British Labour Force Survey and the Office of National Statistics.

Results From England and Wales, 3063 isolates were reported in 1993, 2929 in 1994, and 2452 for 1995 (preliminary). Multidng resistance (MDR:resistance to isoniazid and rifampicin) was seen in $18(0.6 \%)$ cases in $1993,42(1.4 \%)$ cases in 1994, and $55(1.9 \%)$ cases in 1995; chi-square test for trend is significant at $p<0.001$. Demographic information is incomplete for 1995. Over half the MDR cases in 1993/94 were seen in people belonging to the white ethnic group. MDR tuberculosis population rates were highest in the Black African ethnic group but rose most steeply in the white and Indian subcontinent (ISC) ethnic groups between 1993-1994. (See Table One).

Table One: Rates of MDR Tuberculosis in ethnic subgroups, 1993-1994

\begin{tabular}{|c|c|c|c|c|c|c|}
\hline & \multicolumn{2}{|c|}{1993} & \multicolumn{2}{|c|}{1994} & \multirow[t]{2}{*}{$\mathrm{RR}^{* *}$} & \multirow[t]{2}{*}{$95 \% \mathrm{Cl}^{*}$} \\
\hline & Cases & Rate* & Cases & Rate* & & \\
\hline White & $\overline{7}$ & 0.13 & $\overline{23}$ & 0.44 & 3.29 & (1.4-7.7) \\
\hline African & 4 & 13.76 & 6 & 20.63 & 1.50 & $(0.4-5.3)$ \\
\hline Caribbean & 1 & 1.98 & 1 & 1.98 & 1.00 & $(0.1-16.0$ \\
\hline ISC & 4 & 2.52 & 14 & 8.84 & 3.50 & (1.2-10.6 \\
\hline
\end{tabular}

${ }^{*}$ per million, **Rate Ratio, ${ }^{* * *}$ Confidence Intervals

Conclusions Rates of multidrug resistant tuberculosis remain lower in England and Wales compared with high-prevalence areas in the United States, but rates are rising. Measures to ensure prompt and appropriate diagnosis and treatment, and to minimise transmission in health care settings, should be implemented. 


\section{S33 CULTURE POSITIVE TUBERCULOSIS IN HIV}

\section{SEROPOSITIVE PATIENTS IN THE UK, 1993-94}

D E BENNETT, D HOWITT, J HERBERT, M CHADWICK, I FARRELL, $N$ LIGHTFOOT, B WATT, R WILLIAMS,F DROBNIEWSKI and J M WATSON

Introduction HIV has not been considered to have contributed significantly to tuberculosis incidence in the UK in the 1980s and early 1990s. We matched datasets from MYCOBNET, the reference laboratory reporting system in the UK, to the HIV and AIDS reporting systems to describe the recent interactions between the two infections and the risk factors associated with tuberculosis and drug resistance in the HIV seropositive population.

Methods Datasets from MYCOBNET and HIV/AIDS reports were matched using SOUNDEX code and date of birth. Population rates of culture-positive tuberculosis and multidrug resistant (MDR) tuberculosis were calculated using denominators from the 1995 AIDS Projections Working Group.

Results HIV seropositivity was associated with two hundred and eightytwo (4.2\%) of the 6694 cases of culture positive tuberculosis in the UK in 1993-94. Rates of culture positive tuberculosis in the HIV seropositive population in the UK increased significantly between 1993 (400 per million) and 1994 (7400 per million); HIV-associated rates of MDR tuberculosis increased significantly from 120 per million in 1993 to 161 per million in 1994. Nearly half of both the HIV seropositive and HIV seronegative people with tuberculosis came from the white ethnic group (48\% and $47 \%$ respectively), but a larger proportion of the HIV seropositive people were African (32\% vs. $5 \%$ ) or Caribbean ( $1.7 \%$ vs. $0.6 \%$ ) and a smaller proportion were of Indian subcontinent ethnic origin ( $11 \%$ vs. $20 \%$ ). Males predominated in both groups, but to a greater extent in the group with HIV ( $72 \%$ vs. $59 \%)$.

Discussion As the decline in tuberculosis rates has slowed in the UK, people with HIV may be at greater risk of nosocomial infection and development of active disease, and rates may begin to rise more quickly in this population in the mid-1990s. Because MDR tuberculosis is more difficult to treat and cases may remain active and infectious for longer, and because some HIV infected people in this country have lived in developing countries where MDR rates are higher, MDR tuberculosis rates may increase more quickly among this group. It is urgent to implement measures to minimise transmission and assure institution of prompt and appropriate treatment.

S35 Long-term trends in tuberculosis: comparison of age-cohort data in Hong Kong and England and Wales.

Tocque, $K^{1}$, Bellis, MA ', Tam, $\mathbf{C M}^{2}$, Chan, $\mathbf{S L}^{2}$, Syed, $\mathbf{Q}^{1}$, Davies, PDO $^{3}$

${ }^{1}$ CDSC North West, PHL, Fazakerley Hospital, Liverpool, L9 7AL

${ }^{2}$ Dept. of Health Chest Service, Wanchai Polytechnic, Kennedy Rd, Hong

Kong. ${ }^{3}$ Tuberculosis Research Unit, Thomas Drive, Liverpool.

This study compared rates of tuberculosis, between 1954 and 1994, in different birth cohorts in Hong Kong with TB rates in similar birth cohorts in England and Wales, where the number of cases was around ten times lower. In both places, the rate of TB at any given age was lower for each successive birth cohort.

Age-specific TB rates in all birth cohorts showed a typical gradual decline in the probability of developing tuberculosis after the age of 24. That is, until 1978 in Hong Kong and 1984 in England and Wales, after which the rates of tuberculosis in all cohorts born before 1950 stopped declining and began to rise again, irrespective of their age at the time: the probability of developing TB began to rise after the age of 34 in the youngest cohorts (born 1940-49) but not until after the age of 64 in the oldest cohorts (born 1910-19).

Increasing risk of tuberculosis with age has never been observed before in previous cohort studies. The increase at different ages in different birth cohorts shows that increased longevity of the elderly today, with reactivation of latent disease, is not a major factor contributing to recent trends in tuberculosis. Higher levels of disease in immigrants of all ages with transmission of disease to all age groups could explain this ubiquitous increase in risk. However, more complete reporting of tuberculosis in recent years following the increased global awareness of the disease may also be a contributing factor.
S34 TUBERCULOSIS IN HEALTH CARE WORKERS IN THE WEST MIDLANDS 1992 TO 1995

\section{A HILL*, A BURGE+ and C SKINNER*}

Departments of Respiratory Medicine* and Occupational Health+, Birmingham Heartlands Hospital, Birningham B9 5SS

Tuberculosis (TB) is a prescibed occupational disease for health care workers. A 4 year prospective study (1992-1995) was carried out to assess the incidence of TB in NHS hospital staff in the West Midlands and evaluate the effectiveness of occupational health screening and surveillance procedures. Case ascertainment was through occupational health departments (OHD) and the Midlands Thoracic Society (MTS) rare diseases registry.

No case was known to an OHD that was not notified via the MTS registry. In addition, the MTS registry yielded a further six cases not known to an OHD. There were 26 cases of active tuberculosis (8 nurses, 14 doctors and 4 others (mortuary attendant, physiotherapist, radiographer and theatre technician)) and 2 cases of presumed tuberculous infection. 24/26 cases with active tuberculosis presented with symptoms, the other 2 were picked up by community contact screening and occupational surveillance (in error). 12/26 cases had no preemployment screening. The annual incidence of tuberculosis was $5 / 10^{3}$ in nurses, $60 / 10^{5}$ in doctors $\left(239 / 10^{5}\right.$ in indian subcontinent (ISC) doctors), $10 / 10^{5}$ in others and $12 / 10^{5}$ overall compared to $14 / 10^{5}$ in the local population of working age and $165 / 10^{5}$ in the working age local ISC ethnic group. All except one doctor were foreign born, mainly ISC and of recent entry to the UK.

Case ascertainment via the MTS rare diseases registry was complete. The incidence of tuberculosis in hospital health care workers was no more than the local population of working age with the exception of doctors $(p<0.005)$ whose risks appear to be ethnic and recent entry to the UK rather than being occupational. Pre-employment screening especially in doctors is lax. Current British Thoracic Society recommendations for the control and prevention of tuberculosis in health care workers (Joint Tuberculosis Committee. Thorax 1994;49:1193-1200), including prompt reporting of suspicious symptoms, are adequate.

S36 ADMINISTRATION OF THE BCG VACCINATION USING THE MULTIPUNCTURE METHOD IN SCHOOLCHILDREN A COMPARISON WITH THE INTRADERMAL METHOD

N Al Jarad1, R Obeng 2, L Swann 2, M Whyte 2, E A Paul 1, DW Empey1 and G Duckworth ${ }^{3}$

1. East London TB Service 2. Locality Services for Tower Hamlets,

3. Communicable Disease Department, Tower Hamlets

BCG vaccination using the multipuncture device (the Heaf gun) is licensed in the UK for children under two years. The aim of this study is to investigate the rate of conversion of tuberculin test, safety and acceptability of BCG vaccination using the multipuncture device and compare this with the conventional intradermal method in schoolchildren (11-14 years old).

Schoolchildren attending schools in Tower Hamlets who were eligible for BCG vaccination were tuberculin tested using the Heaf gun. Those with a weak reaction (grades 0-1) were randomised to receiving BCG vaccination using either the multipuncture or the intradermal methods. The BCG scar was observed after eight weeks for size and for signs of inflammatory changes. A questionnaire about fear of BCG vaccination and pain and inflammation of the BCG site was administered. Eight weeks after vaccination the Heaf test was repeated and the results were assessed by an examiner who was unaware of the results of the previous Heaf test and the type of BCG received. A change of at least one grade was required for the Heaf test to be considered as converted.

One hundred and sixty nine children completed the study of these 81 received BCG by the multipuncture method. There were 86 males in the sample and the mean age was 11.8 years. One hundred and twenty-five children were Caucasians and the rest were from other ethnic groups.

The Heaf test did not convert in $22 / 81(27.2 \%)$ receiving BCG by the multipuncture device compared with $6 / 88(6.8 \%)$ of those who received the vaccine by the intradermal method, odds ratio $0.2,95 \%$ confidence interval 0.07 . 0.55. The BCG scar was visible in all children who had intradermal BCG compared with $67 / 81(81.8 \%$ ) of the multipuncture group, odds ratio $0.0,95 \%$ confidence interval. The multipuncture method was less painful and caused fewer inflammatory changes than the intradermal method.

In schoolchildren the multipuncture device for administering BCG caused a lower rate of conversion of the Heaf test and less degree of a scar formation than the intradermal method. 
S37 LONG TERM EFFECTS OF NON-INVASIVE INTERMITTENT POSITIVE PRESSURE VENTILATION (NIPPV) ON CHRONIC VENTILATORY FAILURE DUE TO COPD

P.SIVASOTHY, I.E.SMITH AND J.M. SHNEERSON

RSSC, Papworth Hospital, Papworth Everard, Cambridge CB3 8RE

The role of non-invasive ventilation in chronic respiratory failure due to COPD is unclear. We retrospectively studied 29 patients (15 men) mean age 64.4 $\pm 1.7 \mathrm{SEM}$, who presented with chronic ventilatory failure in whom oxygen therapy failed due to a rise in daytime $\mathrm{pCO}_{2}$ in 25 patients and nocturnal transcutaneous $\mathrm{CO}_{2}\left(\mathrm{PtcCO}_{2}\right)$ in 4 . At presentation mean smoking duration was $44 \pm 4.7$ pack years, FEV $127.0 \pm 2.52$ and FVC $62.6 \pm 4.15 \%$ predicted, and the haematocrit was $0.492 \pm 0.01$. All patients were treated with non-invasive ventilatory support (18 NIPPY, 6 Monnal D and 5 BIPAP ventilators). 16 were also treated with supplementary oxygen flow rates of 0.5 to $2 \mathrm{lmin}^{-1}$. The mean baseline blood gases, overnight oximetry $\left(\mathrm{SaO}_{2}\right), \mathrm{PtcCO}_{2}$ data, and haematocrit measurements at 1 month, 6 months and 12 months after starting NIPPV therapy are tabulated below.

\begin{tabular}{|l|l|l|l|l|}
\hline Time/ $\mathrm{n}^{*}$ & baseline(29) & 1 month(28) & 6 month(24) & 1 Year(18) \\
\hline $\mathrm{pCO}_{2}$ & $8.44 \pm 0.2$ & $7.46 \pm 0.1$ & $7.18 \pm 0.2$ & $6.91 \pm 0.2$ \\
\hline $\mathrm{pO}_{2}$ & $6.06 \pm 0.2$ & $7.64 \pm 0.3$ & $8.0 \pm 0.4$ & $8.23 \pm 0.3$ \\
\hline $\mathrm{SaO}_{2}$ (day) & $77.5 \pm 1.8$ & $88.4 \pm 1.0$ & $87.8 \pm 1.4$ & $90.9 \pm 0.9$ \\
\hline $\mathrm{SaO}_{2}{ }^{* *}$ & $79.6 \pm 2.19$ & $89.7 \pm 0.6$ & $90.1 \pm 1.2$ & $91.1 \pm 1.2$ \\
\hline $\mathrm{PtcCO}_{2}^{* *}$ & $8.81 \pm 0.3$ & $6.83 \pm 0.4$ & $6.72 \pm 0.3$ & $6.75 \pm 0.3$ \\
\hline haematocrit & $0.494 \pm 0.01$ & $0.463 \pm 0.01$ & $0.459 \pm 0.01$ & $0.442 \pm 0.01$ \\
\hline
\end{tabular}

*= maximum number of data points ${ }^{* *}=$ mean overnight Comparison of measurements between baseline and lmonth, and baseline and 1 year revealed significant improvement in arterial blood gases, $\mathrm{PtcCO}_{2}$ overnight oximetry and haematocrit. There were no significant improvements between 1 month and six months or 1 month and 1 year Quality of life was assessed in 9 patients, using the SF-36 questionnaire, at initiation of NIPPV and after 6 months and one year. This revealed no significant changes in general health perception, social function and physical function scores. Mean duration of survival was $48.36 \pm 6.95$ months(Kaplan-Meier). Our results demonstrate that in this group of patients with ventilatory failure that NIPPV significantly improved daytime blood gases and overnight oximetry and quality of life was maintained.

S39 THE EFFECT OF VENTILATORY INTERVENTION IN ACUTE RESPIRATORY FAILURE IN MOTOR NEURONE DISEASE

\section{P.SIVASOTHY, I.E.SMTTH AND J.M.SHNEERSON}

RSSC, Papworth Hospital, Papworth Everard, Cambridge CB3 8RE

Ventilatory interventions are often reluctantly undertaken when the diagnosis of motor neurone disease (MND) is known because of the progressive nature of the disease. We retrospectively reviewed two groups of patients with MND; those referred to us from ICU for optimisation of ventilatory support (Group $A$ ) and those referred from home for elective respiratory intervention (Group B). Group A consisted of 12 patients (11 men), mean age $62.2 \pm 3.41$ (SEM). All had complained of breathlessness in the 3 months preceding intubation. The diagnosis of MND was made in 6 patients post-intubation. Group B consisted of 5 patients $(5$ men), mean age $56.12 \pm 3.17$, who underwent elective respiratory intervention for hypercapnia(3/5), nocturnal hypoxia(1/5) or vocal cord dysfunction (1/5). Mean baseline (pre-intubation in Group A or pre-intervention in Group B) arterial blood gas measurements, the ability to walk or dress independently, and the presence of bulbar symptoms are tabulated below.

\begin{tabular}{|l|l|l|l|l|l|l|}
\hline & + & b02 & pCO2 & Walk & dress & Bulbar \\
\hline Group A & $52.8 \pm 4.5$ & $12.6 \pm 3.9$ & $8.43 \pm 0.7$ & 8 & 5 & 9 \\
\hline Group B & $37.2 \pm 1.0$ & $6.5 \pm 0.4$ & $9.42 \pm 0.4$ & 2 & 1 & 3 \\
\hline
\end{tabular}

All patients in group $\mathrm{A}$ were successfully established on nocturnal ventilatory support ( 2 cuirass, 3 tracheal IPPV, 7 nasal IPPV) and had a mean survival of 14.4t2.44 (SEM) months (Kaplan-Meier) and ten patients were followed-up at Papworth, (range 4.3-28.3 months). There were no significant relationships between survival and prior functional leve or bulbar involvement showing that in this group they were poor predictors

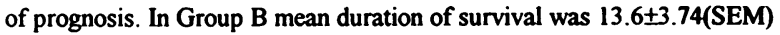
months.

The results from our group of MND patients show that ventilation should not be excluded or terminated without an attempt to wean and establish on alternative ventilatory support on the grounds of poor prognosis. Irrespective of whether the diagnosis is known prior to intubation or made post-intubation the outlook in this group is as good as that of patients referred electively for ventilatory intervention.
S38 RANDOMISED CROSSOVER STUDY OF INSPIRATORY POSITIVE AIRWAY PRESSURE ON GAS EXCHANGE AND DYSPNOEA DURING NASAL VENTILATION IN STABLE COPD

EM WARD, JC BESTALL, TR SEEMUNGAL and JA WEDZICHA

Respiratory Care Unit, London Chest Hospital, London E2 9JX

Nasal positive pressure ventilation (NIPPV) is effective in selected hypercapnic patients with stable COPD, though correction of blood gases may be more difficult to achieve in these patients, than in other causes of respiratory failure. Increasing inspiratory positive airway pressure (IPAP) during pressure cycled NIPPV could improve gas exchange.

We studied 11 stable hypercapnic COPD patients on home NIPPV (median age 63 (42-76)yrs), mean (SD) FEV1 0.91(0.35)I, FVC 1.8 $(0.74)$ l. Pressure cycled ventilation was administered through a BiPAP nasal ventilator. Patients were randomised to either conventional IPAP (Mode A; median IPAP $22 \mathrm{~cm} \mathrm{H} 20$, EPAP $2 \mathrm{~cm} \mathrm{H20)} \mathrm{from} \mathrm{the} \mathrm{BiPAP} \mathrm{ST}$ ventilator for a 2 hour period or the higher IPAP from the BIPAP ST 30 (Mode B; median IPAP $29 \mathrm{~cm} \mathrm{H20}$ ) and then crossed over to the alternative mode. Overnight continuous measurement of $\mathrm{PaCO} 2$ and $\mathrm{SaO} 2$ were performed on both modes. There was a significant reduction in daytime $\mathrm{PaCO} 2$ with Mode $\mathrm{A}$ after 2 hours, with the $\mathrm{PaCO} 2$ falling from $6.57(0.61)$ to $6.16(0.93) \mathrm{kPa}(\mathrm{p}<0.05)$, but a greater fall with Mode $B$ from 6.87(0.58) to $5.48(0.98) \mathrm{kPa}(\mathrm{p}<0.001)$; mean difference $\mathrm{p}<0.01$. There were no significant differences in $\mathrm{PaO} 2$ changes between the two groups. Visual analogue scores after 2 hours showed a reduction in breathlessness with Mode B ( $<<0.02)$. Overnight monitoring of blood gases showed that there were no significant differences between the baseline and overnight mean or baseline and overnight maximum $\mathrm{PaCO} 2$ in the two groups (Mode $\mathrm{A}$ : mean $\mathrm{PaCO} 2: 7.56(0.98) \mathrm{kPa}$, max $\mathrm{PaCO} 2$ $8.49 \mathrm{kPa}$; Mode B: mean $7.57(0.98) \mathrm{kPa}, \max 8.81 \mathrm{kPa})$. There was also no difference in the time spent below $90 \% \mathrm{SaO} 2$ in the two groups.

Increasing IPAP during NIPPV improves daytime gas exchange and reduces dyspnoea, though there were no advantages overnight, perhaps due to increased arousal with the higher pressure. Use of a higher IPAP, producing improved gas exchange, may be useful in acute exacerbations of COPD, or for daytime ventilation in stable COPD. However, it has no additional advantage during home nocturnal ventilatory support in COPD.

\section{S40}

\section{PATTERNS OF ABNORMALITY ON OVERNIGHT OXIMETRY BEFORE AND DURING NIPPV}

SMTTH IE AND SHNEERSON JM

The Respiratory Support and Sleep Centre, Papworth Hospital, Cambridge

There are few reports of the effects of nasal intermittent positive pressure ventilation (NIPPV) on the patterns of abnormality of overnight arterial oxygen saturation ( $\mathrm{SaO} 2)$. We retrospectively scored the oximetry traces of 95 patients (mean age 55, SD 14.1 years, 55 men), before (t0) and during (tl) NIPPV to determine the effects of treatment on the mean and minimum $\mathrm{SaO} 2$ and the incidence of dips in SaO2. Prolonged, profound dips (PPdips) were defined as a fall in $\mathrm{SaO} 2$ lasting for $>5$ minutes, of $>10 \%$ to a nadir of $<85 \%$ and were scored as present or absent. The desaturation index (DI) was defined as the number of dips in $\mathrm{SaO} 2=$ or $>4 \%$ per hour.

Thirty seven patients had a scoliosis, 23 a neuromuscular disorder, 21 COPD and 14 a thoracoplasty for TB. None used added oxygen. At to the means of daytime $\mathrm{PaO} 2$ and $\mathrm{PaCO} 2$ were 7.49 (1.63) $\mathrm{kPa}$ and 8.11 (1.67) $\mathrm{kPa}$ and of overnight mean and minimum $\mathrm{SaO} 2$ were $80.4(8.83) \%$ and 54.1 (16.26) \% respectively. 71 patients had PPdips. Using Chi squared PPdips were more frequent than expected in patients with a neuromuscular disorder and less in those with a scoliosis or thoracoplasty $(p=0.02)$. The median DI was 12 (range 0 to 70). DI was not related to diagnosis and correlated only weakly with $\mathrm{PaO} 2(r=-0.23, \mathrm{p}=0.025$ ). At $\mathrm{tl}$, a median of 3 months later, there were significant improvements in $\mathrm{PaO} 2, \mathrm{PaCO} 2$, mean and minimum overnight $\mathrm{SaO} 2$ with mean differences of $+1.67 \mathrm{kPa},-2.01 \mathrm{kPa},+11.9 \%$ and $+25.4 \%$ (all p values $<0.001$ ). PPdips were still present in 34 patients and were seen de novo in 2 patients. As at to they were less frequent than expected in patients with a thoracoplasty. The median DI was 5 (range 0 to $64)$, which was lower than at to $(p<0.001)$ but it was higher in 9 patients. $\mathrm{DI}$ at $\mathrm{tl}$ correlated with $\mathrm{DI}$ at $\mathrm{tO}(\mathrm{r}=0.37, \mathrm{p}=0.001)$ but not to $\mathrm{PaO} 2$ at $\mathrm{tl}$.

These results show that while daytime blood gas tensions and overnight mean and minimum $\mathrm{SaO} 2$ were improved by NIPPV, many patients still had abnormal dips in $\mathrm{SaO} 2$ and in some these were induced or exacerbated by the treatment. Such dips may have implications for the long term success of NIPPV but were not closely related to the daytime PaO2. Monitoring of overnight $\mathrm{SaO2}$ in addition to daytime arterial gas tensions should be considered in the surveillance of all patients using long term NIPPV. 
DIPS IN OVERNIGHT ARTERIAL SATURATION DURING NIPPV: RELATIONSHIPS WITH SLEEP STAGES AND VENTILATORS

\section{SMTTH IE AND SHNEERSON JM}

The Respiratory Support and Sleep Centre, Papworth Hospital, Cambridge

Mouth leaks and episodes of glottic narrowing (causing obstruction) have been shown to cause dips in overnight arterial saturation $\left(\mathrm{SaO}_{2}\right)$ in subjects using NIPPV. We compared the desaturation index (DI = number of dips in $\mathrm{SaO} 2$ of $=$ or $>4 \%$ per hour of sleep) and the sleep stage relationships and mochanisms leading to the greatest desaturation (Dsat max) between the Monnal D (MDV. Taema, Paris) and the Papworth ventilator (PWV. Si Plan, Stratford upon Avon) a new pressure preset device for NIPPV.

Ten subjects ( 6 men) with a mean age of 56 (16.4) years and a mean duration of NIPPV treatment of 36 (18.9) months using the MDV without additional oxygen were studied. Each had 2 polysomnographic studies, one on their own ventilator and one on the PWV. The order of the studies was alternated for consecutive subjects. In addition to EEG, EOG, EMG and $\mathrm{SaO2}$, mask pressure and inspired and expired volumes at the nasal mask were recorded by a pressure transducer and a pneumotachograph in line between the mask and the ventilator circuit to document leaks and obstructions. The mean overnight $\mathrm{SaO2}$ on the two ventilators was not significantly different. The DI was significantly lower on the PWV (mean difference - 7.3, p = 0.009) though the DI within subjects and between ventilators was highly correlated $(r=0.85, p=0.002)$. The minimum SaO2 using the PWV tended to be higher (mean difference +7.73$)$ but this was not significant $(p=0.084)$. The Dsat max started within 1 minute of wakefulness in 6 subjects when using the MDV and in only 2 with the PWV. The minimum $\mathrm{SaO} 2$ occurred in stage 2 and REM sleep in 6 and 3 subjects and in 3 and 6 subjects when using the MDV and the PWV respectively. Leaks were the cause of the Dsat max in 6 subjects on the MDV while obstructions were associated with the Dsat max in 7 on the PWV. In one subject using the MDV the Dsat max was caused by a fall in tidal volume $(\mathrm{Vt})$ when the patient greatly raised the triggering rate.

The DI was reduced by the PWV probably by a reduction in the impact of leaks. The Dsat max at sleep onset may be due to relative hyperventilation with the MDV during wakefulness while with the PWV the increase in airflow resistance in REM may explain these dips in most subjects. The reduction in Vt when the MDV is triggered is only rarely a limitation.

\section{S43 CRYPTOGENIC FIBROSING ALVEOLITIS DOES NOT APPEAR ASSOCIATED WITH EPSTEIN-BARR VIRUS INFECTION}

A WANGOO 1, AG NICHOLSON2, TC DISS 3, PJ FARRELL4. RM du BOIS 5 and RJ SHAW ${ }^{1}$

Department of Respiratory Medicine ${ }^{1}$ and Ludwig Institute ${ }^{4}$, Imperial College School of Medicine at St. Mary's, Departments of Histopathology 2 and Respiratory Medicine 5, Royal Brompton Hospital, Department of Histopathology 3 , University College Hospital, London.

Cryptogenic fibrosing alveolitis (CFA) is a well-defined clinical entity of unknown aetiology. An association between CFA and the presence of protein indicating Epstein-Barr Virus (EBV) replication within epithelial cells of the respiratory tract has been recently described leading to speculation for a role of EBV in the pathogenesis of CFA. In the present study, we asked whether the presence of immunostaining was accompanied by the presence of EBV-DNA and RNA. Lung tissue was obtained from patients with CFA, lung sarcoidosis, lung scleroderma and one patient with lung lymphoma known to harbour EBV as a positive control. Paraffin blocks of lung tissue were cut and stained for immunochemistry using CS1-4, BZ-1 and VCA antibodies. EBER-1 and EBER-2 antisense oligonucleotide probes were used to look for EBV-RNA. DNA was extracted from the tissue sections and evaluated for evidence of EBV-DNA by PCR. Immunochemistry results with anti EBV antibodies stained epithelial cells in biopsies from patients with CFA, lung sarcoid and lung scteroderma but there was no evidence of the presence of EBV-DNA nor expression of EBER-RNA. This suggests that the anti-EBV antibodies are cross-reacting with proteins expressed in epithelial cells in a range of fibrotic conditions.

\section{S42 AUTONOMIC DYSFUNCTION IN PATIENTS WITH NOCTURNAL HYPOVENTILATION}

\section{J P WATSON' , J NOLAN ${ }^{2}$, S EVANS' and M W ELLIOTT}

Departments of Respiratory Medicine ${ }^{1}$ and Cardiology ${ }^{2}$, Killingbeck Hospital, York Road, LEEDS LS14 6UQ

The autonomic nervous system (ANS) plays a major role in regulating myocardial instability. ANS activity can be reliably assessed by measurement of heart rate variability (HRV). The 24 hour standard deviation of RR intervals (SDNN) reflects sympathovagal balance, and the number of beat to beat $R R$ interval differences $>50 \mathrm{~ms}$ (sNN50) reflects parasympathetic activity. Reduced HRV is associated with an increased incidence of ventricular arthythmia and sudden death in patients with cardiac disease: SDNN $<100 \mathrm{~ms}$ is associated with a $10 \% 1$ year mortality in patients with cardiac failure. It has been suggested that the improved survival in hypoxic patients with cor pulmonale treated with long term oxygen therapy (LTOT) may be due to a reduced risk of cardiac arthythmias. This pilot study used HRV analysis to investigate the relationship between ANS activity and nocturnal hypoxia in patients with kyphoscoliosis. We studied 7 subjects (5 male, 2 female), aged 25-72 years (median 60) with kyphoscoliosis (6 idiopathic, 1 due to spinal TB), recording overnight oximetry, daytime blood gases, and 24 hour ECG. SDNN and sNN50 values were calculated for all subjects.

Results: All had significant noctumal hypoxia (O2 saturation $<90 \%$ for $>5$ hours, mean $6 \mathrm{hr} 57 \mathrm{~min}$ ). Mean(SD) daytime $\mathrm{PaO} 2$ was 7.88 (0.82) $\mathrm{kPa}$. Only one patient had a $\mathrm{PaO} 2<7.3 \mathrm{kPa}$. None was acidotic. Mean (SD) SDNN was low at $66.29(21.27) \mathrm{ms}$. It was $<100 \mathrm{~ms}$ in all cases. Geometric mean (range) sNN50 was also low at 1158.7 (383 - 3986).

Conclusions: The patients in this study with noctumal hypoxia all have severe autonomic dysfunction, even though only one had a daytime $\mathrm{PaO} 2$ meeting the criteria for LTOT. This places them in a high risk category for sudden death. HRV analysis may provide a method of risk stratifying patients with nocturnal hypoventilation to identify those who may benefit from treatment. Further studies with larger numbers are required to determine the prognostic significance of HRV abnormalities in such patients, and the effects of treatment of noctumal hypoxia on autonomic function.

\section{S44 CRYPTOGENIC FIBROSING ALVEOLITIS (CFA) AND LUNG} CANCER - IS THERE AN ASSOCIATION?

\section{JM HARRIS, P CULLINAN and JC MCDONALD}

Department of Occupational and Environmental Medicine, Imperial College (NHLI), LONDON

An association between lung cancer and CFA was described among a large hospital-based series in 1980 (Turner-Wanwick M, Lebowitz M, Burrows B and Johnson A. Cryptogenic fibrosing alveolitis and lung cancer. Thorax 1980; 35: 496-499); several smaller studies have since reported the same relationship. Further evidence of this widely accepted association was sought by comparing co-mortality from CFA and lung cancer with three other fibrotic diseases.

For the years 1985 and 1986 we obtained from the Office of National Statistics details in death certificates from England and Wales with "other alveolar and parietoalveolar pneumopathy" (code 516, ICD9) listed in Parts I or II of the certificate ("mentioned cause"). The frequency with which lung cancer (ICD 162) was also mentioned in these certificates was examined. As a comparison, we investigated the frequency with which lung cancer was mentioned in certificates where one or more of the following pulmonary fibrotic diseases were mentioned; "asbestosis" (ICD 501); "coalworkers' pneumoconiosis" (ICD 500) and "pneumoconiosis due to other silica or silicates" (ICD 502).

Among the 1951 certificates with a mentioned cause of ICD 516 (other alveolar and parietoalveolar pneumopathy), lung cancer was also mentioned in $6 \%$ of certificates compared to $43 \% \quad(n=418)$ with a mentioned cause of ICD 501 (asbestosis), 7\% ( $n=1345)$ with a mentioned cause of ICD 500 (coalworkers' pneumoconiosis) and $8 \%$ $(n=176)$ with a mentioned cause of ICD 502 (pneumoconiosis due to other silica or silicates). These differences remained after stratification by sex and in those aged more or less than the approximate median age of 75 years.

These essentially negative findings suggest the need for further, carefully controlled investigation. 
S45 INDUCED SPUTUM FROM PATIENTS WITH SARCOIDOSIS IS MORE CELLULAR THAN THAT FROM CONTROL SUBJECTS.

\section{O'DONOHOE, VM KEATINGS, DM O'DONNELL, B MONAGHAN*, C O'CONNOR, MX FITZGERALD}

Department of Medicine and Therapeutics, University College Dublin, Department of Physiotherapy*, St Vincent's Hospital, Ireland.

Sputum induction using inhaled hypertonic saline is a method of obtaining airway derived fluid and cells that reflects the findings in bronchial lavage in patients with airways diseases such as asthma and COPD. It has also been used as an alternative to bronchoalveolar lavage in patients for the diagnosis of pneumocystis carinii pneumonia in AIDS. We wished to determine the usefulness of this technique in quantifying pulmonary inflammation in patients with sarcoidosis. Sputum was induced in 9 patients with sarcoidosis, mean age 43.9(5.4)y, mean FEV $192.5(10.1) \%$ predicted, and 12 control subjects mean age 33.5(5.0), FEV $197.1(4.4) \%$ predicted. Total cell counts were $0.53(0.1) \times 10^{6} / \mathrm{ml}$ in control subjects and $1.9(0.7) \times 10^{6} / \mathrm{ml}$ in patients with sarcoid, $\mathrm{p}<0.005$. Macrophage, neutrophil and lymphocyte numbers were all higher in patients with sarcoid compared with control subjects. Whilst examination of induced sputum allowed detection of inflammation, this difference was more significant for macrophage and neutrophil numbers than for lymphocytes. Previous reports suggest that induced sputum is relatively deficient in lymphocytes compared to BALF and these data suggest that bronchoalveolar lavage remains the method of choice in the detection of alveolar lymphocytic inflammation.

\begin{tabular}{llll}
\hline & Controls & Sarcoid & p value \\
\hline Total cells & $55.2(12.9)$ & $190.2(66.3)$ & $<0.005$ \\
Mac. & $38.2(9.5)$ & $114.5(45.3)$ & $<0.01$ \\
Neut. & $15.3(5.7)$ & $58.3(27.5)$ & $<0.0005$ \\
Eos. & $0.3(0.1)$ & $2.1(2.0)$ & n.s. \\
Lymph. & $2.3(2.0)$ & $15.3(8.4)$ & $<0.05$ \\
\hline
\end{tabular}

Mean (SEM) are shown.

Cell counts are $\mathrm{X} 10^{4} / \mathrm{ml}$ induced sputum.

\section{S47 GROWTH HORMONE AND INSULIN-LIKE GROWTH FACTOR-1 GENE EXPRESSION IN BRONCHOALVEOLAR LAVAGE CELLS USING RT-PCR}

\section{C.A. BLOOR, J.T. ALLEN, R.A. KNIGHT and M.A. SPITERI.}

Dept. Respiratory Medicine, North Staffordshire Hospital, Stoke-on-Trent, UK.

Fibrotic damage results from excessive collagen matrix deposition from proliferating fibroblasts beyond that required for normal tissue repairs at a site of lung injury. We have investigated the gene expression of Insulin-like Growth Factor-1 (IGF-1) and of Growth Hormone (GH) in unfractionated bronchoalveolar lavage cells (BALC) from normal subjects and patients with sarcoidosis. IGF-1 is a major mitogen for fibroblasts, and also stimulates their transcription of collagen. GH is the principal regulator of IGF-1 expression. Gene expression was determined using a developed Reverse Transcriptase-Polymerase Chain Reaction (RT-PCR) with Glyceraldehyde-3-Phosphate Dehydrogenase (G3PDH) as internal standard. Samples were initially amplified and screened for $\mathrm{GH}$ gene expression on low -melting point agarose gels, gel purified and re-amplified with nested primers. IGF-1 gene expression was evaluated using a single round of PCR amplification for the same quantity of CDNA. PCR products were authenticated by performing appropriate restriction digests and DNA sequencing. We report expression of GH in BALC from normal non-smokers and sarcoid donors as well as expression of IGF-1, although the levels of expression in comparison to the G3PDH control suggested no difference between normal and patient groups. These data suggest that BALC released IGF-1 may contribute to the development of pulmonary fibrosis. Furthermore, the presence of BALC-derived GH may reflect localised regulation of IGF-1 induced fibrogenesis.

Supported by the British Lung Foundation
S46 FLOW CYTOMETRIC ANALYSIS OF CYTOKINE PRODUCTION IN THE LYMPHOCYTIC ALVEOLITIS OF SARCOIDOSIS

DM O' DONNELL, KJ MCMAHON, C O' CONNOR and MX FITZGERALD

Department of Medicine and Therapeutics, University College Dublin, Ireland.

T-lymphocytes from many infective and auto-immune diseases demonstrate a bias towards one of the active effector phenotypes $\mathrm{T}$ helper 1 (Th1), associated with Interferon-gamma production, or Th2, associated with Interleukin-4 production. The aim of this study was to investigate the pattern of lymphocyte differentiation in pulmonary sarcoidosis by direct assessment of cytokine production at single cell level. Bronchoalveolar lavage (BAL) samples were obtained from 14 sarcoidosis patients with lymphocytic alveolitis (mean percentage lymphocytes $49.8 \%$, range $31 \%$ to $85 \%$ ), 4 of whom had persistent BAL lymphocytosis despite established steroid therapy.

BAL cells were stimulated for 4 hours in the presence of Brefeldin A, to enhance the accumulation of intracellular cytokine. Following fixation and permeabilisation, fluorochrome-conjugated antibodies to interferon-gamma (INF-g), Interleukin-4 (IL-4) and to lymphocyte surface antigens including CD4 were added. Samples were analysed using 2- and 3-colour flow cytometry.

In all patients in the untreated group, accumulation of INF-g was observed within BAL lymphocytes, (mean \% of lymphocytes positive $46.8 \%$, range $27.7 \%$ to $66.75 \%$ ). In contrast, in the 4 patients on steroid therapy, very few lymphocytes expressed INF-g (mean $2.2 \%$, range $0.2 \%$ to $5.13 \%, \mathrm{p}<0.001$ ). In both groups, fewer than $2 \%$ of lymphocytes were positive for interleukin -4 .

These results indicate that the lymphocyte population in untreated sarcoid alveolitis contains a large subset of Th1-like cells and few Th2- like cells. The distinct non-INF-g-producing CD4+ve subset may represent naive T-cells or long-term memory cells which have reverted to a naive phenotype. The results also suggest that patients on steroid therapy with persistent alveolitis display a different pattern of cytokine production which does not reflect either a Th1 or Th2 bias.

S48 ELEVATED EXPRESSION OF INSULIN-LIKE GROWTH FACTOR BINDING PROTEIN-3 (IGFBP-3) IN BRONCHOALVEOLAR LAVAGE FLUID (BALF) OF PATIENTS WITH PULMONARY FIBROSIS

J.T. ALLEN*, R.A. KNIGHT*, K.A. MEADOWS**, J.M.P HOLLY ${ }^{\star \star}$ and M.A. SPITERI ${ }^{\star}$

**Dept. Medicine, University of Bristol and *Dept. Respiratory Medicine, North Staffordshire Hospital, Stoke-on-Trent, UK.

Fibrosis is a process of chronic inflammation characterised by increased numbers of activated alveolar macrophages (AM) proliferation of fibroblast-like cells, and deposition of collagenous interstitial matrix. Insulin-like Growth Factor-1 (IGF-1) is a highly mitogenic polypeptide hormone shown to be expressed and released by activated $A M$ and airway epithelial cells and can be detected in BALF. Using a developed Reverse-Transcriptase Polymerase Chain Reaction we determined IGF-1 gene expression to be present in BAL cells from all subjects. IGF-1 bioactivity can be modulated by a series of associated IGF-BP of which IGFBP. 3 is the principal serum BP. We have determined IGFBP-3 expression directly from BALF supernatants, using Western ligand blot analysis, from 10 normal subjects and 10 fibrosis patients. Supernatant aliquots underwent a modified colorimetric urea assay as a reference marker for BAL dilution of epithelial lining fluid. IGFBP-3 levels were raised in normal smokers compared to non-smokers, and were very significantly increased in fibrosis patients $(p=0.003)$ in comparison with control subjects. Results from In-vitro culture supernatants of $2 \times 10^{6}$ BAL cells incubated 24 hours suggest inflammatory BAL cells can synthesise IGFBP-3 de novo. These data suggest IGFBP-3 enhances IGF-1 fibrogenic activity derived from inflammatory BAL cells of patients with pulmonary fibrosis.

Supported by the British Lung Foundation 
S49 RESPIRATORY TRACT INFECTION (RTI) IN THE COMMUNITY. DOES A CHEST RADIOGRAPH (CXR) INFLUENCE TREATMENT?

\section{JCG SIMPSON, P HULSE, PM TAYLOR and M WOODHEAD}

Department of Respiratory Medicine and Radiology, Manchester Royal Infirmary, Manchester M13 9WL

Little is known about the investigation and management of pneumonia in the community. A 12 month prospective study was performed to investigate the use of CXRs and the effects of the radiological report in the management of adults with RTI.

General practitioners (GP) requested a total of 2538 CXR, of which 111 ( $4.4 \%)$ were reported as showing features of acute infection in adults. For each CXR, the GP $(n=58)$ was sent an explanatory letter and a questionnaire. Non responders were mailed a second time. 102 responses were obtained ( $92 \%$ of the total). Of these 5 were excluded as either no information was offered, or no report on the CXR had been received by the GP resulting in 97 evaluable responses.

The mean age of the population was 58.9 years. 77 patients (79\%) were considered to have an RTI by the GP. Of these the reason for the CXR was to seek features of infection in $45(58 \%)$, to assess treatment response in 33 (43\%) and to seek a possible tumour in 30 (39\%). 35 (38 \%), $36(40 \%)$ and 20 (22\%) of the CXRs were performed at the 1 st, 2 nd and 3 rd visit to the GP for this illness. Assessment of treatment response was more commonly a reason for CXR request in the 3 rd compared to the 1 st group $\left(X^{2}>30 p<0.001\right) .48 \%$ of respondents felt the CXR result had affected treatment. An effect on treatment was significantly more common in those patients who were not receiving antibiotics prior to the CXR (86\% v $55 \%$ $X^{2}=11 \mathrm{p}<0.001$ ). Excluding the 2 patients admitted as a result of the CXR $8(8 \%)$ patients did not receive an antibiotic from their GP. $32 \%$ felt that if the CXR had been normal this would have affected their management, most commonly affecting antibiotic prescription (58\%). Where the CXR report suggested hospital referral more patients were referred $100 \%$ v $20 \%\left(X^{2}>30 p<0.001\right)$, and if the report suggested repeat CXR more had a repeat $78 \%$ v $29 \%\left(X^{2}>12 p<0.001\right)$.

CXRs performed in the community have an impact on the management of RTI and the wording of the radiologist's report is significantly associated with management

\section{S51 ACUTE LOWER RESPIRATORY TRACT ILLNESS (LRTi) IN GENERAL PRACTICE; A STUDY OF THE VIEWS OF 787 PATIENTS AND THEIR INFLUENCE ON ANTIBIOTIC PRESCRIBING.}

\section{MACFARLANE J.T., HOLMES W.F. MACFARLANE R.M.}

\section{Respiratory Infection Unit, Nottingham City Hospital NG5 1PB}

The audit commission has identified both patient pressure and antibiotic use as major contributors to the excess $\$ 275$ million annual prescribing costs in primary care. Using a questionnaire, we have investigated the views of 787 adults regarding the cause and management of their condition when they consulted their GP with an acute LRTi and how their views affected GP management. Patients commonly thought that their problem was caused by infection (85\%: 662/780) and that antibiotics would help (87\%: 656/758). Three quarters had wanted a prescription for antibiotics (72\%: 564/781) and had expected their GP to prescribe antibiotics (72\%: 561/779). A quarter of patients who had wanted an antibiotic asked their GP for one (144/561), compared with $1 \%(2 / 216)$ who had not wanted one $(p<<0.001)$. Patients who wanted or asked for an antibiotic were significantly more likely to be prescribed one $(p<<0.001)$. Of the 555 patients who wanted an antibiotic, the GP stated that the decision to prescribe was affected by patient pressure in 124 (22\%) of cases compared with $10 / 215(5 \%)$ who had not wanted a prescription $(p<<0.001)$. A similar pattern was seen for those who asked for an antibiotic prescription. Of the 125 given antibiotics even when the GP felt they were not indicated, $114(91 \%)$ of these patients had wanted an antibiotic. Of the 205 patients not prescribed antibiotics, only $76(37 \%)$ had wanted a prescription $(p<<0.001) .13$ of the 37 patients $(35 \%)$ who were dissatisfied with the prescribing decision by their GP reconsulted within four weeks compared with $127 / 740(17 \%)$ of satisfied patients $(p=0.01)$.

We conclude that patients with LRTi commonly feel infection is the problem and want or ask for an antibiotic prescription and their views influence GP prescribing even when antibiotics are not felt to be clinically indicated. More emphasis should be placed on patient (and GP) education to break this cycle and reduce inappropriate antibiotic prescribing in the community.
S50 THE INFLUENCE OF ANTIBIOTICS AND OTHER FACTORS ON RECONSULTATION FOR ACUTE LOWER RESPIRATORY TRACT ILLNESS IN PRIMARY CARE

\section{Holmes WF, Macfarlane JT, Macfarlane RM and Lewis S}

Respiratory Infection Unit, Nottingham City Hospital, NG5 IPB, UK

Introduction: Antibiotics are prescribed to a majority of patients with Lower Respiratory Tract iliness (LRTi). Information about its natural history is scarce. We have investigated factors which influence reconsultation in the month following initial treatment of LRTi in general practice.

Methods: During winter 1994/5, 115 GPs documented an "index" consultation for adults presenting with an acute LRTi where cough was the predominant symptom. In 1995, the medical records of a proportion of these patients were examined to identify reconsultation and previous consulting behaviour.

Results: 58 GPs examined the notes of 518 patients. 154 patients (30\%) reconsulted within 4 weeks for similar symptoms. Reconsultation was univariately associated with the number of GP visits recorded in the previous 2 years $\left(p_{\text {troed }}<0.001\right)$, the presence of significant underlying disease $(p<0.001)$, dyspnoea $(p<0.001)$ and wheeze $(p=0.04)$, signs on chest examination $(p=0.02)$ and age $\left(p_{\text {treod }}=0.006\right)$. It was unrelated to gender, the nature of the cough or sputum, the presence of chest pain, sore throat, fevers, aches and pains, and the description applied to the illness by the GP. 393 patients $(76 \%)$ were prescribed an antibiotic at the index consultation. Reconsultation was unrelated to the prescription of antibiotics and the duration of treatment $(p=0.4)$.

Conclusion: Reconsultation is a common outcome in acute LRTi, and is associated with the presence of previous ill health, dyspnoea and a heightened consulting habit. It appears not to be influenced by prescribing antibiotics. GPs need to be familiar with the natural history of LRTi in order to be more confident in reducing unnecessary prescription of antibiotics, and to educate patients about the rate of improvement they can reasonably expect.

\section{S52 ANTIBIOTIC RESISTANCE IN STREPTOCOCCUS} PNEUMONIAE: ONE HOSPITAL'S EXPERIENCE

\section{J.A. SMITH, J.K. STRUTHERS and M.A. WOODHEAD}

Departments of Respiratory Medicine and Microbiology, Manchester Royal Infirmary, Oxford Road, Manchester, M13 9WL

Objective- To assess the frequency of antibiotic resistance in $S$. pneumoniae isolates from a large teaching hospital microbiology laboratory.

Sample- All $S$. pneumoniae isolates from Central Manchester Healthcare Trust and local GP practices, over the 1994-1995 period. MethodsAntibiotic resistance was assessed by the Stokes' method. Only isolates identified as fully resistant were included in the analysis. In the case of penicillin this was equivalent to an MIC of $>1 \mathrm{mg} / \mathrm{l}$. Numbers of penicillin and erythromycin resistant isolates were compared for age, specimen type and speciality.

Results-Of the total number of 742 isolates, 335 (45\%) were from sputum, $169(23 \%)$ from eye swabs and $60(8 \%)$ from blood cultures. $413(56 \%)$ were isolated from adults , $120(16 \%)$ from children and 209 $(28 \%)$ of unknown age. $514(69 \%)$ samples were from hospital inpatients with $158(21 \%)$ from outpatients, $35(5 \%)$ from the community, and $35(5 \%)$ unknown. Frequencies of antibiotic resistance were erythromycin $3.4 \%(25 / 742)$ and penicillin $1.1 \%(8 / 742)$. Of 25 erythromycin resistant isolates, 14 occurred in isolation, 1 was associated with penicillin resistance and 10 with other antibiotic resistance. There was no difference in the rate of resistance according to specimen type $\left(\chi^{2}=1.67\right.$, N.S. $)$, specimen source $\left(\chi^{2}=2.26, N . S\right)$ or patient age $\left(\chi^{2}=2.67, N . S\right)$. Of the 18 patients with resistant respiratory isolates, $4(22 \%)$ had pneumonia, $2(11 \%)$ had exacerbations of chronic bronchitis, $2(11 \%)$ had exacerbations of asthma, $3(17 \%)$ had unspecified chest infections and $7(39 \%)$ were unknown.

Conclusion- Erythromycin resistance was three times as common as penicillin resistance in our hospital but overall antibiotic resistance in $S$. pneumoniae was lower than expected. There was no evidence of increased frequency in any particular group of patients. Antibiotic resistance does not appear to be a clinically significant issue as yet, but needs to be kept under continued surveillance. 
S53 CHLAMYDIA PNEUMONIAE ANTIBODY TITRES ARE SIGNIFICANTLY ASSOCIATED WITH THE USE OF STEROID MEDICATION IN RESPIRATORY DISEASE

\section{PJ COOK, D HONEYBOURNE, R WISE and P DAVIES}

Depts of Thoracic Medicine and Microbiology, City Hospital, and Statistics, Birmingham University, Birmingham, UK

Chlamydia pneumoniae antibodies were measured in 1,827 adult in-patients, who had exacerbation of COPD in 10.9\% and acute asthma in $6.7 \%$. A control group of $82.4 \%$ had non-pulmonary, non-cardiovascular disorders. $71 \cdot 1 \%$ were Caucasian, $18.8 \%$ Asian and 10.1\% Afro-Caribbean. $55.6 \%$ were male. Among patients with acute exacerbations of COPD or asthma, inhaled or oral steroids had been taken regularty prior to the onset of illness in $57.3 \%$; and in the control group, in $7.5 \%$. Multi-factorial analysis was performed, stratified by age, sex, race, smoking habit and use of inhaled or oral steroid medication.

Among patients admitted with acute exacerbation of COPD or asthma, antibody titres indicating acute C. pneumoniae infection were found in $12.5 \%$ of patients on steroids and 7.3\% of those not on steroids; while chronic infection was found in $23.9 \%$ of those on steroids and $16.8 \%$ of those not Among controls, acute infection was found in 5.3\% of patients on steroids and $5.7 \%$ of those not; while chronic infection was found in $19.5 \%$ of those on steroids and $12.1 \%$ of those not. Among patients with exacerbation of COPD or asthma, the odds ratio (OR) associated with steroid medication was 2.59 for acute infection, and 2.18 for chronic infection (95\% Cl 1.14, 4.15). Among the controls, the OR associated with steroid medication was 2.11 for chronic infection $(95 \% \mathrm{Cl} 1.18,3.78)$. These differences were independent of age, sex, race and smoking habit.

We infer that a heightened risk of $C$. pneumoniae infection may be associated with steroid therapy in respiratory disease.

\section{S55 ASTHMA, ITS TREATMENT AND SOCIAL} DEPRIVATION - THE EFFECT ON GROWTH IN CHILDREN

C McCOWAN, R G NEVILLE, I K CROMBIE, F C WARNER, G E THOMAS, R A CLARK, I W RICKETTS, S A GREENE, A Y CAIRNS and $E$ WHITE

University of Dundee, Tayside Centre for General Practice, Kirsty Semple Way, Dundee DD2 4AD

A cohort of 3,347 children with asthma or asthma like symptoms registered with 12 general practices were followed up over a 4-year period for the Tayside Childhood Asthma project (CAP) [Bryce F P et al. Controlled trial of an audit facilitator in diagnosis and treatment of childhood asthma in general practice. $B M J 1995,310,838-842]$. Concurrently but independent from this study, the Tayside Growth Study (TGS) measured the heights and weights of children aged between 3 and 14 at health centres and schools throughout the region [White E M et al. Body Mass Index centile charts to assess fatness of British children. Arch Dis Child 1995, 72, 38-41].

The children from CAP were traced through TGS and their growth measurements converted to standard deviation scores (SDS) referenced to the local population. The SDS of any group selected from TGS should have a mean equal to zero and a standard deviation of one. If the mean SDS for a group of children falls outside a certain range, dependent on the size of the group, that group of children can be said to be significantly different from the reference population. An index of deprivation based on the 1991 census data was assigned to each study child based on their home postcode, and the children were then divided into quartiles based on this index.

Children from the lowest socio-economic group suffered from height ( $\mu=$ $-0.26, \sigma=1.02)$ and weight impairment $(\mu=-0.18, \sigma=1.15)$. Children receiving doses of inhaled steroids equal to or greater than $400 \mu \mathrm{g}$ daily on average and who also attended hospital and their GP for asthma management suffered from a reduction in height $(\mu=-0.62, \sigma=1.01)$ and weight $(\mu=-0.58, \sigma=0.94)$. However, other than this small group, children with asthma did not suffer from growth impairment.

Most children with asthma do not suffer from impaired growth. Those children receiving high dose inhaled steroids and requiring GP and hospital services will suffer from a marked reduction in their growth. This reduction does not seem to be caused by treatment but by other factors, such as how well their asthma is controlled and their socio-economic status.
S54 THE SIMULTANEOUS ADMINISTRATION OF INFLUENZA VACCINE AND 23-VALENT PNEUMOCOCCAL POLYSACCHARIDE VACCINE IN PATIENTS WITH CHRONIC RESPIRATORY DISEASE

T FLETCHER, W TUNNICLIFFE, K HAMMOND, K ROBERTS and JG AYRES

Chest Research Institute, Birmingham Heartlands Hospital, Bordesley Green East, Birmingham B9 5SS

Pneumococcal disease is a significant cause of morbidity and mortality in the UK. The efficacy of pneumococcal vaccination (PPV) is established and is recommended in, amongst others, patients with chronic lung disease. This group is also targeted for influenza vaccination (IV). Co-administration of the vaccines is included in the Department of Health guidelines, but the efficacy of PPV given in this way has been questioned. We examined whether an immunoresponsive interaction exists between 23-valent pneumococcal polysaccharide vaccine (Pnu-Immune, Lederle) and influenza vaccine (Fluarix, Smithkline Beecham). 152 adults with chronic respiratory disease were randomised to receive either PPV and IV on the same day (Concurrent Group: $\mathrm{n}=73$, median age $48 \mathrm{yrs}, 36 \mathrm{male}$ ) or IV followed by PPV one month later (Interval Group: $\mathrm{n}=58$, median age 50yrs, 22 male). At the initial visit and one month following PPV, serum was analysed for antibodies to 6 pneumococcal serotypes. An adequate serological response was defined $a b$ initio as at least a two fold rise in antibody titre following vaccination. The proportions of subjects in each group achieving this rise for each serotype were compared by Chi squared testing.

\begin{tabular}{|c|c|c|c|} 
Serotype & interval Group & Concurrent Group & p-value \\
\hline 4 & $42 / 58(72.4 \%)$ & $46 / 73(63.0 \%)$ & 0.27 \\
$6 \mathrm{~B}$ & $41 / 58(70.7 \%)$ & $45 / 73(61.6 \%)$ & 0.36 \\
9V & $44 / 58(75.9 \%)$ & $53 / 73(72.6 \%)$ & 0.69 \\
14 & $51 / 58(87.8 \%)$ & $55 / 73(75.3 \%)$ & 0.08 \\
$18 \mathrm{C}$ & $44 / 58(75.9 \%)$ & $56 / 73(76.7 \%)$ & 0.99 \\
19F & $35 / 58(55.2 \%)$ & $44 / 73(60.3 \%)$ & 0.60 \\
23F & $45 / 58(74.1 \%)$ & $55 / 73(75.3 \%)$ & 0.99
\end{tabular}

There was no significant difference in the serological responses of the two groups. The incidence and severity of self reported side effects was similar in each group. In patients with chronic respiratory disease, the simultaneous administration of pneumococcal with influenza vaccine appears to be as well tolerated and as immunogenic as its interval administration. Greater coverage of the at-risk population could readily be achieved by routinely offering PPV when patients present themselves for influenza vaccination.

\section{S56 CLINICAL SIGNIFICANCE OF EXCESS COUGH AS A SOLITARY SYMPTOM}

\section{Y J KELLY, B J BRABIN, D HEAF and M G PEARSON}

Liverpool School of Tropical Medicine, Alder Hey Hospital and Aintree Chest Centre, Liverpool, UK

We have reported a significantly increased prevalence of excess cough without wheeze or breathlessness in children (aged 5-11 years) in an area of increased dust pollution. A quarter (27\%) of these children had been labelled as asthmatic by a doctor. This study examines whether a history of excess cough without wheeze or breathlessness (EC) was associated with other clinical correlates of asthma. A case control approach was used to compare risk factors, skin testing and lung function in children with $\mathrm{EC}(\mathrm{n}=66)$ to age, sex, area of residence and school matched asymptomatic controls Parents were interviewed and a questionnaire was completed, during a school visit skin testing and lung function measurements (before and after exercise) were performed. $10.3 \%$ of children were taking antiasthmatic treatment at the time of study and $22.4 \%$ still reported EC as a solitary symptom. EC was associated with maternal asthma, child having eczema, mould in the home, hearing/ear problems (all $p<0.05$ ), respiratory illness when aged $<2$ years old $(p<0.01)$, a history of nocturnal cough $(p<0.001)$ and 'colds going to the chest' $(p<0.05) .18 .2 \%$ of children with EC had positive skin tests compared to $15.3 \%$ of controls. There was no difference in resting FEV1 between children with EC (FEV1 observed/expected $97.7 \%$ ) and controls (100.8\%), a higher proportion of children with EC had a post exercise drop of $15 \%$ or more in FEV1 compared to controls (14.3\% vs $5.7 \%$ ), though not statistically significant. Children with EC have many of the risk factors associated with asthma although only a minority exhibit clinical evidence of disease. Formal assessment should be performed before committing these children to long term treatment. 
S57 PREMORBID INFANT RESPIRATORY FUNCTION AND WHEEZING IN THE FIRST YEAR OF LIFE: A POPULATION BASED STUDY IN LONDON C.DEZATEUX', J.STOCKS ${ }^{2}$, I.DUNDAS ${ }^{2}, \quad$ L.PILGRIM $^{2}$ and
M.FLETCHER

'Epidemiology and Biostatistics, 'Portex Unit of Anaesthesia, Institute of Child Health, London

While studies from Tucson and Perth suggest that diminished airway function in the earty months of life may predict wheezing in earty childhood, further work is required to confirm these findings in other populations. The aim of this prospective longitudinal population-based study in inner London was to determine whether subclinical alterations in respiratory function precede wheezing in infancy.

Healthy Caucasian term (>35 weeks) infants were recruited shortly after birth, those with prior respiratory symptoms being ineligible for respiratory function testing (RFT). Wheezing episodes in the first year were recorded prospectively by parents using daily diary cards and physician diagnosed episodes validated with reference to practice medical records. Plethysmographic lung volume $\left(F R C_{\text {plet }}\right)$, ainway resistance $\left(R_{\text {aw }}\right)$ and time to peak tidal expiratory flow as a proportion of total expiratory time $\left(t_{\text {PTEF }}: t_{E}\right)$ were measured at 5-10 weeks of age (prior to any respiratory illness).

RFTs were completed in 107 infants (56 males), $29 \%$ of whom subsequently experienced at least one episode of physician diagnosed wheezing in the first year of life. Boys, and infants whose mothers smoked were significantly more likely to wheeze. Compared to those who remained wheeze-free, mean (SD) end expiratory $R_{m}$ was elevated, mean (SD) $t_{\text {PTEF }} t_{E}$ diminished, and

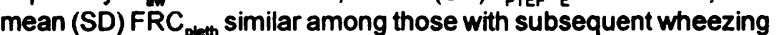
[4.6 (2.8) $\mathrm{kPa} \cdot \mathrm{L}^{-1} \cdot \mathrm{s} ; 0.293(0.06) ; 135(23) \mathrm{mL}$ respectively in those with subsequent wheezing compared to $3.1(1.1) \mathrm{kPa} \cdot \mathrm{L}^{-1} \cdot \mathrm{s} ; 0.336$ $(0.08)$ and $137(23) \mathrm{mL}$ respectively in those without]. End expiratory $R_{\mathbf{m}}$ was significantly elevated in infants whose mothers smoked during pregnancy. These preliminary findings provide further support for the hypothesis that premorbid respiratory function is predictive of wheezing in the first year of life.

\section{S59 ANTIOXIDANT STATUS IN CHILDREN WITH DIFFERENT RESPIRATORY SYMPTOMS}

\section{Y J KELLY, B J BRABIN, G NAIR, L BURGESS and M G PEARSON}

Liverpool School of Tropical Medicine and Aintree Chest Centre, Liverpool, UK

A case control study of primary school children (aged 7-11 years) in an inner city area was performed. Cases had either a history of the symptom triad of cough, wheeze and breathlessness (CWB, $n=54$ ) or a history of excess cough without wheeze or breathlessness (EC, $\mathrm{n}=66$ ). Controls were matched for age, sex, area of residence and school. The purpose of this study was to compare the antioxidant status of children with CWB and children with EC with asymptomatic controls. Antioxidant status was assessed with assays of vitamins A and E measured by HPLC standardised against serum lipid levels. A three day dietary diary was obtained from a representative sample of cases and controls. Vitamin E intakes were lower in children with CWB compared to controls $(3.64 \mathrm{mg} /$ day \pm SD 1.12 vs $4.79 \mathrm{mg} /$ day $\pm 1.83, p<0.01$ ). Children with $E C$ were not different from controls $(4.37 \mathrm{mg} /$ day $\pm 1.57 \mathrm{vs} 4.20 \mathrm{mg} /$ day \pm 1.76 ). Normal ranges of serum vitamin $E$ and vitamin $A$ are 10.0 $21.0 \mu \mathrm{mol} / /$ and $0.9-1.7 \mu \mathrm{mol} / /$ respectively. Serum levels indicate that $19.9 \%(44 / 221)$ of children were vitamin $E$ deficient and $1.8 \%$ (4/221) vitamin A deficient. Children with EC had a higher vitamin $E /$ cholesterol ratio ( 4.40 vs $3.78, p=0.03)$ and vitamin $E /$ total lipids ratio (3.43 vs $2.92, p=0.06$ ) than controls. Children with $C W B$ were not different from controls (3.62 vs 3.33 and 2.79 vs 2.54 respectively). A greater proportion of children with EC had levels of vitamins $\mathrm{A}$ and $\mathrm{E}$ above the upper cut off than children with CWB ( $42.9 \%$ vs $15.2 \%$ and $22.4 \%$ vs $6.5 \%$, both $p<0.05)$. Children with higher levels of vitamins $A$ and $E$ were more likely to have less severe respiratory symptoms in an inner city population with a high prevalence of vitamin $\mathrm{E}$ deficiency.
S58 THE GLU27 B2-ADRENOCEPTOR POLYMORPHISM IS ASSOCIATED WITH CHILDHOOD ASTHMA

HELMS P, HOPES E, MCDOUGALL C, CHRISTIE G, WHEATLEYA, DEWAR J, HALL I

Department of Child Heaith, University of Aberdeen \& Department of Medicine, University of Nottingham.

Polymorphisms of the $\beta 2$ adrenoceptor gene have been shown to be related to the severity and degree of bronchial reactivity in established asthmatic populations ${ }^{1}$. Children attending fracture/dressing clinics were interviewed with a parent and provided a mouthwash sample. DNA was extracted and screened for $\beta_{2}$-adrenoceptor polymorphisms at amino acid position 27 (Gin to Glu) using a PCR/Allele Specific Oligonucleotide (ASO) assay. Age ranoed from 5 to 15 years mean 10.5 years (SD 2.2). The prevalence of reported asthma (24\%), was similar to that observed in a large $(n=4197)$ questionnaire study from the same community ${ }^{2}$. In the 419 children on whom genotyping was successfully performed 93 children (22.2\%) were Ghi27 homozygotes, 107 (25.4\%) were Gin27 homozygotes and 52.3\% were heterozygous. Reported asthma was less frequent in Glu 27 homozygotes (16\%) in comparison with heterozygotes (30\%) or Gin 27 homozygotes (22\%).

\begin{tabular}{|l|c|c|c|}
\hline & No Asthma & Asthma & Totals \\
\hline Gin 27 homazyote & 83 & 24 & 107 \\
\hline GinGlu heterozyote & 156 & 63 & 219 \\
\hline Glu27 homazygote & 78 & 15 & 93 \\
\hline
\end{tabular}

$2=5.95 P=0.05$

Treating the $\operatorname{Gn} 27$ allele as dominant there was a significant association between its presence and reported asthma $\left(x^{2}=4.38,1 \mathrm{DF}, p=0.04\right)$. On logistic regression analysis and with age sex and family history of Atopy accounted for, it was significantly associated with reported asthma (OR $2.18, \mathrm{Cl} 1.13$ to 4.23, $p=0.02$ ). The assumption that the $\mathrm{Gin} 27$ polymorphism operates in a dominant fashion requires confirmation. The mouthwash semple technique was remarkably successful and commends itself for the examination of candidate genes which may contribute to the expression of asthma and wheezing illness.

1. Hall IP, Wheatley A, Widding P and Liggett SB. (1995) Lancet. 345:1213. 2. Omran M, Russel G. (1996) Brit Med J. 312:34.

S60 SERUM DEPENDENCE OF OXYGEN STIMULATED DNA SYNTHESIS IN HUMAN FETAL AIRWAY SMOOTH MUSCLE CELLS: IMPLICATIONS FOR THE PATHOGENESIS OF BRONCHOPULMONARY DYSPLASIA

PANDYA HC, HIRST SJ, TWORT CHC and WARD JPT

Department of Allergy \& Respiratory Medicine, UMDS, St. Thomas' Hospital, London, SE1 7EH, UK

Infants with bronchopulmonary dysplasia (BPD) have poorly reversible airways obstruction and bronchial hyperresponsiveness associated with an increased smooth muscle content in their peripheral airways. Premature exposure to high oxygen partial pressures $\left(\mathrm{PO}_{2}\right)$ and pulmonary plasma protein leak are implicated in the pathogenesis of BPD, but little is known about the relative importance of these factors or their ability to stimulate proliferation of airway smooth muscle (ASM).

Enzymatically dispersed human fetal tracheal smooth muscle cells, initially cultured in standard air incubator conditions (21 kPa PO$)$, were seeded into 24 well culture plates and growth-arrested in $0.5 \%$ fetal calf serum (FCS) at $5 \mathrm{kPa} \mathrm{O}$ for $72 \mathrm{hr}$. ASM cells in culture were exposed to $\mathrm{PO}_{2}$ ranging from $2.5 \mathrm{kPa}$ to $55 \mathrm{kPa}$ in the presence and absence of $10 \%$ FCS. Incorporation of ${ }^{3} \mathrm{H}$-thymidine (1 $\mu \mathrm{Ci} /$ well) into DNA was determined in quadruplet over $24 \mathrm{hr}$. DNA synthesis was maximal at $10 \mathrm{kPa} \mathrm{PO}_{2}(125 \pm 3.9 \%$ of incubator control, ie. $21 \mathrm{kPa}$ $\mathrm{PO}_{2}, \mathrm{P}<0.05, \mathrm{n}=4$ ) in the presence of $10 \% \mathrm{FCS}$, but was reduced at either higher or lower $\mathrm{PO}_{2}$. Addition of superoxide dismutase (up to $1060 \mathrm{U} / \mathrm{mL}$ ) to the culture medium had no effect on stimulated DNA synthesis. Enhancement of DNA synthesis at any $\mathrm{PO}_{2}$ was not seen when FCS was absent.

These results suggest that when fetal ASM is exposed to both serum and an increase in $\mathrm{PO}_{2}$ above in utero values $(>3 \mathrm{kPa})$, such as may occur in premature babies, proliferation of ASM may be enhanced and could contribute to the development of BPD. 


\section{S61 RESPIRATORY SYMPTOMS, SMOKING AND MORTALITY IN OLDER MEN AND WOMEN: AN EPIDEMIOLOGICAL STUDY}

DOW L*, VILLAR T**, COGGON D***, OSMOND C***, CAMPBELL MJ**, AND HOLGATE ST**.

*Care of the Elderly, Bristol University

**Immunopharmacology, Southampton University

***MRC Environmental Epidemiology Unit, Southampton

This study comprised a cohort of 1077 men and 1084 women aged 65 years and over who completed a postal questionnaire (response rate $84 \%$ ) about respiratory symptoms and risk factors for respiratory disease in 1987 . These subjects were originally selected at random from lists at three large general practices in the Southampton area with stratification to ensure equal numbers of men and women and equal numbers in the age group 65 to 74 and in 75 years and over. The cohort was followed up for mortality from 1.5 .87 to 1.12 .91 . Death certificates were obtained for any death that occurred during the study period and coded according to the International Classification of Diseases, ninth revision. A proportional hazards analysis was used to estimate the risk of death from various causes in relation to social class, smoking habits and respiratory symptoms in 1987.

Results: after adjustment for smoking habits, mortality from all causes and from respiratory disease was lowest in social classes 1 and 2. Mortality from lung cancer in respiratory disease was markedly elevated in current and ex-smokers. Respiratory symptoms were associated with increased mortality particularly from respiratory disease. Paroxysmal nocturnal dyspnoea carried the gravest prognosis with death rates being nearly doubled from all causes and those from respiratory disease increased nearly six-fold.

S63 THE IMPACT ON CARERS OF DISABILITY DUE TO CHRONIC OBSTRUCTIVE PULMONARY DISEASE (COPD)

\section{S.T. RUDKIN, R.P. SMITH and R. J. WHITE}

Department of Medicine, Frenchay Hospital, Bristol BS16 1LE.

COPD causes much disability in patients but its effect on carers has not been studied.

We have investigated 28 patients, 15 male, mean age 68.5 [8.3] SD with severe COPD (FEV $1<40 \%$ Pred) and their carers. The patient's activities of daily living were measured using the Nottingham extended activities of daily living scale (NADL). The carer's psychological state was assessed using the Hospital Anxiety and Depression (HAD) scale. Their perception of the patient's dependence was measured using a visual analogue scale and a separate questionnaire examined the effects of their partner's illness on their social, domestic and outside activities.

Spearman's correlation coefficients were performed with the following results. There was a significant negative correlation between the patient's NADL score and both the carer's perception of dependence $(r=-0.59 \quad \mathrm{P}=0.001)$ and the impact of the disability on the carer's life $(r=0.54 P=0.003)$. Levels of anxiety and depression in carers did not correlate with the patient's reduced level of activity, with their perception of dependency, or with the impact of this disability on the carer's activities.

\section{Conclusions}

As expected disability due to COPD causes a marked effect on the carer's life. The impact of the disease, the patient's level of activity and the degree of dependence are not factors in producing anxiety and depression in carers. When assessing the effects of therapeutic intervention such as pulmonary rehabilitation, the effects of treatment on the carers should be included.

\section{S62}

LONG-TERM BENEFITS OF PULMONARY REHABILITATION ( PR ) IN ELDERLY PATIENTS WITH CHRONIC OBSTRUCTIVE PULMONARY DISEASE ( COPD )

\section{J ROOMI, A YOHANNES and M J CONNOLLY}

Department of Geriatric Medicine, University of Manchester

COPD is a major public health problem . PR improves exercise tolerance in elderly COPD patients [ Roomi et al , Thorax 1995;50:A56 ]. Possible long-term benefits have not been examined in such group.

Aim : assess the long-term effects of PR on six-minute walk test (6M) , quality of life (QL) [ Guyatt, Thorax 1987;42:773 ] and hospitalisation days (HD) for respiratory problem during the 1 year before and 1 year after PR

Methods : 33 recruited, 28 completed 8-weeks incremental domiciliary PR (x4 / day unweighted arm raises, step-ups, inflating balloons ). 16 ( 5 female ) returned for 12-month follow up, mean age 77 years, FEV, 0.95 litres ( $48 \%$ predicted ). No exercise maintenance was given after completion of PR . 7 patients died ( 4 died of non-respiratory related disease ) 3 refused to come for follow-up and 2 were physically unable to do 6M ( CVA, hip fracture )

Results : Baseline $6 \mathrm{M}(\mathrm{n}=28)$ increased significantly from $214 \mathrm{~m}$ to $271 \mathrm{~m}(\mathrm{p}=0.0001)$ at 8 -week and to $276 \mathrm{~m}(\mathrm{p}=0.02, n=16)$ at 12 month. No change in FEV $V_{1}$ and QL at 8-week, but dyspnoea score increased significantly $(p=0.02)$ at 12 -month. Mean HD per patient before $P R 18.33$ days $(n=16)$ decreased significantly to 3.38 days after $P R(p=0.003, n=16)$. There were no significant differences in age, baseline values of $\mathrm{FEV}_{1}, 6 \mathrm{M}$ and QL between the attender and non-attender groups at 12-month

Conclusion : PR improves exercise capacity and dyspnoea in elderly COPD patients. The improvement persists for at least 12months and is accompanied by significant reduction in hospitalisation.

\section{S64 CONTRACTILE PROPERTIES OF THE ELDERLY HUMAN DIAPHRAGM}

MI POLKEY, ML HARRIS, CH HAMNEGÅRD, PD HUGHES, D LYONS, M GREEN and J MOXHAM

Respiratory Muscle Laboratory \& Clinical Age Research Unit, Kings College School of Medicine, and Royal Brompton Hospital, London UK

It has previously been reported that ageing is associated with a substantial decrease in diaphragm strength (Tolep et al AJRCCM 1996;152:677-82) . To test this hypothesis we studied $15(10 \mathrm{M}, 5 \mathrm{~F})$ subjects with a mean age of 29 (range 21-40) and 15 elderly (10M, 5F) subjects, mean age 73 (range 67-81). We measured transdiaphragmatic pressure (Pdi) during a maximal sniff (Sniff Pdi) and during bilateral cervical magnetic stimulation (CMS) of the phrenic nerve roots (Tw Pdi). Additionally in 17 subjects ( 9 elderly and 8 young) the Pdi elicited by paired CMS (pTw Pdi) was obtained at interstimulus intervals ranging from 10 to $999 \mathrm{~ms}$, ie 1 to $100 \mathrm{~Hz}$ (Polkey et al J Physiol (Lond) 1996;494P:92P). There was considerable overlap between groups. Mean Sniff Pdi in the elderly was $119 \mathrm{~cm} \mathrm{H}_{2} \mathrm{O}$ compared with $136 \mathrm{~cm} \mathrm{H}_{2} \mathrm{O}$ for the young subjects; this represented a median reduction of $18 \mathrm{~cm}$ $\mathrm{H}_{2} \mathrm{O}$ or $13 \%$ ( $\mathrm{p}=0.0595 \% \mathrm{CI}$ of difference 0 to $33 \mathrm{~cm} \mathrm{H}_{2} 0$ ). Mean Twitch Pdi in the elderly was $26.8 \mathrm{~cm} \mathrm{H}_{2} \mathrm{O}$ compared with $35.2 \mathrm{~cm} \mathrm{H}$, a median reduction of $8 \mathrm{~cm}$ $\mathrm{H}_{2} \mathrm{O}$ or $23 \%\left(\mathrm{p}=0.00495 \% \mathrm{CI} 3\right.$ to $13 \mathrm{~cm} \mathrm{H} \mathrm{H}_{2} \mathrm{O}$ ). At $10 \mathrm{~Hz}$ the elderly tended to generate a higher fraction of the Pdi obtained at $100 \mathrm{~Hz}$ than the young, but this trend did not achieve statistical significance $(p=0.11)$. We conclude that ageing is associated with a reduction in diaphragm strength. However the magnitude of the reduction is small and may be offset by a leftward shift of the forcefrequency relationship. 
S65 THE EFFECT OF SALMETEROL ON SLEEP ARCHITECTURE OF ASTHMATIC PATIENTS OF DIFFERENT AGES

E C SMITHI S J WILSON2 , G LASZLO3 and J C POUNSFORD4 1. Dept of Medicine,University of Bristol 2. Dept of Psychopharmacology, University of Bristol 3. Respiratory Dept.,Bristol Royal Infirmary 4 . Dept of Care of the Elderly,Frenchay Hospital

The effect of inhaled salmeterol $50 \mu \mathrm{g}$ bd (sal) on sleep architecture was compared with placebo (plac) in 27 asthmatic patients $(7$ aged 18 $35 y$ rs, 12 aged $45-54 y r s, 8$ aged $65 y$ rs and over). The study was double blind and of cross-over design. The treatment periods of at least 3 weeks were separated by a one week wash-out period. Polysomnography was performed in the patients' homes on one night towards the end of each treatment period. An acclimatisation sleep study was carried out during the run-in period. Subjects avoided caffeine for $6 \mathrm{hrs}$ and alcohol for $24 \mathrm{hrs}$ before the recording. Recordings were made on the Oxford Medilog MPA system and subjects kept to their normal night-time routine. EEG recordings were analysed using an automatic sleep analyser and confirmed visually (Rechtschaffen \& Kales). Mean values and 95\%CI for sleep efficiency (time asleep'total staging time*100), \% time in stage 3,4 and REM sleep and number of shifts to wake or stage 1 are shown for each age group.

\begin{tabular}{|c|c|c|c|c|c|c|}
\hline Mean & $\begin{array}{l}\text { Under } \\
\text { plac }\end{array}$ & $\begin{array}{c}35 \mathrm{yrs} \\
\text { sal }\end{array}$ & $\begin{array}{l}45-5 \\
\text { plac }\end{array}$ & $\begin{array}{l}4 y r s \\
\text { sal }\end{array}$ & $\begin{array}{l}65+y \\
\text { plac }\end{array}$ & $\begin{array}{l}\text { yrs } \\
\text { sal }\end{array}$ \\
\hline $\begin{array}{l}\text { Efficiency } \% * \\
\text { Stage } 3 \%\end{array}$ & $\begin{array}{c}93 \\
\begin{array}{c}91-96) \\
7.9\end{array}\end{array}$ & $\begin{array}{c}92 \\
(87-97) \\
8.9\end{array}$ & $\begin{array}{c}91 \\
(88-94) \\
7.8\end{array}$ & $\begin{array}{c}89 \\
(85-92) \\
8.6\end{array}$ & $\begin{array}{c}85 \\
(81-90) \\
8.1\end{array}$ & $\begin{array}{c}85 \\
(78-92) \\
8.9\end{array}$ \\
\hline Stage $4 \% *$ & $\begin{array}{l}(5.3-10.4) \\
19.4\end{array}$ & $\begin{array}{l}(5.9-11.9) \\
22.3\end{array}$ & $\begin{array}{l}(5.7-9.8) \\
10.8\end{array}$ & $\begin{array}{l}(5.6-11.6) \\
9.1\end{array}$ & $\begin{array}{c}(4.5-11.8) \\
6.9\end{array}$ & $\begin{array}{l}(6.5-11.3) \\
6.6\end{array}$ \\
\hline REM \% & $\begin{array}{l}(6.0-32.9) \\
21.1\end{array}$ & $\begin{array}{l}(6.0-28.6) \\
21.0\end{array}$ & $\begin{array}{l}(3.7-18.0) \\
23.3\end{array}$ & $\begin{array}{l}(3.9-14.3) \\
22.4\end{array}$ & $\begin{array}{c}(0.5-13.2) \\
24.4\end{array}$ & $\begin{array}{l}(1.3-12.0) \\
21.0\end{array}$ \\
\hline Shifts & $\begin{array}{c}(15.3-27.0) \\
37\end{array}$ & $\begin{array}{c}(16 .+25.6) \\
27\end{array}$ & $\begin{array}{c}(18.9-27.6) \\
46\end{array}$ & $\begin{array}{l}(18.2-26.7) \\
45\end{array}$ & $\begin{array}{c}(20.2-28.6) \\
53\end{array}$ & $\begin{array}{c}(15.7-26.3) \\
54\end{array}$ \\
\hline 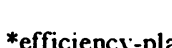 & (22-52) & (21-33) & (33-58) & $(30-61)$ & $\begin{array}{l}(41-66) \\
111 \mathrm{~s})\end{array}$ & $(41-66)$ \\
\hline
\end{tabular}

-plac $p=0.008$ sal $p=0.123$; stage+-plac $p=0.111$ sal $p=0.00$

We conclude that in these asthmatic subjects sleep efficiency and stage 4 sleep decrease in the elderly. This is similar to reported data in normal subjects. There was no difference between the effect of salmeterol and placebo on sleep architecture in the asthmatic subjects studied.

Supported by Glaxo Wellcome Research and Development.

S67 INFLUENCE OF BREATHHOLD ON PEAK AND PLATEAU CONCENTRATIONS OF NITRIC OXIDE IN THE EXHALED AIR OF ADULTS

WS TUNNICLIFFE, TJ FLETCHFR, DC CHAMBERS and JG AYRES

Chest Research Institute, Birmingham Heartlands Hospital, Bordesley Green East, Birmingham B9 5SS

Endogenous nitric oxide (NO) may be important in normal airway function and in the pathophysiology of airway disease. Levels recorded in similar patient groups, by differing investigators and methods, vary considerably and there is some ambiguity as to what exactly is being measured and hence what might affect the results. We investigated the effect of breathholding $(\mathrm{BH})$ on the peak and end expiratory (plateau) concentrations of NO in 34 adults (mean age 34yrs, 16 male, 15 current smokers) using a chemiluminescence NO analyser (sensitivity $1-5000 \mathrm{ppb}$, response time $<0.5 \mathrm{sec}$ ) also equipped for real time measurement of sample pressure, exhaled volume and $\mathrm{CO}_{2}$ (LR2000; Logan Research). The analyser has a feedback control unit allowing flow to be kept constant at $5 \mathrm{~V} / \mathrm{min}$ during expiration. The sampling rate was $250 \mathrm{~V}$ min for all measurements. Measurements were made during exhalation from total lung capacity, without $\mathrm{BH}$, and following a 15, 30 \& $45 \mathrm{sec}$ BH. End expiratory NO values were taken as those corresponding to the plateau of the exhaled $\mathrm{CO}_{2}$ trace. Values were compared using paired ttests.

\begin{tabular}{c|c|c|c|c|c|} 
& No BH & \multicolumn{2}{|c|}{ BH } & \multicolumn{3}{|c|}{ BH duration (seconds) } \\
& & (grouped) & $15 \mathrm{sec}$ & $30 \mathrm{sec}$ & $15 \mathrm{sec}$ \\
\hline [NO]ppb & $8.5(5.1)$ & YIIIIIII/A3.2(12.2) & $43.6(32.0)$ & $53.0(39.2)$ \\
\hline mean(SD) & $4.5(2.2)$ & $4.8(2.3)$ & $4.8(2.3)$ & $4.8(2.3)$ & $5.0(2.4)$ \\
\hline
\end{tabular}

Peak exhaled [NO] increased incrementally with duration of breathhold. The differences between no $\mathrm{BH}$ and each duration of $\mathrm{BH}$ were highly significant $(p<0.000001)$ as were the differences between $15 \& 30$, and $30 \& 45$ second breathhold peaks ( $p=0.00003 ; p=0.02$ respectively). The mean plateau [NO] without breathhold, did not differ significantly from mean plateau values for any duration of BH although the difference between the grouped BH data just achieved significance at the $5 \%$ level $(\mathrm{p}=0.04)$. The magnitude of this difference was very small and is unlikely to be of practical importance. The influence of breathhold on peak concentrations of NO must be considered when values are compared. The differing influence of breathhold on peak and plateau NO concentrations suggest that homeostatic mechanisms for NO in the upper and lower respiratory tracts may not be the same.
S66

UNSUSPECTEI) CHEST RADIO(SRAPHIC ABNORMALITIES IN YOUNG: ANI ELDERLY ACUTE ASTHMA ADMISSIONS

EC Pulford, PM Taylor, CC Hardy, M Woodhead and MJ Connolly Manchester Royal Infirmary, Oxford Rd, Manchester M13 9WL

Admission chest radiographs(CXRs) are usually routinely performed in all acute asthma admissions, even with apparent non-infective exacerbations and in the absence of clinical features of focal pathology. Many studies have demonstrated the value of CXRs in acute asthma, particularly in the elderly: this study focuses on those admissions in whom no focal chest abnormality is suspected from non-radiological evidence, comparing groups of young and elderly asthma admissions and elderly controls. Methods:Admission CXRs of young $(<45)$ and elderly $(>65)$ acute asthma admissions(diagnosed clinically by admitting physician) with apparent non-infective exacerbations, and elderly controls(no chest history, symptoms or signs) were reviewed by a single radiologist without knowledge of the patients' clinical status. Abnormalities were classified radiologically as significant or coincidental.

Exclusions: Smoking >10 pack-years; history or clinical evidence of infective exacerbation; focal chest signs.

Results: Young asthma (mean age 30): 9/14 normal CXRs; 3 significant abnormalities( 2 left basal consolidation, 1 left basal atelectasis); 2 coincidental abnormalities (pacemaker, calcified nodule).

Elderly controls (mean age 79.8): 7/16 normal CXRs; 4 significant abnormalities(basal bronchiectasis, atelectasis, consolidation, upper lobe fibrosis); 6 coincidental abnormalities(hiatus hernia, old TB, old fractures, pleural thickening).

Elderly asthma (mean age 80): 5/24 normal CXRs; 14 significant abnormalities (lobar consolidation and collapse, bronchiectasis, emphysema, atelectasis, pneumomediastinum, pleural effusion and focal opacities); 16 coincidental (including old rib fractures, vertebral collapse osteochondroma, unfolded aorta, pacemaker).

Conclusion: Both elderly groups have more unsuspected CXR abnormalities, as might be expected with increasing age; however, the incidence of significant abnormalities is higher in the elderly asthma group $\left[\chi^{2}=6.9, p=0.032\right.$ vs. both other groups]. This demonstrates the importance of performing a CXR in elderly acute asthma admissions even with apparent non-infective exacerbations.

S68 MEASUREMENT OF LOWER RESPIRATORY TRACT NITRIC OXIDE: VALIDITY OF USING VALUES AT $75 \%$ OF EXHALED VOLUME

\section{CHAMBERS, WS TUNNICLIFFE, TJ FLETCHER and JG AYRES}

Chest Research Institute, Birmingham Heartlands Hospital, Bordesley Green East, Birmingham, B9 5SS

Nitric oxide (NO) has been shown to be an important biologically active molecule with diverse actions in many organ systems. In the lung. NO has been shown to be a potent vasodilator and bronchodilator and serves an important role in cytokine mediated airway inflammation. The use of sensitive and rapid sampling chemi-luminescence analysers has revealed that during a typical exhalation there is a rapid initial peak of [NO] followed by a plateau phase. The initial peak is thought to represent upper respiratory tract air, and the plateau [NO], lower respiratory tract air. Investigators have chosen an arbitrary point along the exhaled $\mathrm{CO}_{2}$ curve, after it has reached the alveolar concentration of $5 \%$, to define the plateau NO (lower respiratory tract) value during an exhalation. This presents some difficulty as the range of potential values will often include the tail of the initial peak, may be variable toward the end of exhalation due to soft palate movement, and the chosen value is subjectively defined. We sought to define a point on the plateau phase which avoided these difficulties and was convenient to measure. The progressive exhaled volume and NO and carbon dioxide concentrations were measured using a chemiluminescence NO analyser (LR 2000, Logan Research) in 34 non-asthmatic subjects who completed two exhalations from total lung capacity while wearing nose-clips. We then compared two different measures of plateau [NO]: an average of all values across the plateau (beyond the threshold $5 \% \mathrm{CO}_{2}$ value) versus a single point measurement at $75 \%$ of exhaled volume. The mean (standard deviation) [NO] for all 68 exhalations measured across the plateau was $4.8 \mathrm{ppb}$ (2.35). The corresponding value for the single point measure of [NO] at $75 \%$ exhaled volume was $4.7 \mathrm{ppb}$ (2.27). Although this difference achieved statistical significance (paired t-test, $p=0.01$ ) it is small and well within the analyser's sensitivity ( $1 \mathrm{ppb})$. A point measurement of [NO] at $75 \%$ of exhaled volume is a convenient and reliable measure of lower respiratory tract [NO]. 


\section{TJ FLETCHER, WS TUNNICLIFFE, DC CHAMBERS, and JG AYRES}

Chest Research Institute, Birmingham Heartlands Hospital, Bordesley Green East, Birmingham B9 5SS

Nitric oxide (NO) is produced throughout the respiratory tract by the activity of NO synthase (NOS). NO is thought to exert a negative feedback effect on NOS. Cigarette smoke contains high concentrations of NO and so may inhibit the formation of endogenous NO. This in turn might explain some of the adverse effects of cigarette smoking. Evidence for this is provided by studies showing lower levels of NO in exhaled air of smokers compared to healthy non smokers. Most studies have measured mixed exhaled air, which includes a component from the nasopharynx, where levels of NO are considerably higher than in the lower respiratory tract. It is not clear whether the observed decrease in NO in the exhaled air of cigarette smokers is due predominantly to a decrease in the upper or the lower airway component. This study was designed to investigate this. Exhaled NO was measured in 19 healthy non smokers (mean age 31yrs, 9 male) and 15 current cigarette smokers (mean age 38yrs, 7 male) using a chemiluminescence NO analyser also equiped for measurement of sample pressure, exhaled volume and $\mathrm{CO}_{2}$. (LR 2000, Logan Research). Subjects exhaled from TLC without a breathhold through a tefion tube at a constant flow rate of $5 \mathrm{~V} / \mathrm{min}$. NO peaks rapidly and thereafter plateaus; the peak representing mixed air from the upper airways, and the plateau representing lower airways air. Nasal NO was measured during a breathhold by sampling from one nostril whilst keeping the cther open, thus allowing a steady flow from one side of the nose to the other. The peak NO level in smokers was lower than non smokers, but this did not reach statistical significance $(6.46 \mathrm{ppb} \pm 1.75 \mathrm{vs} 10.0 \mathrm{ppb} \pm 6.3$, $p=0.08$ ). The plateau level was significantly lower in smokers than non smokers (3.59pp \pm 1.11 vs $5.3 \mathrm{ppb} \pm 2.4, \mathrm{p}=0.02$ ). Nasal levels of NO were also significantly lower in smokers than non smokers (672ppb \pm 237 vs $895 \mathrm{ppb} \pm 260, p=0.01$ ). Cigarette smoking is associated with lower NO levels in both the lower respiratory tract and the nasopharynx, though whether the magnitude of the change in the former is sufficient to explain the pathological effects of cigarette smoking is not known.

\section{S70 NON INVASIVE ASSESSMENT OF RESPONSE TO} INHALED NITRIC OXIDE IN NORMAL SUBJECTS

\section{SJ BRETT, J CHAMBERS*, M ROSENTHAL * and TW EVANS}

Units of Critical Care and Paediatrics*, Royal Brompton Hospital, London, SW3 6NP

Introduction. The role of endogenous nitric oxide (NO) in the normal lung remains unclear. We investigated the response of normal subjects to the inhalation of NO using non-invasive methodology.

Subjects and methods. Subjects were six non-smoking volunteers without a history of respiratory disease. Responses to inhalod NO were characterised using a respiratory mass spectrometer (AMIS 2000, Innovision, Odense, Denmark). This instrument uses a multple inert gas rebreathing technique. Rebreathing manoeuvres were performed after 5 minutes inhalation of air, NO 20 parts per million (ppm), and NO 40ppm. This manoeuvre produces values for functional residual capacity (FRC), 12 carbon monoxide transfer factor (TCO), and effective pulmonary blood flow (EPBF).

Results. Results are expressed as group mean ( \pm SEM).

\begin{tabular}{|c|c|c|c|}
\hline & air & NO 20ppm & NO 40ppm \\
\hline FRC (litres) & $2.88(0.21)$ & $3(0.17)$ & $2.97(0.16)$ \\
\hline $\begin{array}{c}\text { TLCO } \\
\left(\mathrm{mmol} \mathrm{kPa}^{-1} \mathrm{~min}^{-1}\right)\end{array}$ & $7.45(0.5)$ & $7.35(0.52)$ & $6.81(0.5)$ \\
\hline EPBF $\left(1 \mathrm{~min}^{-1} \mathrm{~m}^{-2}\right)$ & $2.8(0.2)$ & $2.67(0.32)$ & $2.45(0.3)$ \\
\hline
\end{tabular}

There were no significant differences detectod by analysis of variance. Conclusion. Using non-invasive methodology, we were unable to detect any effects on the parameters measured. In normal subjects, the inhalation of supra-physiological doses of NO may produce no change in FRC, gas transfer or pulmonary blood flow.

Work supported by the Doverdale Trust.
S71 INHALED NITRIC OXIDE WORSENS GAS EXCHANGE IN PULMONARY FIBROSIS ASSOCIATED PULMONARY HYPERTENSION

\section{E GABBAY, S HAYNES*, PA CORRIS}

Departments of Cardiopulmonary Transplantation and *Anaesthesia, Freeman Hospital and University of Newcastle Upon Tyne

Inhaled Nitric oxide (NO) is a selective pulmonary vasodilator and has been used therapeutically in pulmonary hypertension. Its value in pulmonary hypertension associated with pulmonary fibrosis (PH-PF) has not been well studied. We studied the responses to NO in 5 men with PH-PF. Baseline values were measured whilst breathing $30 \% 0_{2}$ and patients then breathed incremental concentrations of $\mathrm{NO}$ as haemodynamic and arterial blood gas measurements were recorded. All had restrictive lung function [mean (SD) \% predicted VC, 50.6 (11.4)] and four were hypoxaemic on breathing air [mean (SD) $\mathrm{PaO}_{2}, 6.8$ (2.0) lpa]. The effects of NO are shown in table 1. All results as median (range).

\begin{tabular}{|c|c|c|c|c|}
\hline & Baseline & $\begin{array}{l}\text { 40ppm } \\
\text { No }\end{array}$ & $\begin{array}{r}\text { Median } \\
\text { change } \\
\text { (range) } \\
\end{array}$ & \\
\hline $\begin{array}{l}\text { Mean PAP } \\
\text { (mmHg) }\end{array}$ & $49(32-63)$ & $\begin{array}{l}39(24- \\
51)\end{array}$ & $-8(-4$ to -13$)$ & $p=0.05^{* *}$ \\
\hline $\begin{array}{l}\text { Mean } \\
\text { systemic BP } \\
\text { (mmHg) }\end{array}$ & $84(72-92)$ & $\begin{array}{l}85(70- \\
89)\end{array}$ & $1(-3$ to +2$)$ & $\mathrm{p}=0.80^{* *}$ \\
\hline $\begin{array}{l}\text { Cardiac } \\
\text { Index } \text { lm }^{-2}\end{array}$ & $\begin{array}{l}2.08(1.28 \\
-2.93)\end{array}$ & $\begin{array}{l}2.12(1.5 \\
7-2.94)\end{array}$ & $\begin{array}{l}-0.03(-0.04 \text { to } \\
+0.29)\end{array}$ & $p=0.74^{* *}$ \\
\hline $\begin{array}{l}\mathrm{PaO}_{2}(\mathrm{kppa}) \\
\mathrm{FO}_{2} \mathbf{0 . 3}\end{array}$ & $\begin{array}{l}14.1(8.9- \\
18.7)\end{array}$ & $\begin{array}{l}11.2(7.7 \\
-18.2) \\
\end{array}$ & $\begin{array}{l}-2.2(-0.5 \text { to }- \\
3.5) \\
\end{array}$ & $\mathrm{p}=0.10^{* *}$ \\
\hline
\end{tabular}

Conclusion Inhaled NO acts as a selective pulmonary vasodilator in PHPF but does not improve cardiac index at rest and may worsen gas exchange probably due to worsening VAIQ mismatch.

\section{S72 EXHALED NITRIC OXIDE IS NORMAL IN SARCOIDOSIS PATIENTS WITH ACTIVE ALVEOLITIS}

\section{DM O' DONNELL, VM KEATINGS, C O' CONNOR, * P MCLOUGHLIN and MX FITZGERALD}

Department of Medicine and Therapeutics and * Department of Physiology, University College Dublin, Ireland.

Peak exhaled nitric oxide (NO) values are abnormally elevated in patients with asthma. In this study, 10 patients $(9$ male mean age $34.4+1-9.9$ years) with active sarcoidosis were recruited to investigate the hypothesis that acute alveolitis causes an increase in exhaled NO concentrations. All had a contemporaneous bronchoalveolar lavage showing active alveolitis (mean percentage lymphocytes $54.4+1-17.4$ ) and none were on oral or inhaled steroid therapy. 10 control subjects (6 male, mean age $29.0+/-6.0$ years) were healthy non-smokers with no history of lung disease or allergic rhinitis and no current respiratory symptoms.

Simultaneous exhaled NO and exhaled carbon dioxide (CO2) were measured continuously throughout exhalation using a rapidly responding chemiluminescence analyser and a rapidly responding infrared analyser respectively. The analogue signals were timecorrected to compensate for experimentally determined differing response and lag times of the instruments. All subjects performed three maximal effort vital capacity manoeuvres, the results of which were averaged. Three different parameters were analysed: peak exhaled NO, the highest recorded NO value during expiratory effort, mean alveolar NO, the mean of all NO values corresponding to the plateau phase of the $\mathrm{CO} 2$ curve and end-tidal NO, the mean of NO values in 2 seconds preceding the peak $\mathrm{CO} 2$.

Results for each group are shown in ppb, mean \pm standard deviation.

\begin{tabular}{|l|ccr|}
\hline & Peak Exhaled NO & Mean Alveolar NO & End-Tidal NO \\
\hline Patients & $12.7 \pm 5.97$ & $7.4 \pm 4.39$ & $6.67 \pm 4.46$ \\
Controls & $10.51 \pm 5.91$ & $6.86 \pm 4.57$ & $6.54 \pm 4.41$ \\
p value & $\mathbf{p}=\mathbf{0 . 2 5}$ & $\mathbf{p}=\mathbf{0 . 7 7}$ & $\mathbf{p}=\mathbf{0 . 6 6}$ \\
\hline
\end{tabular}

These data show that exhaled nitric oxide is not elevated in patients with active alveolitis due to sarcoidosis. 
S73 EXHALED NITRIC OXIDE (NO) IS NOT ELEVATED IN PATIENTS WITH CYSTIC FIBROSIS OR BRONCHIECTASIS COMPARED TO NORMALS

\section{L.P. HO, J.A.INNES and A.P GREENING}

Respiratory Unit and Scottish Adult Cystic Fibrosis Service, Westem General Hospital, Crewe Road, Edinburgh EH4 2XU

Airways inflammation has been associated with increased NO in the exhaled breath (Bames, ERJ (6),1993). We therefore questioned whether exhaled NO could act as an indicator of the severity of airways inflammation in the suppurative lung diseases, cystic fibrosis (CF) and bronchiectasis (Br). Methods: Single exhalation NO levels were measured using the chemiluminescence NO analyser (Logan Research, Kent); detection limit $0.3 \mathrm{ppb}$. Upper airway NO production was excluded by maintaining a constant mouth pressure (4-5 $\mathrm{cm} \mathrm{H}_{2} \mathrm{O}$ ) during exhalation. This pushes back the soft palate and excludes air originating from the nose during exhalation. Values quoted are plateau levels at the end of exhalation, against a flow restrictor. Patients: All patients were recruited from our outpatient clinics. All except 3 CF patients have fully defined genotypes. $\mathrm{Br}$ was diagnosed by $\mathrm{CT}$ or classical CXR changes. All subjects were non smokers. 6 asthmatics were on inhaled steroids. All levels were taken when patients were stable. Results:

\begin{tabular}{llllll}
\hline & $\begin{array}{l}\text { normal } \\
\mathrm{n}=17\end{array}$ & $\begin{array}{l}\mathrm{CF} \\
\mathrm{n}=31\end{array}$ & $\begin{array}{l}\mathrm{Br} \\
\mathrm{n}=6\end{array}$ & $\begin{array}{l}\mathrm{Br}+\text { ster } \\
\mathrm{n}=5\end{array}$ & $\begin{array}{l}\text { Asthma } \\
\mathrm{n}=7\end{array}$ \\
\hline NO & $\mathbf{5 . 5 ( 3 . 6 )}$ & $\mathbf{4 . 5 ( 2 . 6 )}$ & $\mathbf{6 . 6 ( 3 . 4 )}$ & $\mathbf{5 . 9 ( 1 . 4 )}$ & $\mathbf{1 5 . 0 ( 6 . 1 )}$ \\
\hline Age & $32.8(16.1)$ & $27.2(8.7)$ & $49.3(8.4)$ & $57.8(13.3)$ & $39.6(16.3)$ \\
\hline FEV1 & - & $54.4(24.1)$ & $61.0(22.8)$ & $57.8(13.3)$ & - \\
\hline
\end{tabular}

(All valucs are mean (SD), NO in $\mathrm{ppb}$. Br= Bronchictasis, Ster = inhaled fluticasone, budesonide or beclomethasone, FEVI $=\%$ predicted.)

These data suggest that NO in the exhaled breath of patients with CF and $\mathrm{Br}$, in contrast to asthma, are not elevated. Explanations include a) poor diffusion of NO across increased and viscous airway secretion b) down regulation of iNOS in chronic suppurative conditions. Our findings in bronchiectasis contrast with those of Kharitonov et al (AJRCCM (151) 1995). This may be due to different methodologies.

S75 EFEECT OF OUTDOOR TEMPERATURE CA DAIIY IUNG FUNCTION AND EXACERBATIONS IN PATIENTS WITE COPD PATIENTS

GC DONALDSON, T SEEMUNGAL, C EVANS, EA PAUL and JA WEDZICHA (for the East London COPD collaborative group).

Queen Mary and Westfield College, Mile End Road, E1. London Chest Hospital, Bonner Road, London, E2.

Pulmonary function worsens and exacerbations increae in COPD patients during winter, but the role of outdoor temperature is controversial.

Between October 1995 and March 1996, 71 COPD patients (52 M, 19F; mean age (SD) 67.1 11 COPD years; $p_{1} \mathrm{O}_{2} 8.88 \pm 1.08 \mathrm{kPa}, \mathrm{EEV}_{1} 1.06 \pm 0.431$, FVC $2.46 \pm 0.81$ l) recorded at home morning peak fiow and symptoms on monthly diary cards. Exacerbation was determined by one physician. In 25 patients (22M, 3F, mean age $66.1 \pm 9.1$ years; : $0.028 .79 \pm$ $1.23 \mathrm{kPa}$, FEV $1.12 \pm 0.441$, EVC $2.46 \pm 0.641)$ daily $\mathrm{FEV}_{1}$ and FVC were also recorded. Central-Iondon temperature data were obtained from the Meterological office. For each subject, regression coefficients were separately calculated for EDV. EVC and peak flow on same-day mean temperature, with Cochrane-orcutt allowance for serial correlation and day number included as an independent variable to account for annual decline in lung function. Logit regression with allowance for serial correlation was used to analyse the relationship between symptoms and temperature.

Median coefficients were $0.35^{\circ}\left(\mathrm{ml} / \mathrm{min} /{ }^{\circ} \mathrm{C}\right)$ for peak flow, $2.60^{\circ}\left(\mathrm{ml} /{ }^{\circ} \mathrm{C}\right) \mathrm{FEV}_{1}, 3.11^{\circ}\left(\mathrm{ml} /{ }^{\circ} \mathrm{C}\right)$ EVC, $-0.061^{\circ}$ shortness of breath , $-0.109^{\circ}$ increased sputum colour, $-0.112^{* *}$ increased sputum amount, $-0.059^{\circ}$ cold, $-0.055^{\circ}$ increased wheeze, $-0.087^{\circ}$ sore

throat, $-0.124^{\circ}$ increased cough, $-0.081^{\circ}$

throat, $-0.124^{\circ}$ increased cough, $-0.0811^{\circ}$ exacerbation: $P<0.05, " P<0.01, \cdots P<0.001$
Wilcoxon signed-rank test that median $=0$.

These decreases in $\mathrm{FEV}_{1}$ and EVC with fall in temperature may be sufficient to compromise patients with chronic respiratory disability. The mechanisms may involve changes in airway resistance, increased respiratory infection or changes in intra-thoracic blood volume.

\section{S74 FACTORS PREDISPOSING TO EXACERBATIONS IN} PATIENTS WITH COPD

T SEEMUNGAL, EA PAUL, GC DONALDSON, JA WEDZICHA (FOR THE EAST LONDON COPD COLLABORATIVE GROUP)

The London Chest Hospital, London E2

Queen Mary and Westfield College, London EI

Exacerbations of COPD occur commonly in patients with moderate or severe disease but factors affecting frequency are not well known.

Between October 1995 and May 1996, 88 COPD patients (60M, 28F, mean(SD) age 68.1(10.3) yrs, FEVI 1.02(0.43) I, FVC 2.40(0.81) I, FEV1/FVC 44\%(14), $\mathrm{PO}_{2} 8.84(1.12) \mathrm{kPa}$ ) from East London were given diary cards on which they recorded various parameters including daily peak flow and respiratory symptoms. Diagnosis of exacerbation was based on Anthonisen et al (Ann Intern Med. 1987:106; 196-204), incorporating primary symptoms (dyspnoea and sputum) and various secondary symptoms. This was determined by the same physician when patients were reviewed monthly from diary card data (unreported exacerbation) or at acute visit (reported exacerbation). In 66(75\%) of these patients there were 166 exacerbations of which 96(58\%) were reported. The mean fall in FEVI to first reported exacerbation was $0.035(0.18) 1$. The frequencr of exacerbations was compared with possible predisposing factors (p-value), sex $(0.67)$, chronic sinusitis or rhinitis $(0.17)$, cardiac failure $(0.72)$, number of lower respiratory tract infections in the previous year $(0.04)$, currently smoking $(0.34)$, smoking pack years $(0.41)$, daily cough $(0.57)$, daily dyspnoea $(0.50)$, daily wheeze $(0.04)$, daily sputum $(0.16)$, inhaled steroid dose (0.49), oral steroid dose (0.49), long term oxygen therapy (0.58), hypoxia $\mathrm{P}_{\mathrm{g}} \mathrm{O} 2<8 \mathrm{kPa}(0.37), \mathrm{P}_{2} \mathrm{CO} 2>6.5 \mathrm{kPa}(0.23)$, FEVI $<$ 0.81 (0.94).

Thus patients with a number of previous exacerbations and daily reported wheeze are at greater risk of exacerbation. This supports the classification of COPD patients into "exacerbators" and "non-exacerbators".

(Supported by the British Lung Foundation)

\section{S76 SYMPTOMATIC AND SPIROMETRIC CHANGE DURING EXACERBATIONS OF CHRONIC OBSTRUCTIVE PULMONARY DISEASE (COPD)}

\section{DAVIES, RM ANGUS, MG PEARSON, PMA CALVERLEY}

\section{Aintree Chest Centre, Fazakerley Hospital, Liverpool}

Changes in spirometry are not good predictors of functional improvement in stable COPD (Hay et al. ERJ 1991). To determine whether this was true in acute exacerbations we studied prospectively 31 patients, mean age 65 (9.3) years, mean FEV1 on admission 30.2 (17)\% predicted, excluding those with a $\mathrm{pH}<7.26$, during an exacerbation of COPD. All were treated with oxygen, antibiotics, nebulised beta agonist and anticholinergic drugs and some received oral corticosteroids +/theophylline. Spirometry and peak flow (PEF) were measured at admission before and after $5 \mathrm{mg}$ nebulised salbutamol, then daily thereafter. Symptom diary cards were completed daily and scored on a Likert scale and a VAS wellbeing was scored on discharge. Mean duration of stay was 9 days and time to medical discharge was unrelated to age. Complete data were available in 29 patients, 11 of whom improved their FEV1 by $2200 \mathrm{ml}$ from admission. Improvement in FEV1 was not dependent upon baseline lung function or symptom severity scores. FEV1 improvers and non-improvers showed equally significant $(p<0.01)$ improvements in total symptom scores and their components. The change in symptoms, however assessed, was unrelated to the relative changes in FEV1 or PEF. Spirometric improvement is not necessary for useful changes in symptoms to occur when a COPD exacerbation is treated. 
S77

CRITERIA FOR NON- INVASIVE VENTILATION IN CHRONIC OBSTRUCTIVE PULMONARY DISEASE(COPD): WHO IS ELIGIBLE?

\section{M.J. DOHERTY and M.A. GREENSTONE}

Medical Chest Unit, Castlehill Hospital, Hull

Non-invasive positive pressure ventilation(NPPV) has been successfully used to treat ventilatory failure due to exacerbations of COPD. Arterial blood gas(ABG) criteria for NPPV has varied between studies, as selection criteria varies so will the resulting resource implications. We set out to study this in the setting of a district general hospital. The names of all patients admitted with an ICD code implying a diagnosis of COPD in a two month period were recovered and an attempt was made to obtain all notes. How many of these patients fulfilled each of 3 published criteria for NPPV was then calculated. These criteria were; 1 .) $\mathrm{Ph}<7.33$ and/or $\mathrm{PaCO}>7.18 \mathrm{kPa}$ and $/$ or $\mathrm{PaO}_{2}<7.98 \mathrm{kPa}$; 2.) $\mathrm{PCO}_{2}>$ $6 \mathrm{kPa}$ and $\left.\mathrm{PO}_{2}<7.5 \mathrm{kPa} ; 3\right) . \mathrm{Ph}<7.35$ and $\mathrm{Pa} \mathrm{CO}_{2}>6 \mathrm{kPa}$. One hundred and sixty three patients were coded for COPD but after allowing for incorrect diagnoses(20 patients, $12 \%$ ), absence of blood gas data( 9 patients, $6 \%$ ) and unobtainable notes $(40$ patients, $24 \%), 94$ patients were suitable for analysis. Of the remaining 94 patients, $51(54 \%)$ fulfilled none of the criteria, $42(45 \%)$ fulfilled the first criteria( 1 ventilated and 6 deaths), 29(31\%) fulfilled the second criteria( 1 ventilated and 5 deaths) and $17(18 \%)$ fulfilled the third set of criteria ( 1 ventilated and 5 deaths). This study suggests that the resource implications of NPPV would be massive if the most lax of these criteria were used but that more stringent criteria (especially the need for a respiratory acidosis) will result in fewer patients needing treatment. Only one patient died who fulfilled the first set of criteria but none of the others. The exact criteria which will best balance benefit and resources is yet to be defined.

$\begin{array}{ll}\text { 1). Eur. Resp. J. 1996;9:422-430. } & \text { 2). Lancet 1993;341:1555-7. }\end{array}$

3). Am. J. Resp. Crit. Care Med. 1995;151:1799-1806.

S79 ASSESSMENT OF THE APPROPRIATENESS OF ADMISSIONS OF PATIENTS WITH EXACERBATION OF CHRONIC OBSTRUCTIVE PULMONARY DISEASE (COPD).

E Skwarska, K Skwarski, W MacNee.

Respiratory Medicine Unit, Department of Medicine, Royal Infirmary, Lauriston Place, Edinburgh, EH3 9Yw

COPD is a major cause of morbidity and mortality in Scotland. Between 1981-1993 exacerbations of COPD was the fastest growing component of the rise in emergency admissions, increaseing by $234 \%$. The aim of this pilot survey was to assess the appropriateness of admissions for COPD using a simple 16 item questionnaire completed by the admitting Respiratory Registrar of the patient's history, clinical condition, social circumstances, and results of the objective measurements such as arterial blood gas level and changes on the CXR. Each of the 16 items on the questionnaire scored one if present or zero if not present. 120 patients (64 M; 56 F; mean age 68 (range 43-89 years) were admitted with exacerbations of COPD in patients presenting with exacerbations of COPD presenting to the Royal Infirmary of Edinburgh over a 4 month period. The presence of the impaired level of consciousness, acute confusion, abnormality on the CXR or respiratory acidosis $(\mathrm{H}+>50 \mathrm{nmo} / /)$ were regarded as "absolute" indications for admission. $42.5 \%$ of the patients who were admitted did not have any of the "absolute" indications for admission. Their total questionnaire score was $5.9 \pm 3.2$ (range 0 16). There was a positive correlation between total score and the presence of the "absolute" indicators for admission ( $r=0.66$; $p<0.01$ ) suggesting that the more "absolute" indicators for admission present, the more likely the total score being higher, thus the more severe the exacerbation of COPD. $34 \%$ of patients had only one "absolute" indication for admission abnormal CXR being the most frequent cause (90.6\%). $23 \%$ of patients had 2 to 4 "absolute" indicators for admission. A significant proportion of patients $(42.5 \%)$ who did not have any of the "absolute" criteria for admission and some of those patients with CXR abnormalities could be safely discharged home with domiciliary nursing support so reducing the numbers of admissions. Supported by the Scottish Office.
S78 Severity Scoring in Acute Exacerbations of Chronic Obstructive Airways Disease (COAD). Stell IM, Edwards RJ, Polkey MI, Williams AJ, Moxham J, Rees J

No simple measure exists to grade the severity of acute exacerbations of COAD. This study was designed to develop a scoring system from simple clinical measures which might have predictive value, and be useful in clinical trials.

Features, which taken in combination have been said to indicate a severe exacerbation include heart rate $>110 / \mathrm{min}$, respiratory rate $>25$ breaths/min, increased dyspnoea at rest, use of accessory muscles, peak expiratory flow rate (PEFR) $<100 \mathrm{l} / \mathrm{min}, \mathrm{PaCO}_{2}$ $>6 \mathrm{kPa}$ and $\mathrm{PaO}_{2}<8 \mathrm{kPa}$ (Siafakas NM et al. ERS consensus statement - Optimal assessment and management of COPD. Eur Respir J 1995;8:1398-1420.)

These variables, and in addition calculated $\left[\mathrm{HCO}_{3}{ }^{-}\right]$and $\mathrm{pH}$, were recorded on 62 consecutive patients attending A\&E with acute exacerbations of COAD. Numerical values were assigned to dyspnoea and accessory muscle use on a four point scale (0-3), and the absolute values of the other variables were used for individual analysis. These values were correlated with clinical 'indicators' of severity: the decision to admit, and length of admission.

The individual variable most predictive of admission and the length of admission was PEFR. A better predictor was a combined score of six of the variables together. In combined scores one point each was assigned for pulse $>110 / \mathrm{min}$, dyspnoea of moderate degree or worse, accessory muscle use of moderate degree or worse, PEFR $<100 \mathrm{l} / \mathrm{min}, \mathrm{pH}<7.38$ and $\mathrm{pO}_{2}<8 \mathrm{kPa}$. The score $0-6$ was significantly correlated with length of admission $r=0.41$, and highly discriminating for admission. Mean score for patients admitted $(n=47) 3.71$, and for those not admitted $(n=15) 1.64(p$ $<0.0005$ ).

We conclude that this six point measure is a reasonable predictor of clinical decisions on admission and length of stay. It could be useful in the objective evaluation of acute exacerbations of COAD for clinical studies.

\section{S80 IS VENTILATORY BREAKAWAY IN HEAVY EXERCISE REALLY DUE TO METABOLIC ACIDAEMIA? STEPHEN C MORRISON}

Department of Thoracic Medicine, Royal Brisbane Hospital and Dept of Medicine, University of Queensland, Herston, BRISBANE, Queensland 4029, Australia

Background: The disproportionate increase in ventilation found during high intensity exercise (ventilatory breakaway, VB) is traditionally attributed to accumulation of lactic acid resulting from anaerobic metabolism, and has been termed the "anaerobic threshold"; VB has however been observed when lactate formation is impeded or prevented. This study was undertaken to determine whether VB is abolished when acidaemia in heavy exercise is prevented by infusion of alkali. Methods: Eight healthy males underwent incremental cycle ergometry to exhaustion. Ventilation mixed expired $\mathrm{O}_{2}$ and $\mathrm{CO}_{2}$, blood lactate $(\mathrm{La})$ and $\mathrm{pH}$ were measured each min. On a separate day, $4.2 \% \mathrm{NaHCO}_{3}$ solution was infused during exercise to keep blood pH close to pre-exercise level. Results: Mean exercise duration was $17.9 \pm 2.0$ (SD) $\mathrm{min}$ and peak $\mathrm{VO}_{2} 4.00 \pm 0.30 \mathrm{l} / \mathrm{min}$. On the control day blood $\mathrm{pH}$ at rest was $7.41 \pm 0.01$, falling to $7.27 \pm 0.07$ at peak exercise, and to $7.22 \pm$ 0.07 in early recovery. Infusion of alkali commenced $6.6 \pm 1.9 \mathrm{~min}$ prior to exercise cessation, and $307 \pm 77 \mathrm{mmol}$ was required to maintain blood $\mathrm{pH}$ near pre-exercise level $(7.39 \pm 0.03$ at peak exercise, $7.35 \pm 0.03$ in early recovery). Although ventilation at peak exercise was lower after the infusion than in the control study (132.5 vs $147.4 \mathrm{~V} / \mathrm{min}$ respectively, $\mathrm{p}=0.03$ ), ventilatory pattern was not altered by the infusion; VB was evident in 7 of the 8 subjects in the control study, and remained so during the infusion study. $\mathrm{VCO}_{2}$ values at peak exercise were insignificantly different in infusion and control studies, but peak $\mathrm{La}$ was significantly higher in the infusion study than in the control (16.6 vs $13.6 \mathrm{mmol} / /$ respectively, $\mathrm{p}=$ 0.004). Conclusion: Persistence of VB in the absence of metabolic acidaemia indicates that factors additional to acid-base disturbance in the blood contribute to the commonly found ventilatory pattern during heavy exercise. Higher blood La following alkali infusion may be due to facilitated transport of $\mathrm{La}$ from muscle, or to an increased rate of glycolysis, or both. 
S81 CARBON DIOXIDE REPLACEMENT DURING EXERCISE IN PATIENTS WITH IDIOPATHIC HYPERVENTILATION
C.J.WARBURTON,
S.JACK,
M. BAKER,
L. DAVIES M.G.PEARSON

Aintree Chest Centre, Fazakerley Hospital, Liverpool

Ten patients with idiopathic hyperventilation defined as an end-tidal CO2 (PETCO2) level of less than $30 \mathrm{~mm} H$ for more than 1 minute during exercise performed two maximal exercise tests (cycle ergometer) one week apart. During the second exercise test controlled $\mathrm{CO} 2$ replacement to keep the PETCO2 between 36 and $40 \mathrm{mmHg}$ throughout exercise was carried out (maximum inspired $\mathrm{CO} 2$ concentration did not exceed 68 in any patient (mean $4 \%$ )). The ventilatory responses to exercise were compared using paired students t-tests.

5 male and 5 female patients were studied with a mean age of 48 years (range 34 to 59 ). The peak work rate was 7 watts higher during $\mathrm{CO} 2$ replacement ( 86 vs 93 watts, $p=N S$ ), however the maximal oxygen uptake (VO2) was significantly greater during the $\mathrm{CO} 2$ replaced exercise test $(1.347$ vs $1.762 \quad 1 / \mathrm{min}, \mathrm{p}<0.05)$. This difference represents an 18 mean increase in the percent predicted maximal oxygen uptake ( $60 \%$ vs $78 \%, p<0.05)$. No difference was noted between the maximum heart rate achieved during the two exercise tests (141 vs 144 bpm) however a significantly higher maximum minute ventilation was demonstrated during $\mathrm{CO} 2$ replacement ( 55 vs $821 /$ min, $p<0.005$ ).

This study suggests that the abolition of the symptoms of hyperventilation during exercise by the addition of $\mathrm{CO} 2$ to the inspired air has only minor effects upon maximal work rate. $\mathrm{CO}$ replacement appears to exaggerate the ventilatory response to exercise in these patients with documented hyperventilation.

S83 COMPARISON OF DIFFERENT LEVELS OF NASAL CONTINUOUS POSITIVE AIRWAY PRESSURE (NCPAP) IN PATIENTS WITH SEVERE CONGESTIVE HEART FAILURE (CHF) IN SINUS RHYTHM (SR) AND ATRIAL FIBRILLATION (AF)

\section{J L KIELY, A BUCKLEY, P SHIELS, P C DEEGAN, B MAURER} AND W T MCNICHOLAS

Departments of Respiratory Medicine and Cardiology, St. Vincent's Hospital, Dublin, Ireland

We have previously shown a reduction in awake cardiac output (CO) following $5 \mathrm{~cm}$ H2O NCPAP application among patients with severe CHF in AF (Eur Respir J 1995; 8: 430-435). We wished to expand these observations by comparing the awake effects of different levels of NCPAP, and also by comparing the effects in patients with AF and SR Ten patients (6 AF and 4 SR) were enrolled, and haemodynamic measurements were made via Swan Ganz catheterisation. All patients had severe but stable CHF (mean left ventricular ejection fraction $=25 \%$ ), with no recent change in cardiac therapy. After baseline measurements, 0,5 and $10 \mathrm{~cm} \mathrm{H2O} \mathrm{NCPAP} \mathrm{were} \mathrm{applied} \mathrm{in} \mathrm{random} \mathrm{order,} \mathrm{each} \mathrm{for} 30$ minutes, and a recovery period with the NCPAP mask removed was given between each pressure application. Cardiac output (CO) was measured by the thermodilution technique at times 0 and 30 minutes of each NCPAP application, and 20 minutes after mask removal RESULTS: CO rose in the SR group by $0.48+0.23 \mathrm{~L} / \mathrm{min}$ (mean $+\mathrm{SE}$ ) on $5 \mathrm{~cm} \mathrm{H} 20 \mathrm{NCPAP}$ and by $0.45 \pm 0.33 \mathrm{~L} / \mathrm{min}$ on $10 \mathrm{~cm} \mathrm{H} 20$, but fell in the AF group by $0.13 \pm 0.19 \mathrm{~L} / \mathrm{min}$ on $5 \mathrm{~cm} \mathrm{H} 20$ NCPAP and by 0.45 $\pm 0.09 \mathrm{~L} / \mathrm{min}$ on $10 \mathrm{~cm} \mathrm{H} 20$ respectively ( $p<0.05$ for both pressures) These data indicate a fundamental difference in the response of patients with CHF to NCPAP based on underlying cardiac thythm and give important insight into the effects of NCPAP on cardiac function. The data also support previous reports that NCPAP may provide clinical benefit to patients with CHF who are in sinus rhythm.

\section{S82 DIAPHRAGM AND QUADRICEPS STRENGTH} IN CHRONIC HEART FAILURE

PD HUGHES, MI POLKEY, D HARRINGTON, AJS COATS, J MOXHAM, and M GREEN

Royal Brompton and King's College Hospitals, London

There are conflicting reports of respiratory muscle weakness in chronic heart failure (CHF). We have assessed diaphragm and quadriceps strength in a group of 12 patients, (mean age: 61, SD 9) with moderate to severe CHF (left ventricular ejection fraction: mean $28 \%$, SD 8). Sniff and twitch transdiaphragmatic pressure (Sn Pdi, Tw Pdi), quadriceps maximum voluntary contraction (MVC $Q$ ) and twitch contraction force (TwQ) were measured. Diaphragm and quadriceps stimulation was performed using a Magstim 200 stimulator, which allows non-volitional measurement of muscle strength. The figures show plots of diaphragm and quadriceps strength for each patient, with laboratory normal lower limits marked. Only one patient had very mild diaphragm weakness when the results of volitional and nonvolitional tests were combined. We were unable to detect a relationship between Tw Pdi and any index of CHF severity eg. ejection fraction, symptom severity score or maximum oxygen uptake.

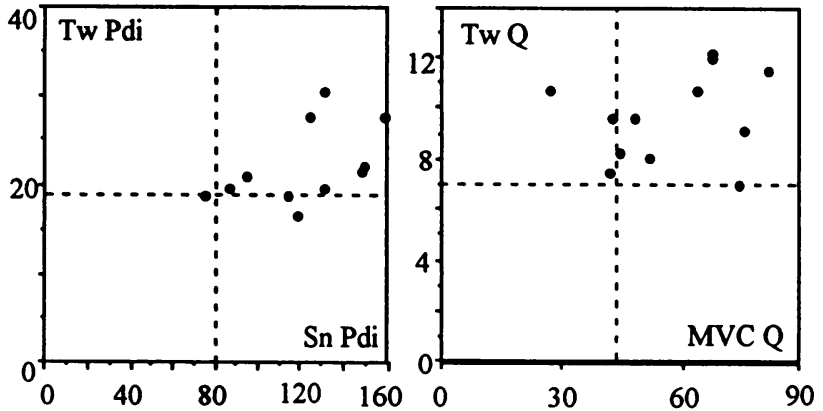

We conclude that none of our patient group had weakness of either quadriceps or diaphragm likely to contribute significantly to their symptoms.

S84 FREOUENCY DEPENDENCE OF THE LENGTHTENSION RELATIONSHIP OF THE DIAPHRAGM IN MAN

MI POLKEY, C-H HAMNEGẢRD, D KYROUSSIS, PD HUGHES, ML HARRIS, GF RAFFERTY, I STELL, J MOXHAM \& M GREEN

Kings College \& Royal Brompton Hospitals, London UK

The effect of length on tension generation by the human diaphragm has previously only been described using single bilateral phrenic nerve stimuli, but in peripheral skeletal muscle the length tension relationship is dependent on the frequency of stimulation (Rack \& Westbury J Physiol(Lond) 1969;204:443-60). We therefore studied 8 healthy volunteers using paired supramaximal bilateral phrenic nerve stimuli (Yan et al Eur Resp $J$ 1993;6:211-8). Stimuli were given anteriorly using two $40 \mathrm{~mm}$ coils each of which was powered by 2 Magstim 200 stimulators. Each pair of stimulators was linked by a BiStim module which allowed a minimum of 3 stimuli to be given at the following interstimulus intervals; $999 \mathrm{~ms}(1 \mathrm{~Hz}), 100 \mathrm{~ms}$ $(10 \mathrm{~Hz}), 50 \mathrm{~ms}(20 \mathrm{~Hz}), 33 \mathrm{~ms}(30 \mathrm{~Hz})$ and $10 \mathrm{~ms}(100 \mathrm{~Hz})$, and at the following lung volumes; RV, FRC, 1/3 IC, 2/3 IC and TLC. Results are shown in the figure; $50 \mathrm{~ms}$ and $33 \mathrm{~ms}$ were similar to $10 \mathrm{~ms}$ and are therefore omitted for clarity. Increasing lung volume caused the greatest reduction in the Pdi elicited by stimuli $100 \mathrm{~ms}$ apart (ie 10 $\mathrm{Hz}$ ). We conclude that the length-tension relationship of the diaphragm is frequency dependent. Given that phrenic nerve firing rates in vivo are approximately $10 \mathrm{~Hz}$ this may contribute to impaired diaphragm function in patients who are hyperinflated.

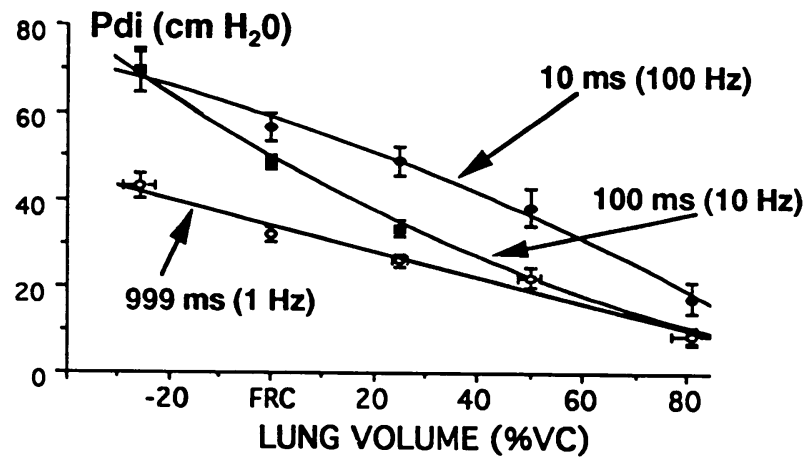


S85 Wheezing illness in childhood - the changing contribution of non-virus-associated wheeze.

Russell G, Ninan TK, Omran M.

Department of Child Health, University of Aberdeen.

Three questionnaires administered during the past 30 years have demonstrated a marked change in the prevalence of wheezing illness in Aberdeen schoolchildren aged 8 to 12 years:

$\begin{array}{lccc} & 1964 & 1989 & 1994 \\ \text { Number studied } & 2510 & 3403 & 4034 \\ & \% & \% & \% \\ \text { Wheeze } & 10.4 & 19.8 & 25.4 \\ \text { Doctor-diagnosed asthma } & 4.1 & 10.2 & 19.6 \\ \text { Eczema } & 5.3 & 12.0 & 17.7 \\ \text { Hay fever } & 3.2 & 11.9 & 12.7 \\ \text { Wheeze only with URTI (WI) } & 6.7 & 4.2 & 7.8 \\ \text { WI as \% total wheeze } & 64.0 & 21.4 & 30.7 \\ \text { Wheeze + hay fever (W+H) } & 1.4 & 5.2 & 6.3 \\ \text { W+H as \% total wheeze } & 12.2 & 26.2 & 24.7\end{array}$

Thus, although there has been a dramatic increase in the prevalence of wheeze, doctor diagnosed asthma, eczema and hay fever, the prevalence of wheeze occurring only in the presence of upper respiratory tract infection has remained fairly constant, and has declined as a proportion of total wheeze. In contrast, the proportion of children in whom wheeze is associated with hay fever, an allergic airway disease closely associated with asthma, has risen

Previous studies ${ }^{1}$ from Aberdeen have shown that children who wheeze only with URTI have a much better long-term prognosis than other children with wheeze. It is likely therefore that the current "epidemic" of childhood asthma, with its accompanying increased use of medical resources, will persist into the adult agegroup in whom the prevalence of wheezing illness is likely to continue to increase over the next 25 years.

1. Ross S, Godden D, McMurray D, et al. Social effects of wheeze in childhood: a 25 year follow up. BMJ 1992;305:545-8.

\section{S87 FACTORS EFFECTING SYMPTOM FREQUENCY IN ADOLESCENTS WITH WHEEZE}

\section{*NJ WITHERS, * JL LOW, *ST HOLGATE AND \#JB CLOUGH \\ *University Medicine and \#University Child Health, Southampton General Hospital, Southampton}

Previous studies have shown that adolescent asthmatics with frequent wheeze are more likely to suffer symptoms in adulthood (Kelly et al BMJ 1987; 294:1059-1062). As part of a large cohort study we have examined those factors influencing the frequency of wheeze amongst symptomatic 14-16 year olds.

In January 1995 a respiratory questionnaire was distributed to all traceable parents of children in a cohort under study since 1987, when aged 6-8 years. This questionnaire also contained questions concerning personal and family history of atopy, personal and household smoking habits, birthweight of the child, number of other children in the household, gas cooker usage and household pets. From replies received, children with reported current wheeze (wheeze in the previous 12 months) were divided into those with frequent symptoms (at least one episode/week) and those with infrequent symptoms. A multivariate logistic regression model was used to examine the independent effect of potential risk factors on the likelihood of having frequent symptoms. Significance of inclusion in the model was tested using chi-squared.

Of 2289 returned questionnaires, 414 parents (18.2\%) reported their child had current wheeze. Amongst these, 73 (17.6\%) had frequent symptoms. Symptoms were more likely to be frequent in children who had had reported wheeze in 1987 (odds ratio 2.88; 95\% C.I. 1.43-4.55, $p=0.001$ ), children who were regular smokers (2.50; 1.21-5.15, $<<0.02)$, and those who lived in households with other children $(1.68 ; 1.13-2.50, p=0.01)$ or with cats $(1.45 ; 1.07$ $1.96, p=0.02$ ). Frequent symptoms were significantly less comon in children with higher birthweight $(0.59 ; 0.35-0.97, p=0.04)$ and in children with atopic siblings $(0.38 ; 0.20-0.70, p<0.01)$.

We have demonstrated several factors which appear to increase the likelihood of frequent symptoms in adolescents with wheeze.

\section{BODNER, S ROSS, J G DOUGLAS, J LITTLE, J S LEGGE, $J$ A R FRIEND and D J GODDEN}

Department of Medicine and Therapeutics, University of Aberdeen, Aberdeen, AB9 2ZD

Risk factors associated with the development of adult onset wheeze were examined among 102 subjects who reported wheeze since age 15 years and 217 controls. All subjects, aged 39 to 45 , were identified from a cohort of asymptomatic children originally studied in 1964 (Bodner et al., Thorax 1995; 50(Suppl 2): A57). Logistic regression was used to determine predictors of wheezing in all cases and in two distinct subgroups: cases with doctor diagnosed asthma $(n=24)$ and cases reporting cough with phlegm for as much as 3 months/year suggestive of $\operatorname{COPD}(\mathrm{n}=31)$.

\begin{tabular}{|c|c|c|c|}
\hline Covariate & $\begin{array}{c}\text { All cases } \\
(n=102)\end{array}$ & $\begin{array}{c}\text { Asthma } \\
(n=24)\end{array}$ & $\begin{array}{l}C O P D \\
(n=31)\end{array}$ \\
\hline Smoking habit & & Odds ratios & \\
\hline Former & $1.6(0.8$ to 3.1$)$ & $1.2(0.4$ to 3.8$)$ & $5.4(1.0 \text { to } 28.4)^{*}$ \\
\hline Current & $2.1(1.1 \text { to } 4.0)^{\bullet}$ & $0.8(0.3$ to 2.5$)$ & $12.2(2.7 \text { to } 56.1)^{*}$ \\
\hline \multicolumn{4}{|c|}{ Atopy (skin test. total IgE, RAST) } \\
\hline One positive & $1.5(0.7$ to 3.2$)$ & $1.1(0.3$ to 4.8$)$ & $0.6(0.1$ to 3.0$)$ \\
\hline Two positive & $1.6(0.8$ to 3.2$)$ & $1.0(0.3$ to 3.9$)$ & $1.5(0.5$ to 4.5$)$ \\
\hline Three positive & $3.3(1.4 \text { to } 8.0)^{*}$ & $4.2(1.1 \text { to } 15.6)^{*}$ & $3.7(0.9$ to 14.3$)$ \\
\hline \multicolumn{4}{|c|}{ Eamily history of asthma eczema or hayfever } \\
\hline$\leq 1$ in 3 relatives & $1.5(0.8$ to 2.9$)$ & $1.3(0.3$ to 5.2$)$ & $2.2(0.7$ to 6.5$)$ \\
\hline $\begin{array}{l}>1 \text { in } 3 \text { relatives } \\
\text { Social class }\end{array}$ & $4.9(2.6 \text { to } 9.2)^{*}$ & $7.5(2.7 \text { to } 21.2)^{*}$ & $4.1(1.4 \text { to } 12.0)^{*}$ \\
\hline Manual & $2.6(1.5 \text { to } 4.5)^{*}$ & $1.6(0.6$ to 4.4$)$ & $3.1(1.2 \text { to } 8.2)^{*}$ \\
\hline
\end{tabular}

${ }^{*} p \leq 0.05$

Significant independent predictors of adult onset wheezing (all cases) were smoking habit, atopic status, family history and social class. Gender was not related to the risk of wheezing. Analysis of the subgroups showed that the risk factors differed depending on the nature of the wheezing illness. Asthma was related to atopy and family history; whereas COPD was related to smoking habit, family history and social class.

Supported by the National Asthma Campaign.

\section{S88 INFLUENCE ONMORTALITY TRENDSOF 'FALSE POSITIVE'} ASTHMA DEATH CERTIFICATION IN ELDERLY SUBJECTS

T AIKEN, D REID, $V$ HENDRICK, WT BERRILL' and DJ HENDRICK

Department of Respiratory Medicine, Newcastle General Hospital, University of Newcastle upon Tyne, NE4 6BE, and 'West Cumberland Hospital, Whitehaven, CA28 8JG

Thirty five respiratory physicians, distributed in panels of 3 , reviewed the hospital and general practice records of 210 subjects thought to have had asthma who died in 1991/2 in the Northern Health Region. Each acted independently and without sight of the death certificates. The certificates indicated that asthma had been certified as the direct cause of death in 103 (Group 1), as a contributory cause in 70 (Group 2), and as of no relevance in 37 (Group 3). Each panel reviewed a batch of 15 cases, knowing them to contain cases from each certification group. For 190 cases there were sufficient data for panels to express a majority or unanimous conclusion as to whether asthma was the direct cause of death, a contributory cause, or not relevant:

\begin{tabular}{|c|c|c|c|}
\hline Panel Conclusion & $\begin{array}{l}\text { Group } 1 \\
(n=86)\end{array}$ & $\begin{array}{l}\text { Group } 2 \\
(n=67)\end{array}$ & $\begin{array}{l}\text { Group } 3 \\
(n=37)\end{array}$ \\
\hline Direct & 31 & 1 & 4 \\
\hline Contributory & 13 & 5 & 4 \\
\hline Not Relevant & 42 & 61 & 29 \\
\hline
\end{tabular}

There was concordance between panels and certifying physicians that asthma was the direct cause of death in only $36 \%$ of the evaluable cases from Group 1, and was of no relevance to death in $78 \%$ of the evaluable cases from Group 3. The degree of discordance within Group 1 (ie 'false positives') was related to age at death, being $45 \%$ for those aged $<65 \mathrm{y}$, but $75 \%$ for those who were older. If such discordance occurs nationally, the estimated number of 'false positive' certifications could account fully for the apparent increase in mortality evident from national statistics over recent decades. The error probably arises from increasing diagnostic transfer from other diseases, principally COPD. The 'false positive' certifications may, however, be counterbalanced overall by a failure to identify true asthma deaths (ie 'false negative' certifications). 
S89 THE RATE OF DECLINE OF FORCED EXPIRATORY VOLUME IN ONE SECOND (FEVI) PREDICTS MORTALITY FROM CORONARY HEART DISEASE IN MEN AND WOMEN

\section{UPTON, C HART, G WATT, D HOLE and G DAVEY SMITH}

Department of General Practice, University of Glasgow, Woodside Health Centre, Barr Street, GLASGOW, G20 7LR

Prospective cohort studies have consistently shown that cross-sectional FEV1 predicts not only mortality from chronic respiratory disease, but also mortality from coronary heart disease (CHD), even in life-long nonsmokers (Hole et al, Br Med J; in press). Cross-sectional FEV1 is a composite signal, determined by processes underlying growth and functional decline. It is not yet clear which components of this signal are important to the risk of mortality from CHD. In the Renfrew-Paisley Study between 1972 and 1978, 3549 men and 4327 women aged 45 to 64 years had complete coronary risk profiles recorded as well as 2 measurements of FEV1 on average 4 years apart. Percent predicted FEV1 (\%FEV1) was estimated from sex-specific age-height regressions for asymptomatic life-long non-smokers. The rate of decline of \%FEV1 (longitudinal \%FEV1) was estimated as the absolute difference in \%FEV1 divided by the time interval in days between measurements. After adjustment for age, baseline \%FEV1, smoking status, social class, systolic blood pressure and cholesterol concentration, and compared to men in the first (slowest) quartile of longitudinal \%FEV1, men in the second, third and fourth quartiles had relative rates (RRs) of mortality from $\mathrm{CHD}$ of $1.17,1.31$ and 1.54 respectively (trend $\mathrm{p}=0.002$ ). For women, the fully adjusted RRs were $1.35,1.47$ and 1.84 respectively (trend $\mathrm{p}=0.002$ ). The trends in CHD mortality persisted in strata defined by current cigarette smoking (smoker/non-smoker). Since participants underwent spirometry on only 2 occasions, these data will underestimate the true effect of longitudinal \%FEV1 on CHD mortality because of imprecision in the estimates of longitudinal \%FEV1. It has been suggested that FEV1 may provide one link between growth in early life and childhood, and adult coronary risk (Walker et al, Int $\mathrm{J}$ Epidemiol $1989 ; 18: 602-606)$. This abstract demonstrates (1) that factors associated with the rate of decline of FEV1 in adult life also determine coronary risk, and (2) the association between the rate of decline of FEV1 and $\mathrm{CHD}$ mortality is not explained by current cigarette smoking.

S91 RADIOLABELLED NEUTROPHIL SCANS FOLLOWING PULMONARY TRANSPLANTATION

O AFOLABI, E GABBAY, T HAWKINS, $P$ KEAVEY and PA CORRIS

Departments of Cardiopulmonary Transplantation and Medical Physics, Freeman Hospital, Newcastle upon Tyne, NE7 7DN

Routine bronchoalveolar lavage of patients following pulmonary transplantation demonstrates higher yield of neutrophils than in normal control subjects. Moreover, chronic allograft rejection is associated with neutrophil sequestration. We were interested to study neutrophil traffic to transplanted lungs and have carried out Tc99m labelled neutrophil scans in 6 patients $(5$ post single lung for emphysema, 1 post bilateral lung transplantation). The neutrophils were labelled using a standard technique in our laboratory and static scans performed at one and 5 mins post injection. Washout curves were constructed over $45 \mathrm{mins}$ and $t \frac{1}{2}$ clearance times calculated. The results of the scans at one and 5 mins were compared with standard $99 \mathrm{~m}$ labelled albumin scans in order to correct for differences in perfusion to the two lungs. There was a significantly greater proportion of neutrophil activity in the transplant lung compared to the native lung at one and 5 minutes post injection, however, the ratio of activity was the same as the ratio of perfusion. Moreover the $t \frac{1}{2}$ clearance was the same in both transplanted and native lungs (meantSD [ $1.5 \pm 0.84 \mathrm{~min}$ vs $1.74 \pm 0.62 \mathrm{~min}] p$ $=0.64)$. We conclude that initial distribution of neutrophils was identical to relative perfusion and clearance from the transplanted lung was the same as native emphysematous lungs.
S90 RESULTS OF PULMONARY TRANSPLANTATION IN PATIENTS WITH CYSTIC FIBROSIS COLONISED BY MULTIPLY RESISTANT PSEUDOMONADS

\section{E GABBAY, U NKERE, N WRIGHTSON, FK GOULD, JH DARK, PA CORRIS}

Department of Cardiopulmonary Transplantation, Freeman Hospital and University of Newcastle upon Tyne

The decision as to whether or not patients with cystic fibrosis (CF) colonised by multiply resistant pseudomonads should be accepted for transplantation remains controversial. We have elected to accept patients providing they have no other relative contraindication and are well preserved from a nutritional view point. To date 42 patients with $C F$ have undergone transplantation, 27 colonised by sensitive strains of P.aeruginosa (Group 1) and 15 by multiresistant strains (Group 2), including 5 with B.cepacia. The overall one year survival is $75 \%$. We have found no significant differences in either $\mathbf{3 0}$ day or one year survival between groups 1 and 2 . There are no differences in number of deaths due to sepsis ( 3 vs 3 ) or episodes of treated pseudomonads pulmonary infections in the first 30 days ( 8 vs 4 ) between groups 1 and 2 respectively. From a functional view point surviving patients are classified 13 BOS 0,1 BOS 1 and 1 BOS 3 in group 1 and 8 BOS 0, 1 BOS 1, 1 BOS 2 and 1 BOS 3 in group 2. We conclude that patients with CF colonised by multiply resistant pseudomonads including B.cepacia may be accepted for pulmonary transplantation and that our results do not suggest they have a worse outcome than patients with sensitive strains.

\section{S92 QUANTITATIVE PCR FOR THE DIAGNOSIS OF CMV DISEASE IN LUNG AND HEART TRANSPLANT RECIPIENTS}

JJ EGAN, L BARBER, A FOX, A TURNER, N YONAN, A EL GAMEL and AA WOODCOCK.

The North West Lung Centre, Wythenshawe Hospital, Public Health Laboratory, Withington Hospital, Manchester, M23 9LT

Qualitative PCR for CMV is not a strong predictor of CMV pneumonitis in lung and heart transplant recipients. We prospectively studied quantitative PCR (QPCR) for CMV glycoprotein B gene (gp58) in peripheral blood polymorphonuclear leucocytes (PMNL) for the diagnosis of CMV infection and disease (DIS) in lung ( $n=9)$ and heart $(n=23)$ transplant patients (pts). A 25 mer oligonucleotide primer for the glycoprotein B gene (149 bp) was used in a PCR assay using an internal standard for quantitation. QPCR results were compared to serology, CMV antigenaemia, BAL DEAFF test and histology. CMV disease was defined as histological evidence of end organ damage caused by CMV. The median level of CMV genome equivalents in pts with DIS was 4082 / $2 \times 10^{5}$ PMNL (range 1200-61606) compared to $100 / 2 \times 10^{5}$ PMNL (range 20-14622) with infection but no DIS $(p=0.036)$. All patients who developed CMV DIS had genome equivalent levels $>1000 / 2 \times 10^{5}$ PMNL. A cut off level of CMV genome equivalent of $>1000 / 2 \times 10^{5}$ PMNL had a positive predictive for CMV DIS of $71 \%$ and a negative predictive value of $100 \%$. The first detection of levels of CMV genome equivalents above a level of $1000 / 2$ $x 10^{5}$ PMNL was at a median of 58 days (range 47-147) post transplant. Quantitative diagnostic techniques for the diagnosis of CMV infection may predict patients at risk of CMV DIS and allow targeted antiviral therapy. Supported by the Wellcome Foundation. 


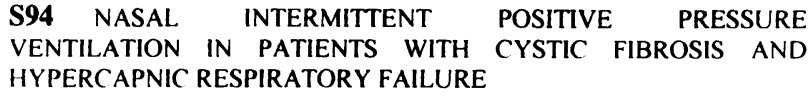

\section{AT HILL. FP EDENBOROUGH. RM CAYTON ${ }^{*}$ and DE STABLEFORTH}

Adult Cystic Fibrosis Unit and Department of Respiratory Physiology. Birmingham Heartlands Hospital, Birmingham, B9 5SS

Nasal Intermittent Positive Pressure Ventilation (NIPPV) has been used as a bridge to transplantation in patients with cystic fibrosis (CF)(Hodson et al liur Respir J 1991;4:524-527). We report the use of NIPPV from 1991 to 1996 at the Birmingham Regional Adult CF Unit and discuss its potential role in CF patients in respiratory failure.

Patients with respiratory failure unresponsive to medical treatment and who were candidates for lung transplantation were offered a therapeutic trial of NIPPV

Twelve patients, six male, of mean (SE) age of 26(1.4) years, had a trial of NIPPV. At recruitment the mean \% predicted forced expired volume in one second $\left(\% \mathrm{FEV}_{1}\right)$ was $15.1(1.2) \%$; \%predicted forced vital capacity (\%FVC) $26.2(3.4) \%$; body mass index $(\mathrm{BMI}) 16.9(0.5) \mathrm{Kg} / \mathrm{m}^{2}$; arterial carbon dioxide $\left(\mathrm{PaCO}_{2}\right)$ 8.7(0.6) $\mathrm{kPa}$; arterial oxygen $\left(\mathrm{PaO}_{2}\right) 7.4(0.6) \mathrm{kPa}$ and arterial bicarbonate $\left(\mathrm{HCO}_{3}\right) 40.1(1.6) \mathrm{mmol} /$.

Ten cases tolerated NIPPV for 1-15 months, mean 5(1.3) months. Compliance was good with subjective improvement in headache and quality of sleep. There were no complications. Data available on 5 patients at 3 months showed significant improvement in $\% \mathrm{FVC}, \mathrm{PaCO}_{2}$ and $\mathrm{HCO}_{3}$ $(p<0.05)$. Subsequently three cases had lung transplantation. 4 died on the active list and three are awaiting organs. Two patients failed to tolerate NIPPV due to abdominal bloating and increasing hypercapnia and died at 2 and 6 months respectively.

In our experience NIPPV improves symptoms in CF patients with hypercapnic respiratory failure and may lead to inprovement in lung function and blood gas parameters. We suggest there may be a possible long term role in selected patients beyond a short term bridge to transplantation. FP EIDENBOROU/(FH is supported by the (ystic Fibrosis Trust

\section{S95}

RANDOMISED CONTROLLED TRIAL OF OUT PATIENT PULMONARY REHABILITATION IN COPD : PRELIMINARY RESULTS R GARROD, J C BESTALL, R GARNHAM. E A PAUL, P W JONES, J A
WEDZICHA

Pulmonary Rehabilitation Unit, The London Chest Hospital and Division of Physiological Medicine, St. George's Hospital Medical School.

Physical training as part of pulmonary rehabilitation programmes in COPD patients improves exercise capacity, while education programmes alone appear to have little benefit. However, most of this data has come from uncontrolled studies of rehabilitation and few controlled studies have been reported

We have performed a randomised controlled study of an eight week out-patient supervised rehabilitation programme. 49 COPD patients, stratified into the Medical Research Council (MRC) grade 3 and 4 breathless scale, median age 69 (range 49-81) years, mean FEV $0.95(0.36) 1$, FVC $2.6(0.76) 1, \mathrm{PaO}_{2} 8.79(0.99)$ $\mathrm{Kpa}$, were randomised into an active group receiving twice weekly physical training sessions with education and a Control group receiving the education package alone. Assessments before and after the programme included the Shuttle walking (incremental paced) test, Borg scores, questionnaires, St. Georges Quality of Life Questionnaire (SGRQ), The Nottingham Extended Activities of Daily Living (ADL) and the Hospital Anxiety and Depression (HAD) questionnaire.

Baseline walking distance was similar in both groups $(p=<0.605)$ but increased significantly in the Active group from $212.4 \mathrm{~m}$ to $267.5 \mathrm{~m}(\mathrm{p}=<0.001)$. In the Control group there was a fall in the walking distance from $231.5 \mathrm{~m}$ to $194.7 \mathrm{~m}$ ( $\mathrm{p}$ $<0.05)$ with a mean difference between the two groups of $91.9 \mathrm{~m} \mathrm{(p<0.0003)}$ There was no significant differences in SGRQ, ADL, or HAD scores between the two groups at the eight week assessment. There were no changes in Borg scores, despite improvement, suggesting desensitisation of dyspnoea may account for some of the improvement in exercise capacity. Compliance with the programmes was satisfactory (76 (29.5) \%) and anxiety or depression, low motivation or poor quality of life scores were not predictive of attendance at pulmonary rehabilitation. This randomised controlled trial shows that pulmonary rehabilitation programmes that incorporate physical training result in improved exercise capacity as opposed to education programmes alone.

Supported by the NHS R \& D Programme on Physical and Complex Disabilities
S96 THE MEDICAL RESEARCH COUNCIL BREATHLESSNESS SCORE IS USEFUL IN SELECTING COPD PATIENTS FOR PULMONARY REHABILITATION

BFSTALI, JC, GARROD R, GARNHAM R, PAUL EA, JONES PW, and WFDZICHA JA

Department of Pulmonary rehabilitation, London Chest Hospital and Division of Physiological Medicine, St George's Hospital Medical School

The Medical Research Council Breathlessness Score (MRC BS) has been used to grade perceived respiratory disability and consists of five statements relating to perceived breathlessness and mobility. Since Pulmonary rehabilitation programmes are tailored to the needs of the individual we used the MRC BS to allocate patients to either rehabilitation sessions as hospital outpatients or rehabilitation in the patients home. 90 stable COPD patients were entered into the programme (52M,38F; median(range) age $70(43-$ 81)yrs; Mean(SD) FEV1 0.89 (0.37)l, FVC 2.27(0.79)l). All patients were assessed with spirometry, Shuttle walking test with Borg scores for perceived breathlessness, Quality of Life - St George's Respiratory Questionnaire (SGRQ), Extended Activities of Daily Living (ADL) score, and Hospital Anxiety and Depression (HAD) score.

Patients choosing statements 3 or 4 (group 3 walking slowly due to breathlessness or group 4 stopping for rests) were entered into hospital rehabilitation sessions. Those choosing statement 5 (Group 5 housebound due to breathlessness) were entered into the home based programme.

The MRC BS showed significant differences between the 3 groups on FEVl $(p<0.014)$ and FVC $(p<0.005)$ though no significant differences between groups for blood gases or gas transfer. Significant differences were found between groups on Shuttle $(p<0.0001)$, median walking distance group $3(270 \mathrm{~m})$, group $4(140 \mathrm{~m})$ and Group $5(70 \mathrm{~m})$ and for Borg scores before exercise $(p<0.006)$ and after exercise $(p<0.04)$. There were significant and progressive differences between groups on all components of the SGRQsymptoms $(p<0.015)$, activities $(p<0.0001)$, impacts $(p<0.0001)$ and total score $(p<0.0001)$. Similar differences were found for the HAD anxiety $(p<0.009)$ and depression $(p<0.0001)$ scores. ADL scores were significantly different between groups ( $p<0.0001$ ), group 5 had significantly lower EADL scores than group 3 or 4 reflecting their greater disability.

The MRC BS is a successful method of stratifying patients according to disability as shown by measures of ADL and exercise capacity, supported by differences between groups on QOL and mood state. The MRC BS is a useful application in stratifying COPD patients for pulmonary rehabilitation. 
S97 ADMINISTRATION OF THE CHRONIC RESPIRATORY DISEASE QUESTIONNAIRE; THE IMPORTANCE OF IDENTIFYING PREVIOUS RESPONSES SJ SINGH, J WILLIAMS and MDL MORGAN

The Department of Respiratory Medicine, The Glenfield Hospital, Leicester

The Chronic Respiratory Disease Questionnaire (CRDQ) (Guyatt et al 1987) is frequently employed to assess health related quality of life (HRQOL). Within a pulmonary rehabilitation programme it is used to detect changes in HRQL that occur as a consequence of rehabilitation. Traditionally the patient is reminded of their baseline response. This form of administration is often criticised for provoking a positive response. The purpose of this study was to compare the effect of reporting the previous response against not reporting it in two groups of patients with COPD (previous response $(P R)$ and response unknown (RU). All patients were recruited from our rehabilitation programme. Upon graduation from the course the CRDQ was repeated with 13 patients unaware of their previous answer (RU) FEV (mean,SD) $1.23(0.4) 1$ age $70.8(8.2)$ years, 10 males). The RK group were sex, age, and FEV matched ( $n=13$ FEV mean (SD) $0.94(0.3) 1$, age 69.7 (6.5) years, 10 males) tô the RU group. There was no significant difference in baseline FEV $_{1}$, age, shuttle distance or treadmill endurance time between the two groups. The CRDQ was scored for the four components of dyspnoea, fatigue, mastery and emotional function. There was a significant improvement $(p<0.05)$ for both groups in all four components. The magnitude of change was not significantly different between the RU and RK groups for any of the four components $(p>0.05)$. Significant increases in the shuttle walking test and the treadmill endurance test after the course of rehabilitation were observed in both groups of patients $(p<0.0001)$.

The CRDQ is sensitive to change as a consequence of rehabilitation. In addition, in this group of patients, being unaware of the previous answer does not alter the sensitivity of the CRDQ.

S99 DO PATIENTS WITH CHRONIC OBSTRUCTIVE PULMONARY DISEASE ATTENDING A PULMONARY REHABILITATION PROGRAMME ADHERE TO THEIR PRESCRIBED HOME EXERCISE PROGRAMME?

LJ HUNTER, * SJ SINGH and MDL MORGAN

*UCL and Middlesex Hospital School of Physiotherapy, London. Department of Respiratory Medicine, The Glenfield Hospital, Leicester

Prescribed walking is an important component of many pulmonary rehabilitation programmes. We prescribe aerobic walking to be perfomred at home. The aim of this study was to examine patients' adhereance to their prescribed regime. Adherance to prescribed aerobic walking, was measured in eleven patients (mean (SD) age 67 (9.6) years, FEV $1.63(0.78)$ L, 1 female and 10 males) with chronic obstructive pulmonary disease (COPD) attending a pulmonary rehabilitation programme (PRP) using a $\mathrm{Z80} \quad \mathbf{- 3 2} \mathrm{k}$ V1 Int) activity monitor. These activity monitors had previously been used to distinguish brisk walking from other dally activities in a healthy population (Robinson 1995) and patients with COPD (Singh 1996). The patients were required to wear the monitors on a belt round the waist for periods of one week at a time whilst simultaneously completing a walking diary recording the time of day they performed their prescribed walk and the duration of the walk. Each monitor was calibrated for each patient. The calibration walk (using the appropriate shuttle endurance test (Revill 1995) was at 50\% of the patients' VO, peak, predicted from their previous shuttle walking test performance. The values (counts/min) from this calibration walk were compared with the recordings from the monitor which corresponded to the period of prescribed walking recorded on the patient diary sheet. The results showed that in this group, the patients walked more frequently (mean (SD) $136 \%(44)$ ) for shorter durations $(94 \%(26))$ and more intensely $(159 \%(29))$ than their prescription requires. This study demonstrates that patients with COPD not only adhere to their home exercise programme, but complete more walks and at greater intensity than prescribed.
S98 DO ANXIETY AND DEPRESSION AFFECT OUTCOME OF REHABILITATION IN SEVERE CHRONIC OBSTRUCTIVE PULMONARY DISEASE

\section{R.P. Smith, S.T. Rudkin, R.J. White}

Department of Medicine, Frenchay Hospital, Bristol, BS16 1LE.

Although the benefit of pulmonary rehabilitation in COPD is well established, the outcome varies considerably between individuals. We have examined the relationship of baseline anxiety and depression levels with the outcome of a six weck outpatient pulmonary rehabilitation programme in 79 patients with severe COPD (FEV $1<40 \%$ predicted). Assessments were made using the Hospital Anxiety and Depression scale (HAD) and the Chronic Respiratory Disease Questionnaire (CRDQ). Physical performance was measured using the shuttle walking test. HAD scores equal to or greater than 8 were taken to indicate significant anxiety or depression; these two sub-groups were analysed separately. A HAD score improvement of $>1$ was regarded as clinically important.

We confirmed that this group of patients had high levels of both anxiety (mean [SD] HAD score 7.62 [4.4]; 49\% $\geq 8$ ) and depression (6.16 [3.3]; $33 \% \geq 8)$. Rehabilitation significantly lowered anxiety $(1.26 ; p=0.008)$ and depression scores $(1.8 ; \mathrm{p}=0.003)$ in those with high levels at baseline. There were statistically significant improvements $(p<0.001)$ in the individual CRDQ dimensions of emotion, mastery, dyspnoea and fatigue in both subgroups. Although anxiety levels correlated strongly with the baseline CRDQ emotion score $(r=0.62, p<0.001)$, and depression correlated with both the baseline fatigue $(r=-0.501, p<0.001)$ and mastery scores $(r=0.542$, $\mathrm{p}<0.001$ ), the change in $\mathrm{HAD}$ scores did not correlate with the improvement in any of the individual CRDQ dimensions. In the group as a whole, there was an improvement in shuttle distance from 169 [115] to 204 [121] metres following rehabilitation $(p<0.0001)$ which did not correlate with the reduction in depression and only weakly with the reduction in anxiety $(r=0.38, p=0.002)$. We conclude that high levels of anxiety or depression do not adversely affect outcome in pulmonary rehabilitation. The improvement in anxiety and depression in those with clinically significant baseline levels appears to be independent of the other improvements seen.

S100 ARE ACTIVITY MONITORS SENSITIVE ENOUGH TO DETECT SPEEDS PRESCRIBED TO PATIENTS WITH COPD?

\section{LJ HUNTER,* SJ SINGH and MDL MORGAN.}

*UCL and Middlesex Hospital School of Physiotherapy, London. Department of Respiratory Medicine, The Glenfield Hospital, Leicester.

Prescribed home walking is an important component of many pulmonary rehabilitation programmes. However, to date it has been impossible to measure how accurately patients adhere to their exercise prescription in the home environment, as patients completed diaries and verbal reports have been the only means of measurement avallable. The aim of the study was to test whether ( $\mathrm{Z} 80$ - $32 \mathrm{k} \mathrm{V1}$ Int) activity monitors were sufficiently sensitive to detect different walking speeds prescribed for COPD patients in a home exercise programme.

Nine activity monitors were worm in a belt and tested for sensitivity, on five separate occasions, while an individual walked at four different speeds $(1.77,3.06,4.34$ and 5.63 kilometres per hour) on a treadmill (Powerjog). Data was expressed as counts/min and collected at 30 second intervals. Data from the monitors was downloaded using a dedicated software package.

The monitors were shown to be sensitive to alteration in speed of walking, even at the lower levels of activity. There was a significant difference between speeds (counts $/ \mathrm{min}$ ) for each individual monitor $(\mathrm{p}>0.05)$. The counts/min values were not identical for each of the monitors. Each Monitor was sensitive but had individual characteristics. The monitors appear to be sensitive enough to detect various speeds of walking and therefore to measure episodes of prescribed walking at home in patients with COPD. 


\section{S101 COULD INSPIRATORY PRESSURE SUPPORT (IPS) BE A USEFUL ADJUNCT IN PULMONARY REHABILITATION ?}

MI POLKEY, D KYROUSSIS, TA FLEMING, CN WOOD, RA SHERWOOD and J MOXHAM

Kings College School of Medicine, London UK

A physiological training benefit from pulmonary rehabilitation is more probable if the exercise intensity exceeds the anaerobic threshold; a convenient marker of anaerobic metabolism being elevation of plasma lactate. Plasma lactataemia is buffered by bicarbonate with release of $\mathrm{CO}_{2}$; in severe COPD this places an unsustainable load on the respiratory muscle pump. In COPD IPS ameliorates the loading experienced by the inspiratory muscles during treadmill exercise (Polkey et al $A J R C C M$ 1996; in press). In the present study we sought to extend exercise induced lactataemia in patients with severe COPD using non-invasive inspiratory pressure support (IPS). 5 men with severe COPD (mean FEV 0.661 ) performed 2 constant rate treadmill walks to a condition of severe dyspnoea; the second walk was supported by IPS delivered from a NIPPY ventilator (Friday Medical, London UK) and a full face mask. Plasma lactate was measured in arterialised blood drawn at baseline and at end exercise. A significant elevation in mean plasma lactate from baseline $(1.83 \mathrm{mM} / \mathrm{L})$ to end exercise of both the free (to $3.48 \mathrm{mM} / \mathrm{L}$ ) and IPS assisted (to $2.82 \mathrm{mM} / \mathrm{L}$ ) walks was observed $(p<0.05)$. IPS resulted in a mean $136 \%$ increase in walking distance $(p<0.05)$. We conclude that patients with severe COPD can prolong exercise induced lactataemia for longer if assisted with IPS. This technique warrants further study since it may prove to be a useful adjunct in pulmonary rehabilitation.

P2 OBSERVATIONS ON THE STRUCTURE, PROCESS AND CLINICAL OUTCOMES OF ASTHMA CARE IN GENERAL PRACTICE

HOSKINS G, NEVILLE RG, SMITH B, and CLARK RA

Tayside Centre for General Practice, University of Dundee

There is a need to establish whether the structure of asthma care in general practice is associated with measures of process and with primary and secondary care clinical outcomes. Debate about how to resource general practice asthma care is hampered by a lack of observational data from throughout the United Kingdom.

The National Asthma Management Study was designed to observe the present system of FHSA accreditation of asthma clinics based on measures of structure associated with measures of process or clinical outcome. 225 UK practitioners enrolled in a project and recorded details of how they organised asthma care and provided data from 6732 patients on general practitioner and nurse consultations, asthma attacks, symptom control, emergency treatments and hospital attendances covering a 12 month period. FHSA approval for a Chronic Disease Management Asthma Clinic was associated with favourable patterns of structure and process but not clinical outcome. Practice audit and employment of a nurse with an asthma diploma were associated with favourable patterns of structure, process and clinical outcome.

Practices ( $n=143)$ who had recently audited asthma patient care ( $n=4259)$ compared to those who had not (82 practices, 2473 patients) had fewer patients who had attended an accident and emergency department in the past 2 months [121(3\%):96(4\%), Odds ratio 1.38,95\% Confidence Intervals 1.04-1.83] or hospital outpatients [247(6\%):180(7\%), 1.28,1.04-1.56] and fewer patients with respiratory symptoms on assessment [2400(56\%):1465(59\%), 1.34,1.18-1.52] and days lost from work or school [375(9\%):296(12\%), $1.48,1.25-1.74]$

Findings from a large UK sample of practices are subject to participant bias and show association rather than causative links. The present FHSA asthma CDM accreditation system based on structure is not associated with favourable clinical outcomes. This opens the debate as to whether accreditation should be linked to recent experience of audit, which does appear to be associated with favourable clinical outcomes.

\section{P1 GENERAL PRACTITIONER PRESCRIBING HABITS IN} ASTHMA/COPD

\section{$K$ MOUSLEY, M RUDOLF and M PEARSON}

Abacus International, Oxfordshire, OX6 OYP. Ealing Hospital, Middlesex, UBI 3HW. Aintree Chest Centre, Liverpool, L9 7AL

A study has been carried out in nine UK general practices to consider the prescribing costs in Asthma/COPD patients. Using the practices' computerised prescribing records, a search was carried out to identify all patients over 40 years of age, who had been prescribed a Beta-agonist during the previous six month period and who had a positive smoking history. The medical notes for these patients were reviewed and only those satisfying the following criteria were included in the study: consistently low lung function, sputum production and a history of chest infections. The age, sex, current diagnosis and prescribing history over the six months were manually recorded for the study group

434 patients were identified, 224 female and 210 male, with an average age of 65 years. The diagnosis as recorded by the GP on the computer records was asthma in $52 \%$ and COPD (including emphysema and chronic bronchitis) in $45 \%$; $3 \%$ of cases had no or other diagnoses

Each prescription written for these patients during the six month period was costed. The total cost of treatment for all patients was $£ 51,920$. For bronchodilators, $£ 16,730$ was spent on Beta-agonists, $£ 4295$ on anticholinergics ( $23 \%$ of patients) and $£ 1887$ on combination preparations containing a beta-agonist and an anticholinergic ( $12 \%$ of patients)

351 patients (81\%) were receiving steroid therapy at a cost of $£ 29,008$; an average cost of $£ 82.65$ patient. Assuming that the criteria for entry into this study actually identified patients with COPD and that only $10-15 \%$ of such patients may benefit from steroid therapy, it can be estimated that the treatment costs of steroids could potentially be reduced to $£ 5380$, a saving of $£ 23,628$

This study demonstrates the economic implications of prescribing for asthma/COPD patients. Some of these resources may be better utilised by improving the accuracy of diagnosis and the appropriateness of treatment.

P3 THE PREVALENCE OF DIAGNOSED ASTHMA AND COPD IN A COMMUNITY POPULATION IN NOTTINGHAMSHIRE

L J WALSH, C A WONG, S COOPER, A R GUHAN, M PRINGLE and A E TATTERSFIELD

Division of Respiratory Medicine, City Hospital, Nottingham NG5 1PB

In a survey of five large general practices with fully computerised patient records for at least four years we have determined the prevalence of diagnosed asthma and COPD in patients over the age of four. Patients were identified from a computer search of practice records and individual records were then reviewed. From a total population of 38865 (52\% F) 3692 patients $(9.5 \%$ ) had a diagnosis of asthma and/or COPD of whom $90 \%$ had received treatment within the past four years. The majority (3260; 8.4\%) had a diagnosis of asthma alone, compared to $108(0.3 \%)$ with asthma and COPD and 318 with COPD alone (0.8\%). The age distribution of patients according to diagnosis is shown; a quarter were aged 5-16 years. Overall 53\% of patients with asthma were female compared to $40 \%$ of patients with a diagnosis of COPD and $43 \%$ of patients under the age of 16 . Amongst the $83 \%$ of patients over the age of 16 years with a smoking history recorded $22 \%$ were current smokers and $20 \%$ ex smokers in the asthma only group compared to 29 and $40 \%$ of patients with a label of COPD. Using computerised records obviates the problems of non-compliance seen in most community based surveys of asthma/COPD. The data emphasises the marked variation in diagnosed asthma in the community in relation to age.

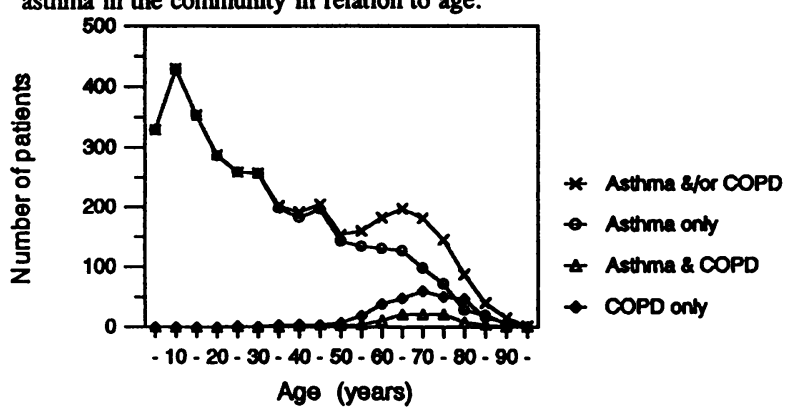

